\title{
PEQUEÑO ATLAS LINGUISTICO DE COSTA RICA
}

\author{
Miguel Angel Quesada Pacheco
}

\begin{abstract}
This article presents a set of 77 linguistic maps which describe, on the level of linguistic geography, some phonetic, morphosyntactic, and lexical features of Costarrican Spanish.

Although such a work was planned since years, it is the first real attempt to carry out the linguistic atlas of Costa Rica.
\end{abstract}

\section{Introducción}

El Pequeño atlas lingüístico de Costa Rica es un estudio cartográfico formado por 77 mapas que dan a conocer, de manera resumida, la situación linguiística actual de Costa Rica, de acuerdo con la distribución geográfica de ciertas particularidades fonéticas, morfológicas y léxicas del español hablado en este país. En ellos se pueden apreciar, en su conjunto, algunos rasgos característicos del habla costarricense y sus variedades regionales. Desde una perspectiva cultural, este atlas contribuye a dar a conocer y rescatar algunos rasgos lingüísticos tradicionales de Costa Rica, considerando que el habla de un pueblo, región o país constituye una parte importante de su patrimonio cultural, y teniendo presentes los cambios que está sufriendo el costarricense hacia un régimen de vida más desligado de tantos aspectos propios que lo han identificado como tal.

\section{Tarea y breve historia de la geografia lingüística}

Hacer mapas lingüísticos e interpretarlos es tarea fundamental de la geografía lingüística, una rama de la dialectología que nació en el siglo XIX como una de las respuestas del Romanticismo al interés por los estudios de la cultura nacional y local (costumbres y habla populares). Fue el alemán Georg Wenker (1874) el primero que se interesó por esta clase de estudios. Se dedicó a distribuir a los maestros de escuela de todo el territorio alemán unos cuestionarios con 40 frases que debían ser traducidas al dialecto local, con el fin de hacer mapas que reflejaran la composición dialectal alemana de la época. Dichos mapas se han estado publicando desde 1927. ' Pero a quien le cabe el honor de realizar un atlas linguístico nacional, completo, es al suizo Jules Gilliéron, el cual confeccionó el ya clásico Atlas linguistic de la France (Paris, 1902-1910) con un cuestionario de 1900 preguntas aplicadas en 639 localidades del territorio francés.

El efecto inmediato de la obra de Gilliéron fue la motivación que sintieron otros investigadores por la realización de atlas linguiísticos en Europa, entre los que se pueden citar el Atlas lingüístico etnográfico de Italia y del sur de Suiza (Jaberg y Jud 1928), el Atlas lingüístico de Andorra (Griera 1960), el Atlas lingüístico etnográfico de Andalucía (Alvar, Llorente y Salvador, 1963-1964), el Atlas lingüístico etnográfico de la Islas Canarias (Alvar, 1975), el Atlas lingüístico etnográfico de Aragón, Navarra y Rioja (Alvar y otros, 1979) y el Atlas lingüístico rumano (1956). En América Latina tenemos el Atlas de Puerto Rico trazado por T. Navarro (1948), el Atlas lingüístico etnográfico del Sur de Chile (Araya y otros, 1973), y el Atlas lingüístico etnográfico de Colombia (Buesa y Flores, 1981-1982).

Respecto de Costa Rica, el interés por realizar un atlas lingüístico se manifiesta públicamente en 1964 con Arturo Agüero quien afirma:

Elaborar un atlas linguiístico de mi país ha sido siempre mi anhelo, desde hace diez años, cuando comencé los estudios del español que hablamos aquí. (Agüero 1964, I; 151) 
El profesor Agüero llegó incluso a preparar algunos cuestionarios. Sin embargo, diversos problemas tanto de índole académica como financiera obstaculizaron el avance del proyecto.

Desde principios de la década de 1970 salen trabajos de graduación en nuestras universidades, cuyo tema es la dialectología, y en varios de ellos se manifiesta un interés por contribuir a la elaboración de un atlas lingüístico de Costa Rica (Monge 1971, Vindas 1971, Gómez 1975, Román 1976, Chavarría et. al. 1977, Zamora 1977, Alfaro 1979, Meza 1980, Quesada Pacheco 1981). No obstante, si bien los estudios citados muestran una gran cantidad de datos que podrían ser utilizados en un atlas lingüístico, con excepción de Quesada Pacheco, en ninguno de los citados aparecen mapas que den cuenta de la distribución geográfica de los rasgos tratados, siendo precisamente ese el fin de un atlas lingüístico.

Mención especial merece el estudio de J. Wilson (1970), quien es en realidad el primero en trazar mapas linguiísticos de algunos rasgos fonológicos del español costarricense, desde el punto de vista de la gramática generativa. Por otra parte, V. Sánchez (1983) publica un cuestionario para el estudio de la fonología y fonética de nuestro español. ${ }^{2}$

\section{Elaboración del Pequeño Atlas Lingüístico de Costa Rica}

Con la confección de un pequeño cuestionario he logrado trazar 77 mapas lingüísticos, los cuales reflejan, de manera global, la distribución espacial de ciertos rasgos fonéticos, morfológicos del español de Costa Rica y los nombres con que se designan diversos aspectos de la cultura costarricense. Además, darán base para una redefinición de las zonas dialectales de Costa Rica, como se verá más adelante.

El cuestionario que he utilizado ha sido uno elaborado por mi propia cuenta, el cual consta de 100 preguntas e incluye los siguientes aspectos: fauna, flora, léxico del café, de la caña de azúcar, del maíz, además de algunos aspectos fonéticos y, en menor escala, morfosintácticos.Respecto de la recolección de datos, se aplicó el estilo de encuesta indirecta a setenta informantes, para quienes quiero dejar constancia de mi agradecimiento, ya que se dignaron sacar un rato de su tiempo para contestar mis preguntas. Los entrevistados provienen de los siguientes cantones: ${ }^{3}$
Provincia de San José: Puriscal, Tarrazú, Aserrí, Acosta, y Pérez Zeledón.

Provincia de Alajuela: Grecia, Alfaro Ruiz, San Carlos, y Upala.

Provincia de Cartago: Paraíso.

Provincia de Heredia: Santa Bárbara, Santo Domingo.

Provincia de Guanacaste: Liberia, Nicoya, Santa Cruz, Carrillo, La Cruz, Nandayure, Cañas, Abangares y Bagaces.

Provincia de Puntarenas: Puntarenas, Buenos Aires, Aguirre, Parrita, Osa y Corredores.

Provincia de Limón: Pococí, Siquirres, Matina y Talamanca.

La encuesta no fue aplicada a un solo informante, sino que, según los intereses del investigador y la experiencia del informante, se escogieron los que eran idóneos para los fines propuestos. Por ejemplo, en la mayoría de los casos los que suministraron los datos léxicos no necesariamente suministraron los morfológicos o fonéticos, y aun dentro del léxico se recurrió a veces a otros testimonios. Los datos se presentan organizados dentro de los niveles fonético, morfosintáctico y léxico.

\section{Resultados}

\subsection{Nueva división dialectal de Costa Rica}

Los mapas lingüísticos que se verán en esta investigación me han llevado a grandes sorpresas. En primer lugar, nos muestran que la ya tradicional división dialectal de Costa Rica - Valle Central y Guanacaste- ha quedado atrás, y que es urgente redefinirla. El país presenta una situación dialectal mucho más compleja de lo que se ha creído, ya que los movimientos migratorios internos en el presente siglo han innovado, alterado y reestructurado su mundo linguístico. De esta manera, y apoyado en algunos rasgos fonéticos y léxicos peculiares, propongo el estudio geográfico-linguiístico de Costa Rica según las siguientes zonas:

1. Valle Central: comprende las provincias de San José (menos el Cantón de Pérez Zeledón), Cartago, además de las partes altas de las provincias de Heredia y Alajuela;

2. Zona Noroeste: la provincia de Guanacaste, la banda oriental del Golfo de Nicoya hacia Esparza, hasta el límite con el río Jesús María, y la sección noroeste de la provincia de Alajuela; 
3. Zona Atlántica: las llanuras de la provincia de Limón;

4. Zona Norte: las llanuras de San Carlos, tomando como centro irradiador Ciudad Quesada;

5. Zona Sur: el cantón de Pérez Zeledón y a sección de la provincia de Puntarenas.

Los rasgos linguísticos en que me apoyo para definir las zonas susodichas son:

-realización de / e,o / en posición postónica

-realización de / s / como sibilante predorsal o dental -realización de / s / en posición final o ante consonante

-realización de / tr /

-realización de / dr / después de / n / y / 1 /

-realización de / r /

-realización de $/ \overline{\mathrm{r}} /$

-realización de / y / en posición inicial

-deshiatización y su correspondiente ultracorrección -recursos para la derivación

-presencia del marcador de infinitivo ante enclíticos -extensión geográfica de ciertos rubros léxicos

\subsection{Subagrupaciones dialectales}

Cada una de las zonas propuestas presenta subdivisiones susceptibles de ser estudiadas en microzonas. Así, en la Zona Central, concretamente dentro del Valle Central, se marca una división entre el norte y el sur de dicho valle, cuyo limite lo forma el río Virilla. ${ }^{4}$ Uno de los rasgos ¿ivisorios son la realización de los fonemas vocálicos / e,o / en posición postónica como [ -i, -u ] en la parte norte de dicho río (pueblos de las provincias de Heredia y Alajuela, además de algunos rubros léxicos.

La Zona Norte comparte muchos rasgos con el Valle Central, debido a las corrientes migratorias procedentes del Valle Central (cfr. Skoruppa 1982: 261), pero tiene muchos rasgos fonéticos y léxicos que la acercan a la Zona Noroeste, además de la zona fronteriza con Nicaragua (Los Chiles, por ejemplo).

Respecto de la Zona Noroeste, los rasgos más peculiares que forman una división dialectal interna son la realización predominante de / tr / como oclusiva dental sorda + vibrante simple, la realización de / $\mathrm{r}$ / como vibrante múltiple, y la deshiatización. De esta manera, se observa una alta frecuencia de dichas realizaciones desde $\mathrm{La}$ Cruz hasta Nicoya, incluyendo Liberia, Filadelfia, Santa Cruz y pueblos aledaños. El resto de la
Península de Nicoya (Carmona, Jicaral, Lepanto, Coyote, Cóbano) y la sección oriental del Golfo de Nicoya (Bagaces, Cañas, Puntarenas y Esparza), se caracterizan por una tendencia a la africación de / tr /, a la fricativización de $/ \overline{\mathrm{r}} /$, al ensordecimiento de / $\mathrm{r} /$ en posición final y a no variar los hiatos. Se nota, además, que toda la zona, en mayor o menor grado, aspira el fonema / s /en posición final y ante consonante y, en una franja que se extiende desde Bagaces hasta San Mateo, se realiza / s / como dental fricativa sorda.

La situación se torna más complicada y menos definida en las zonas Atlántica y Sur, debido a la presencia de grupos étnicos con una lengua materna que no es el castellano, y por la reciente inmigración de grupos de diversos ámbitos culturales y dialectales, tanto del país como del exterior. Aquí es menester citar los grandes grupos de emigrantes procedentes de la Zona Noroeste, los cuales han llegado a conformar conglomerados donde se practican sus hábitos lingüísticos en varias partes de la Costa Atlántica y del Pacífico Sur, las poblaciones de vallecentraleños y la presencia de nicaragüenses y salvadoreños en el valle de Matina y de La Estrella (en la provincia de Limón), y en los asentamientos bananeros en la Zona Sur. ${ }^{6}$ Además, los contactos fronterizos con Nicaragua y Panamá, y la creciente influencia de la ciudad de San José como centro de las operaciones gubernamentales y económicas del país, nos indican que debemos esperar un par de generaciones para poder enmarcar dichas zonas dentro de un patrón dialectal autónomo y bien caracterizado.

\subsection{Zonas dialectales limítrofes}

En los presentes mapas lingüísticos se dejan ver rasgos que indican coincidencia de variantes. Grosso modo, las siguientes son las más relevantes demarcaciones fronterizas:

a. los límites políticos nacionales con Nicaragua y con Panamá;

b. los pueblos colindantes entre Pérez Zeledón y Buenos Aires, en la Zona Sur;

c. la zona comprendida entre Esparza, San Mateo, y la sección noroeste de la provincia de Puntarenas. Al margen de la delimitación de esta zona fronteriza, he escuchado con mucha frecuencia que hablantes adultos y mayores de Atenas aspiran /s/ frente a cualquier consonante 
sonora, lo cual indica que la zona de la aspiración de /s/, sea cual fuere el entorno que la condiciona, está -o ha estado- más extendida de lo que parece. Por lo tanto, fuera de los límites acordados o convenidos, se debe hacer concesiones y tratar de estudiar el fenómeno con mucho cuidado.

\subsection{Enclaves lingüísticos}

Además, en los mapas lingüísticos se ponen de relieve los enclaves migratorios que han dejado sus huellas dialectales en zonas lejanas a su origen. Entre ellos tenemos los lugares poblados por vallecentraleños en la Zona Noroeste (Tilarán, Naranjo, y Zapote en la Cordillera de Guanacaste; Carmona, Cerro Azul, Hojancha y Río Oro en la Península de Nicoya) y los focos de emigrantes guanacastecos en las zonas Atlántica y Sur.

\section{Limitaciones}

Para un futuro atlas linguiístico integral, se deben tener presentes las siguientes dificultades que salen al camino. En primer lugar, la variación climática de Costa Rica. Es de observar que los atlas linguíísticos tradicionales han sido confeccionados para zonas bastante homogéneas, sin cambios tan drásticos en su configuración climática como los que presenta Costa Rica. De ahí que la encuesta no se pudo aplicar de manera total en las regiones estudiadas. Si el clima es caliente, hay carencia de cultivos como el café; si es frío, se dan con dificultad cultivos como el maíz o el banano. De la misma manera se comportan la flora y la fauna, lo cual explica los campos vacíos en algunos mapas.

En segundo lugar, la movilización demográfica que el país ha sufrido en las últimas décadas, principalmente en las zonas periféricas al Valle Central, ha dado como resultado una mezcla dialectal que todavía no tiene visos de ser nivelada. En Matina me sucedió que, a una distancia de un kilómetro, habitaban dos familias de distintas procedencias por espacio de más de treinta años. Al confrontar con ellas las respuestas que me dieron, muchas de las palabras no fueron reconocidas por una o por otra familia. Habrá, pues, que aguardar a que la escuela sirva de niveladora en las generaciones jóvenes, las cuales sin duda serán las que decidan los rasgos lingüísticos que conformarán sus hablas.
En tercer lugar, hay que tener presente que las respuestas de los informantes tienen un contexto social y sicológico. Debido al poco prestigio de que gozan las hablas campesinas de Costa Rica (cfr. Q.P. 1989), muchos de los entrevistados se mostraban parcos, lacónicos, debido a que temían decir alguna palabra o frase que los delatara como campesinos. Algunos sentían que se los estaba examinando y se limitaban a responder con las palabras técnicas empleadas por el agrónomo o veterinario del pueblo. Por lo tanto, se corre el riesgo de que los verdaderos usos queden enterrados en el miedo y no sean llevados a flote.

\section{Final}

Debo aclarar que, dada la carencia de estudios dialectológicos sobre el español de Costa Rica, la división geográfico-dialectal propuesta es sólo tentativa, general, y responde a mis observaciones en el terreno. La continuidad en esta clase de estudios irá modificando dicha división dialectal del país y la enmarcará dentro de su realidad linguiística, según corresponda a los resultados que deparen tales estudios.

En segundo lugar, y apoyado en la historia de la lengua española en nuestro país (Quesada Pacheco 1987, 1990), los mapas permiten apreciar las grandes contribuciones que el habla del Valle Central y el habla del Guanacaste han dado a otras partes del territorio nacional, en particular la Zona Norte, la Zona Atlántica y la Zona Sur. Lo anterior se explica por el flujo de emigrantes. Más significativo aún es el intercambio de rasgos dialectales que se ha dado en distintas regiones del territorio a causa de la migración. Un ejemplo bien representativo es la sección suroeste de la Península de Nicoya, a partir de Hojancha y Carmona, donde los inmigrantes oriundos del Valle Central han incorporado el léxico del sabanero guanacasteco, y éste, por su parte, ha tomado designaciones vallecentraleñas para la siembra y procesamiento de algunos productos agrícolas tradicionales.

En suma, el Pequeño Atlas Lingüístico de Costa Rica es un paso más en la consecución de una obra que, sin lugar a dudas, llegará a enriquecer y transformar el panorama dialectológico de Costa Rica.

\section{Mapas}




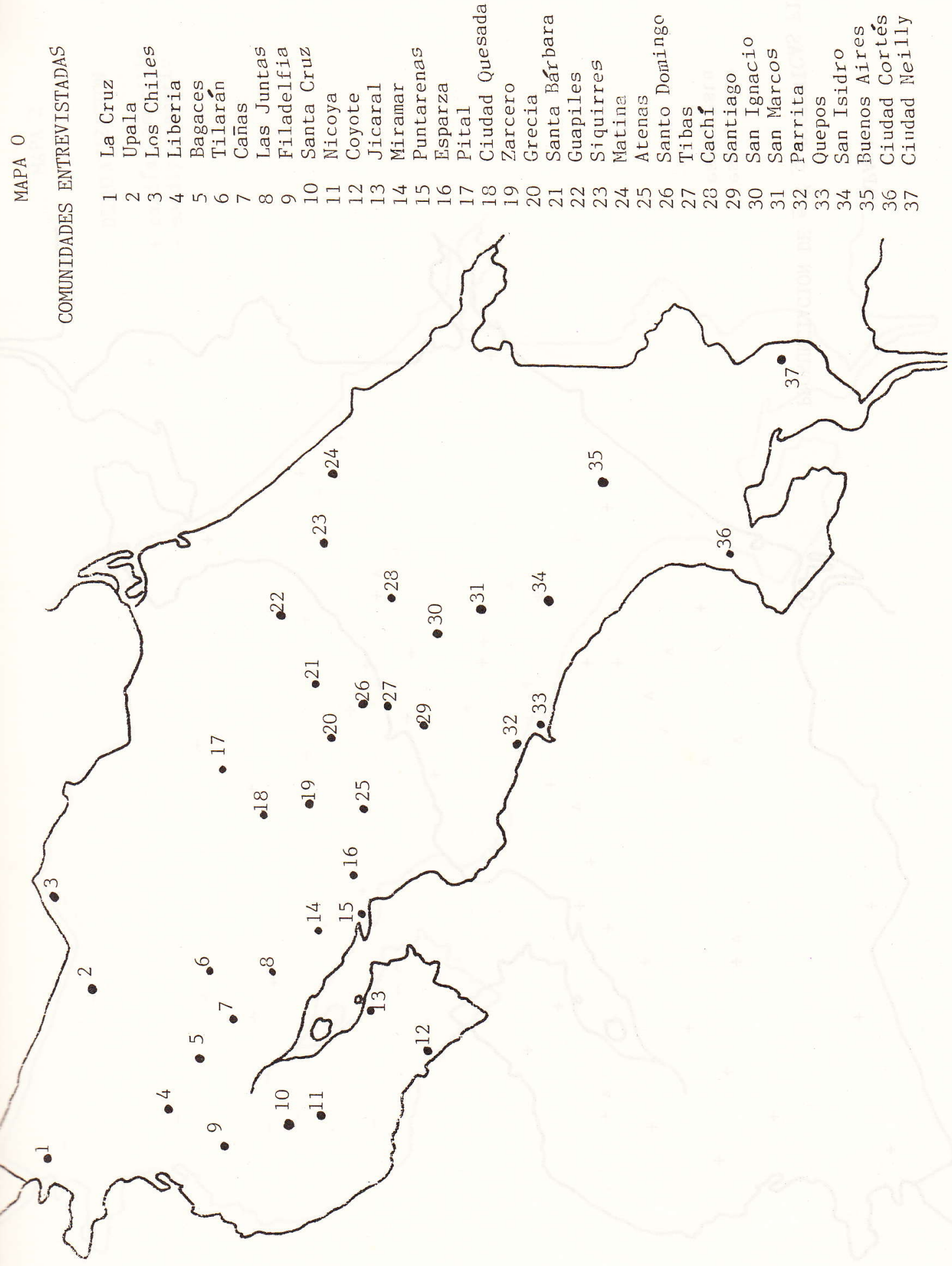




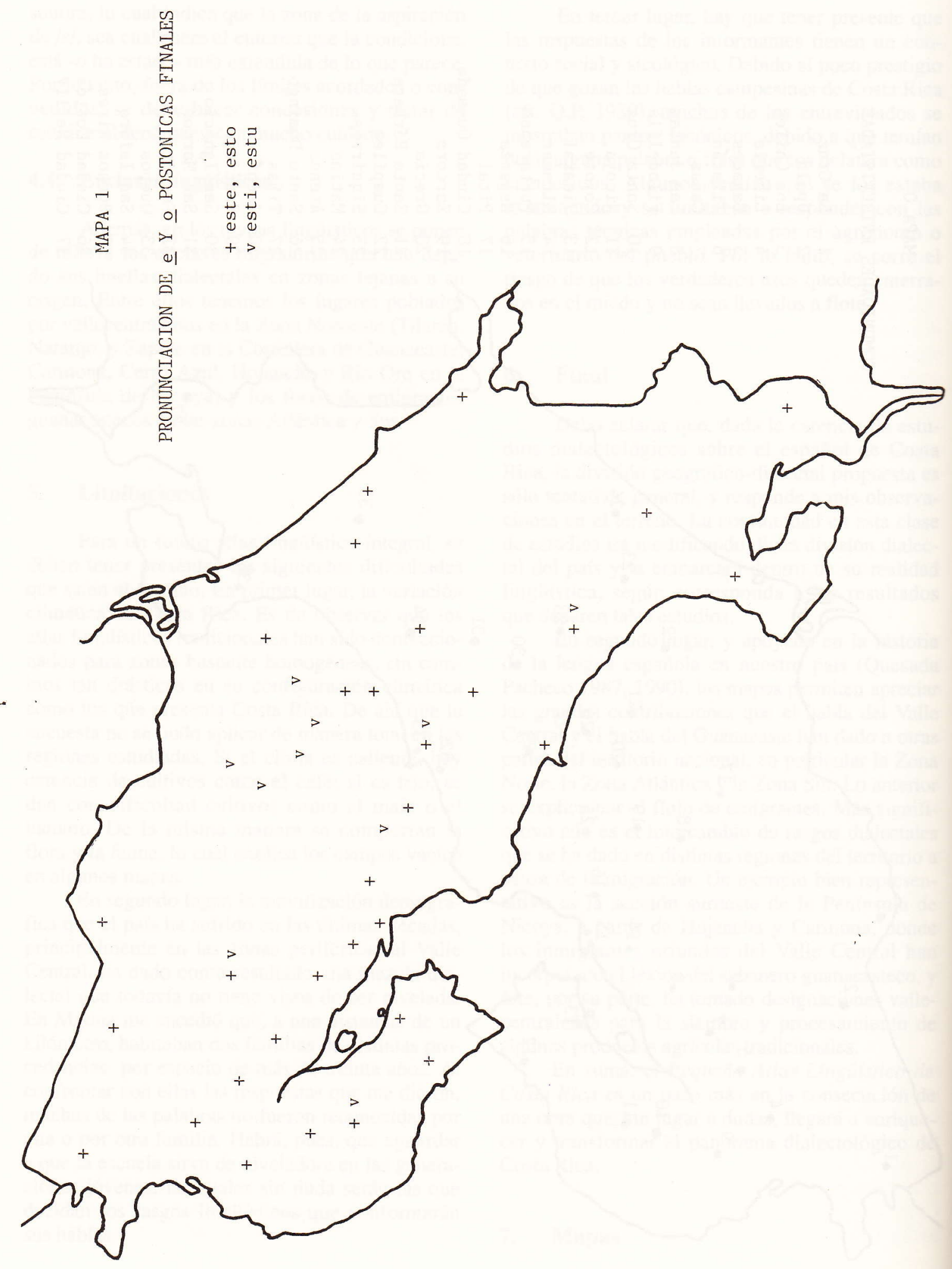




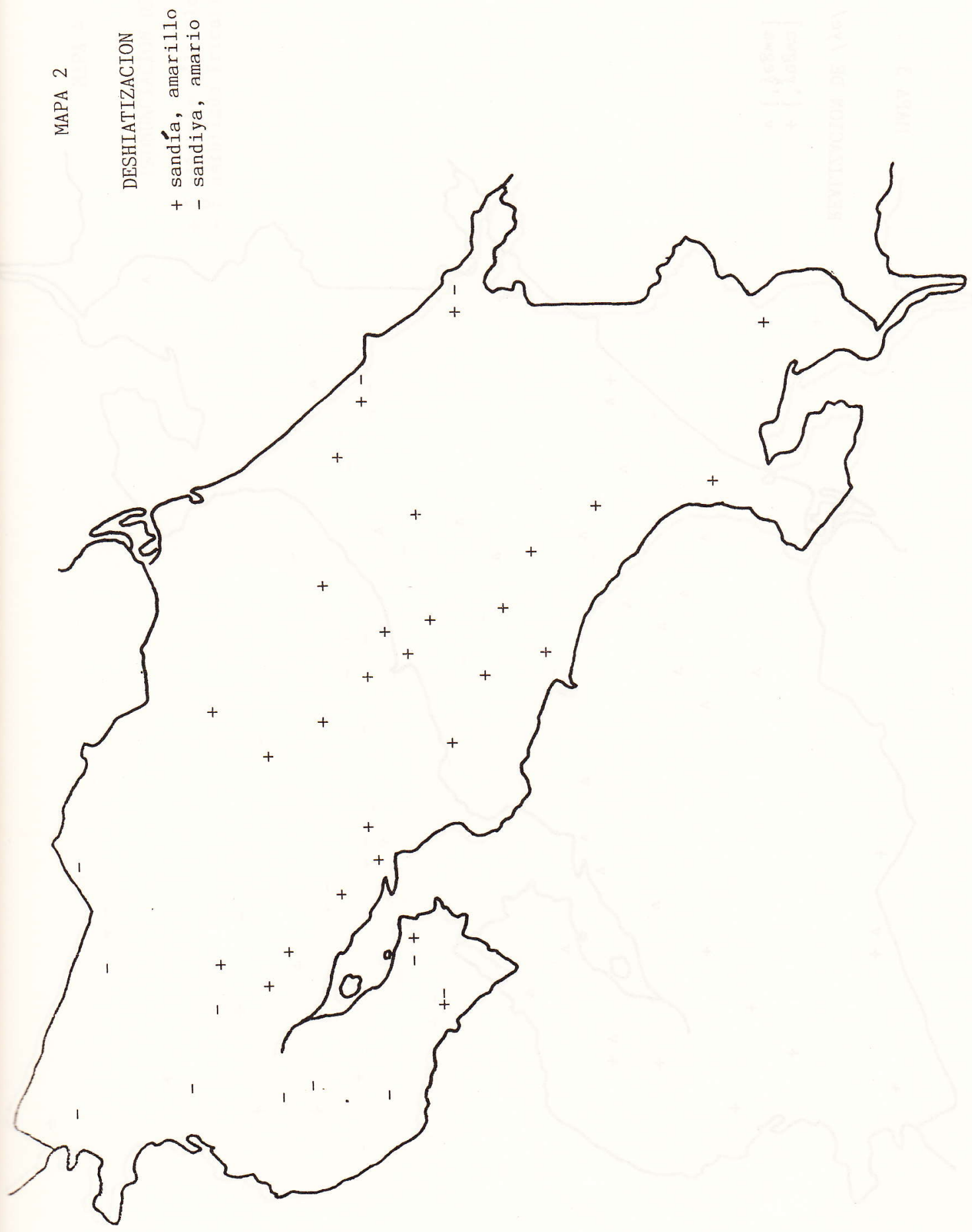




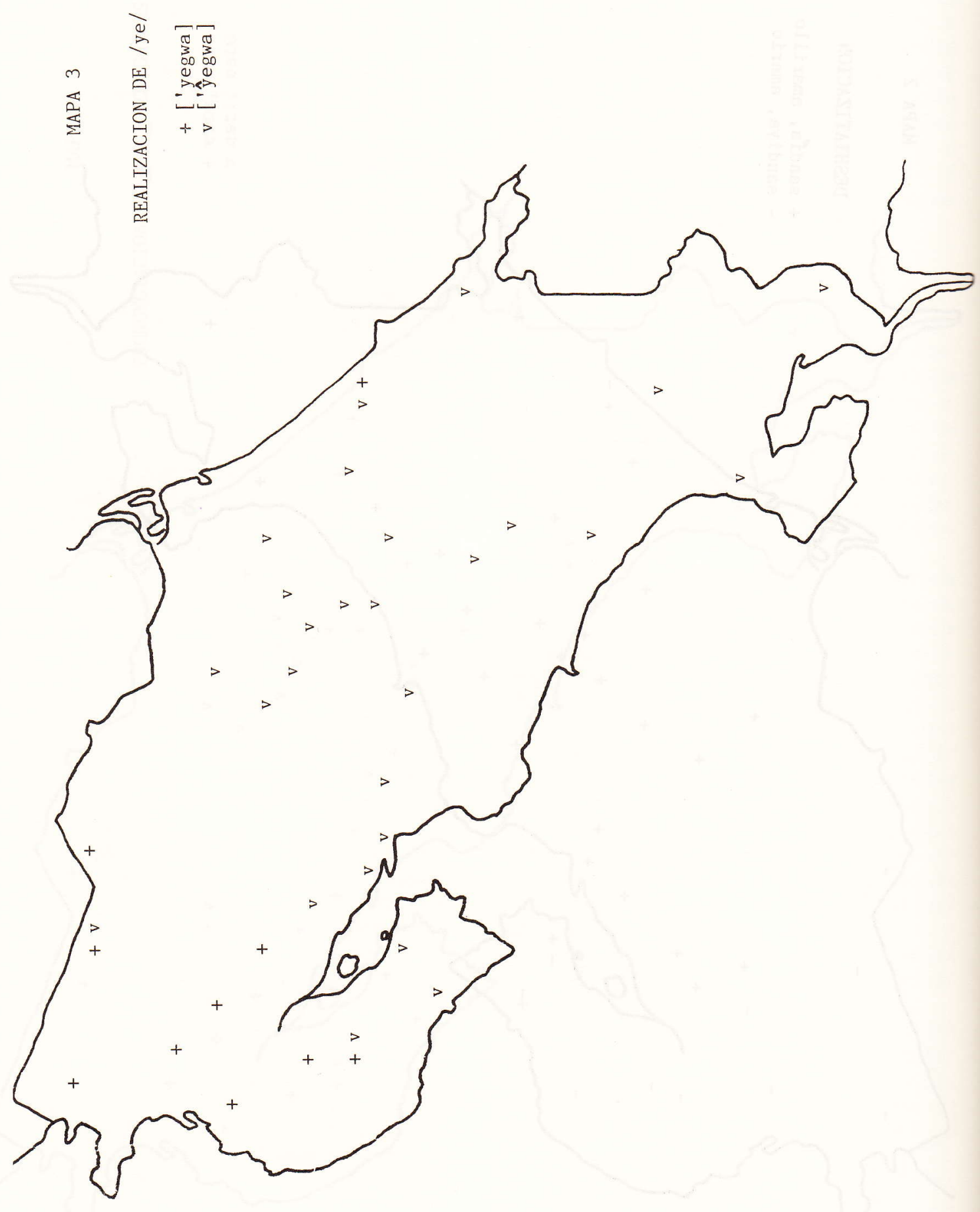




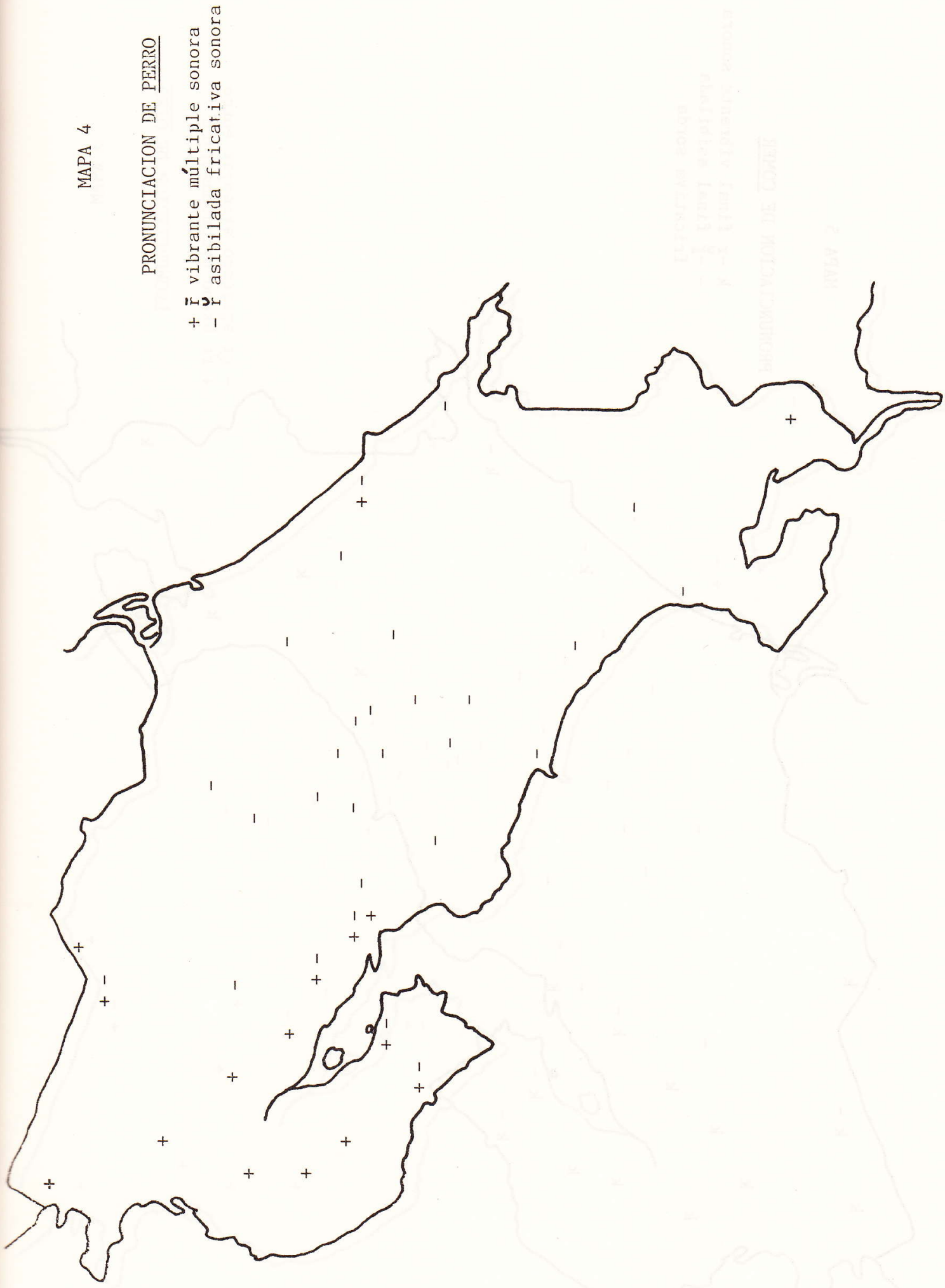




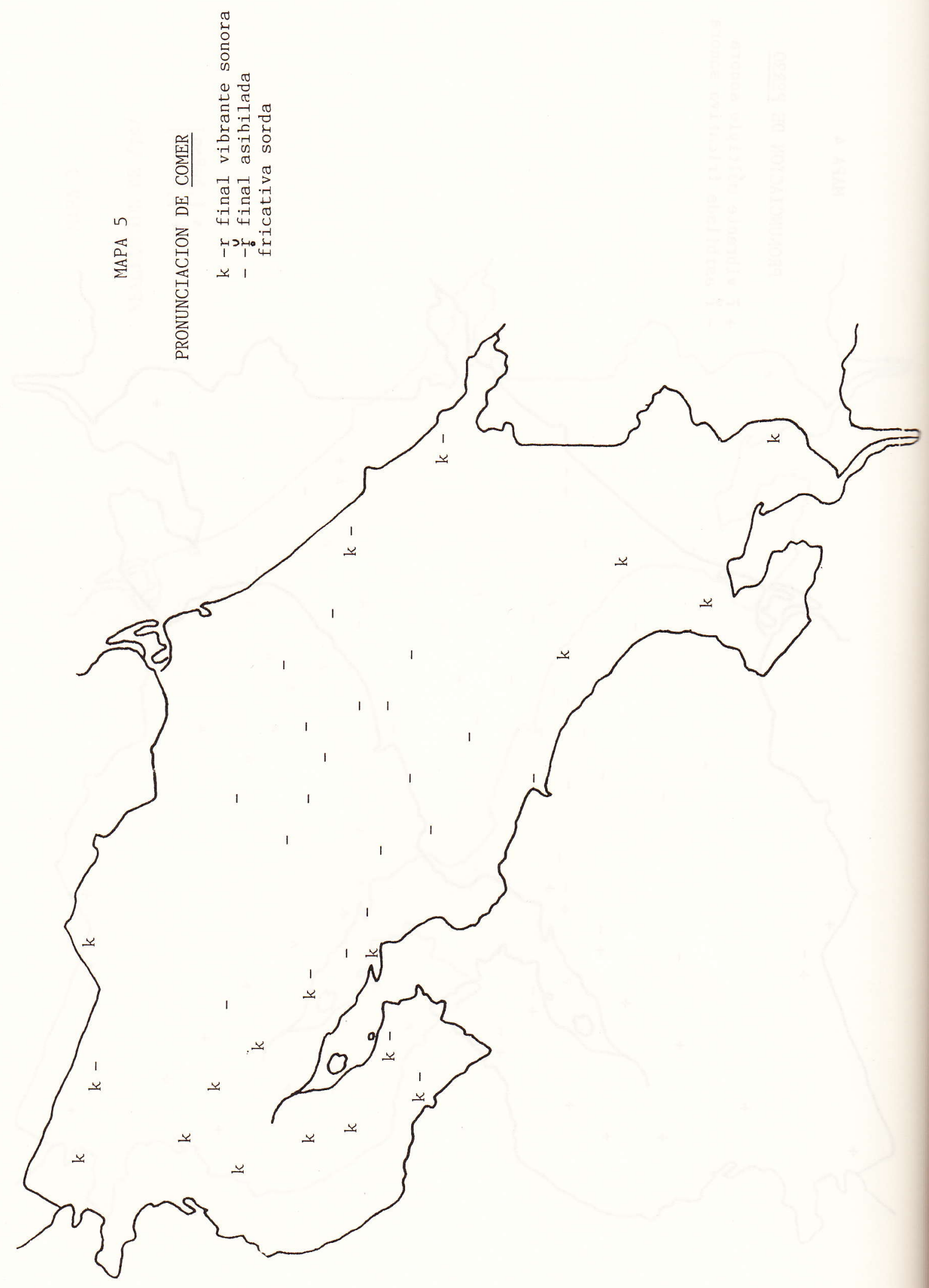




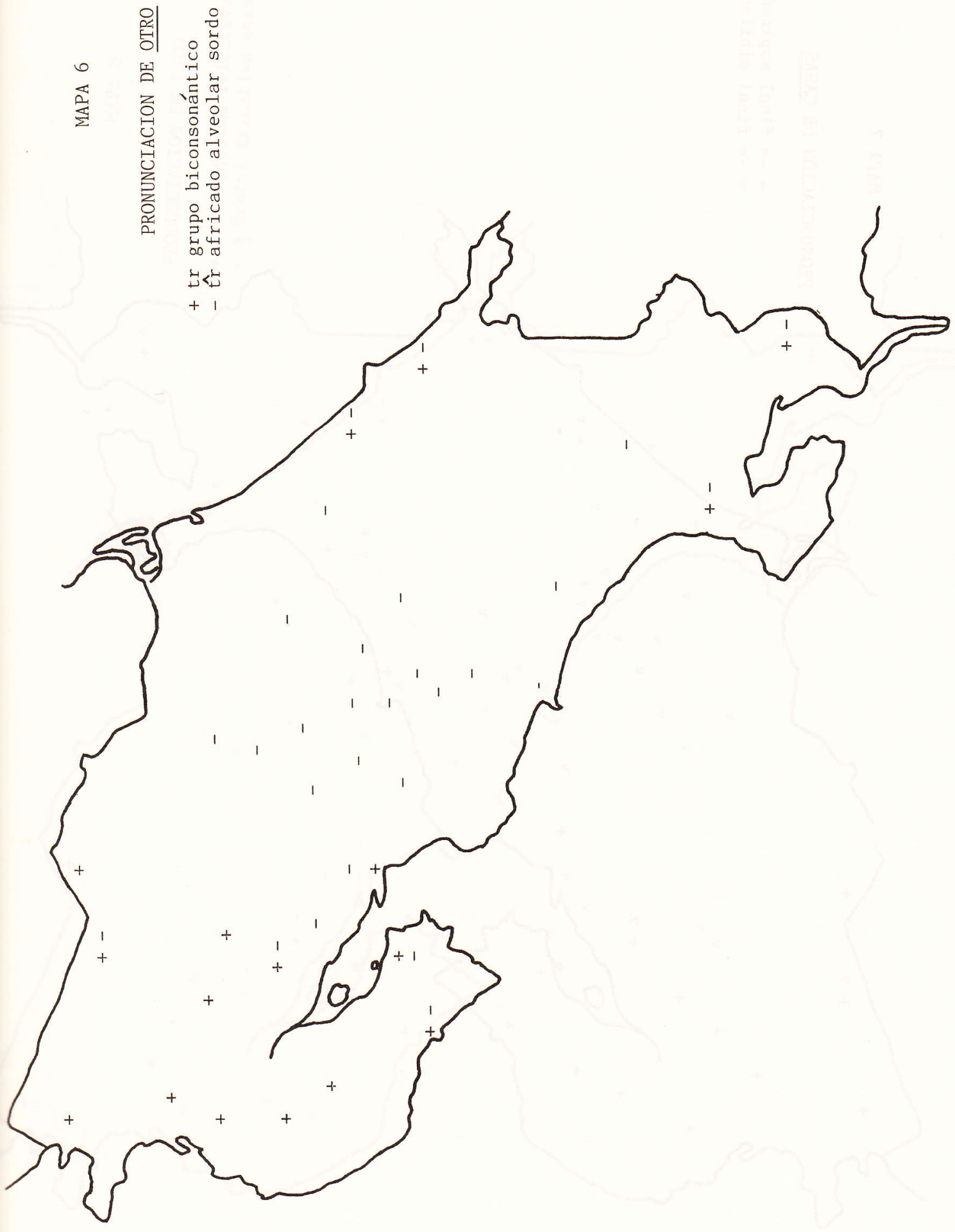




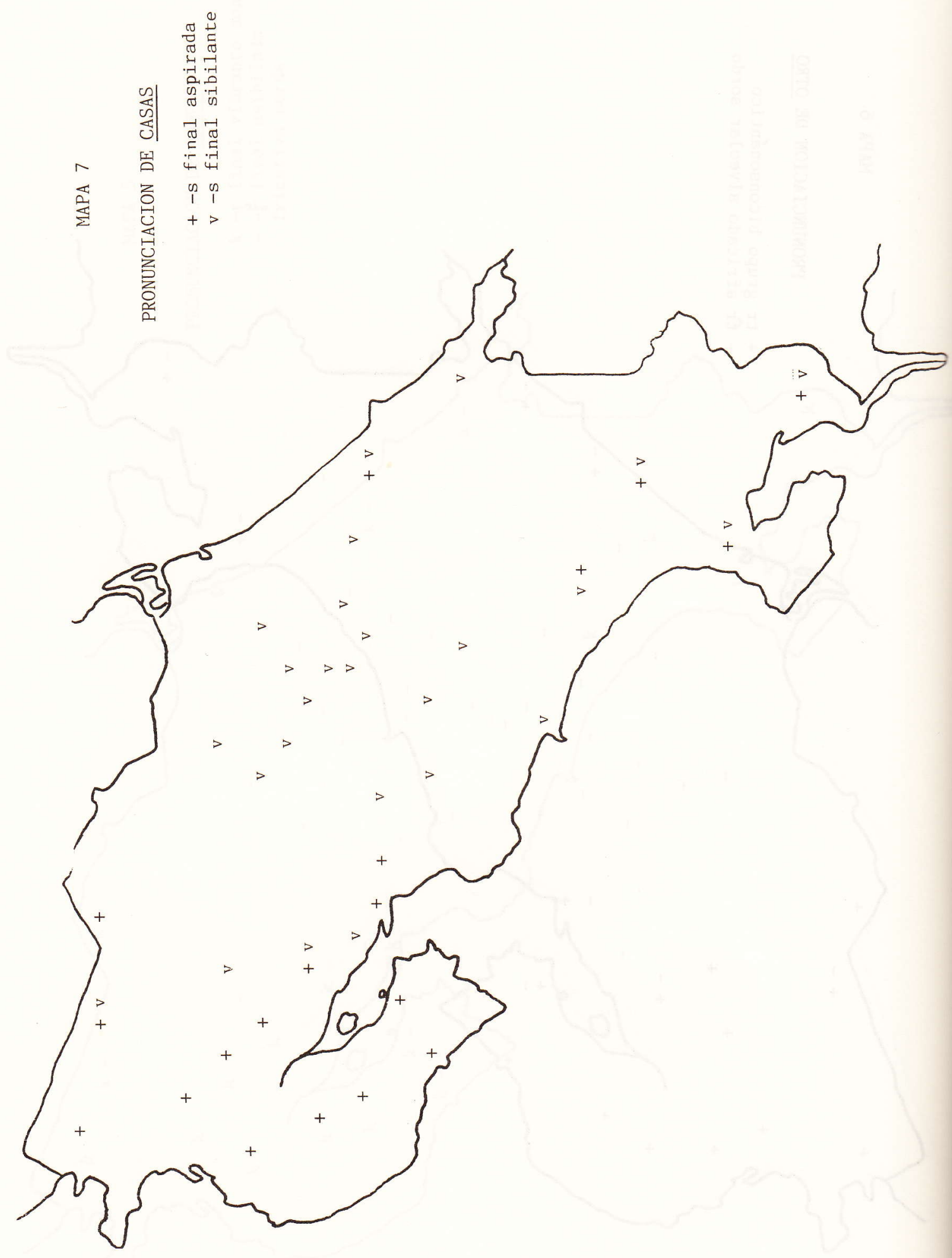




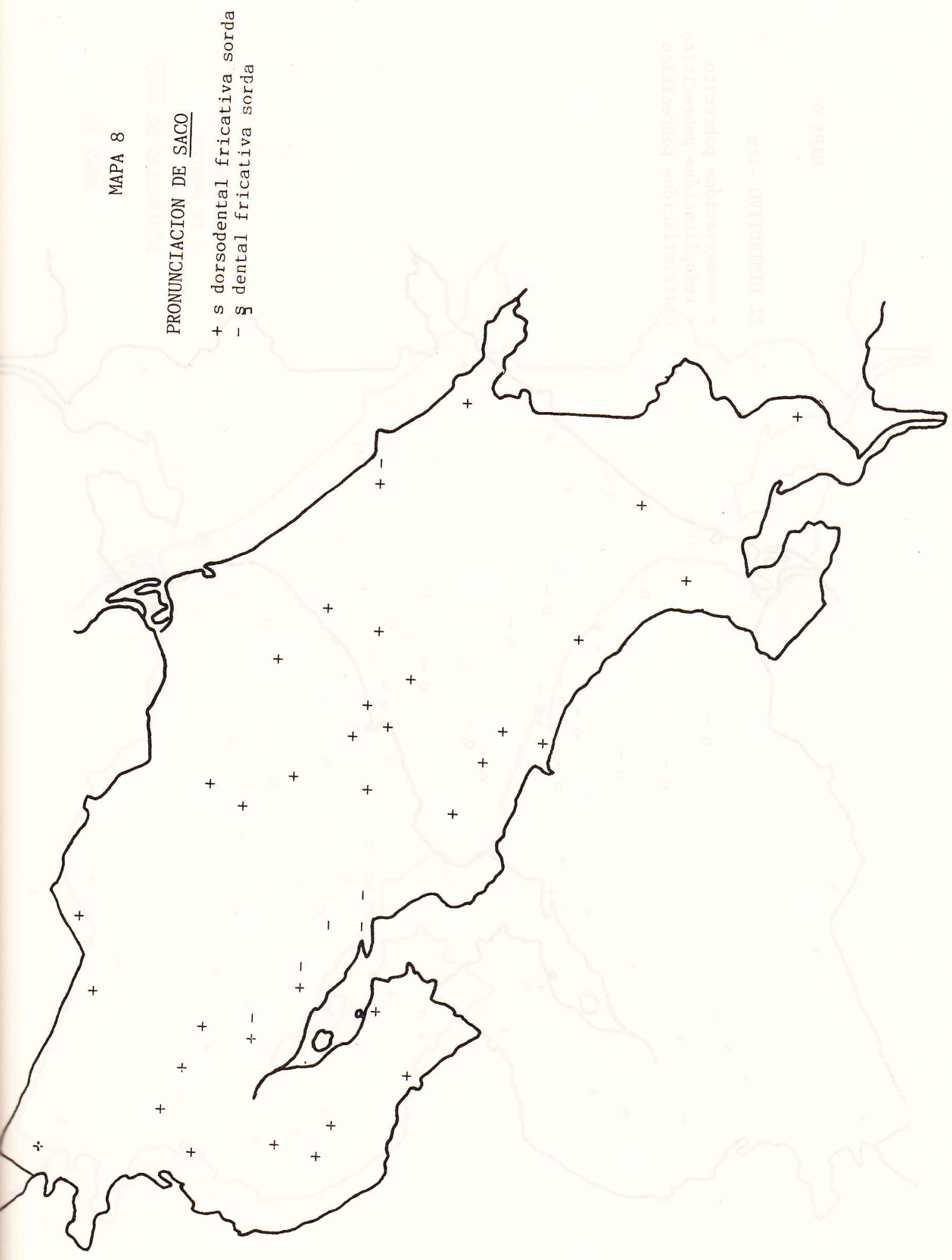




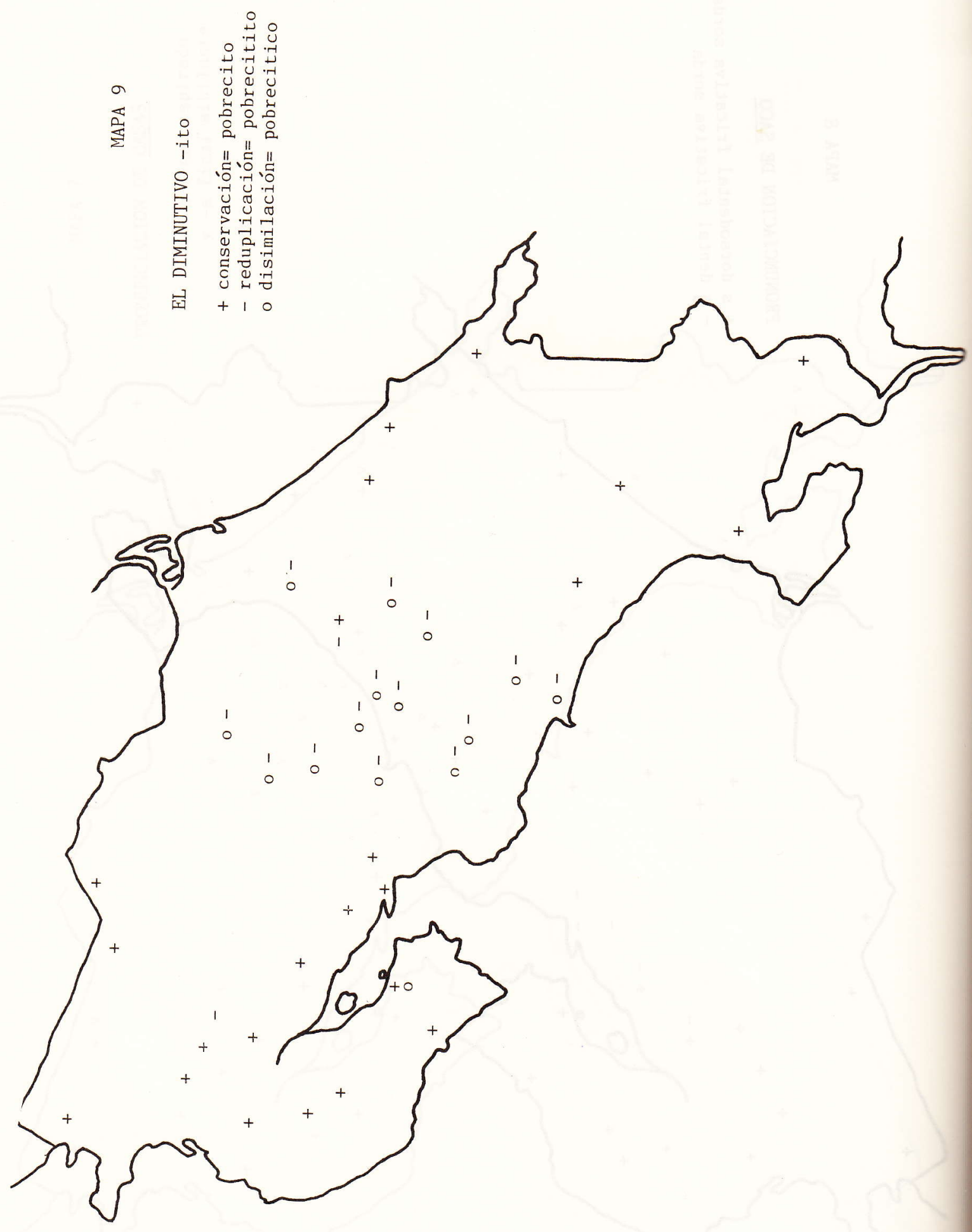




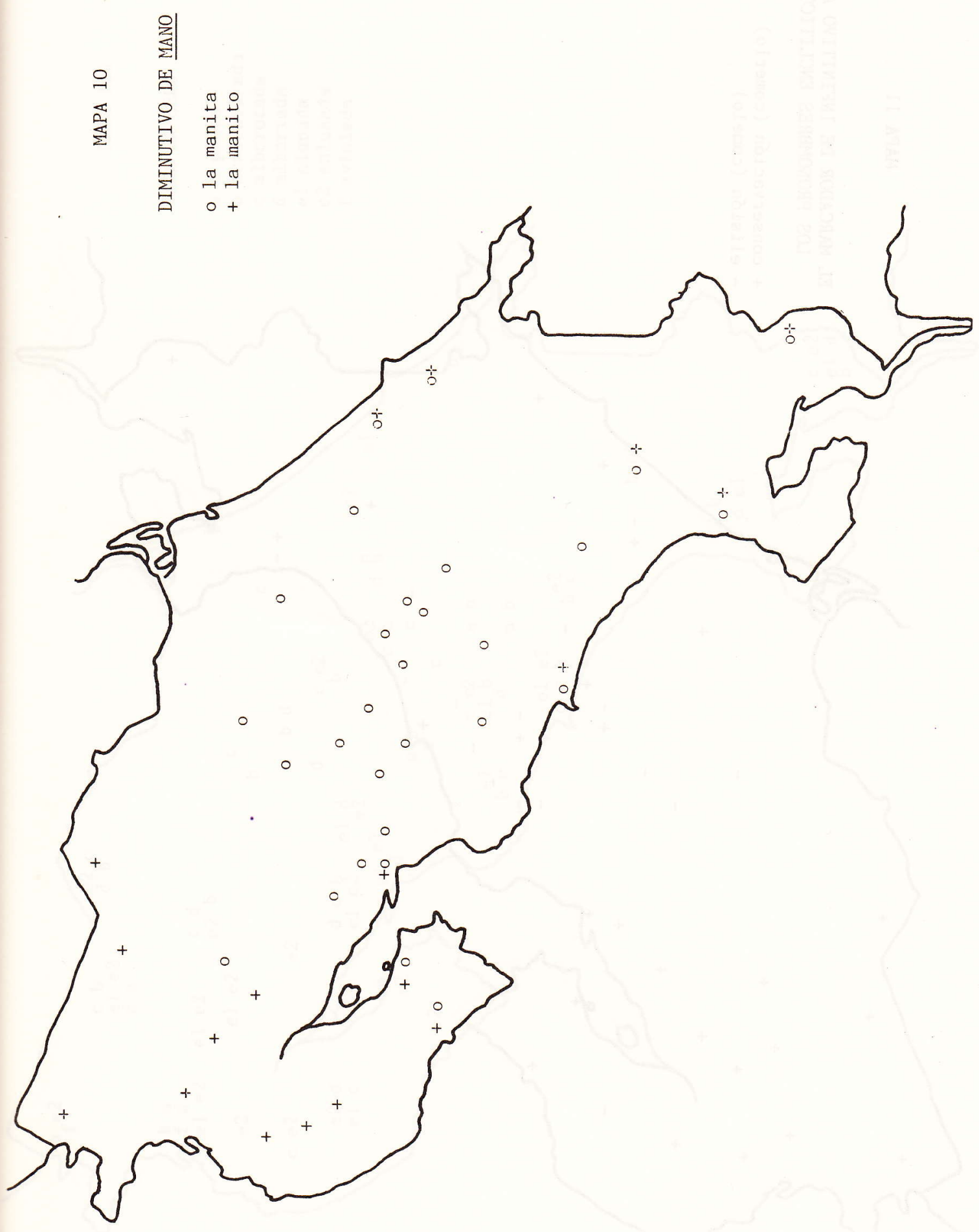




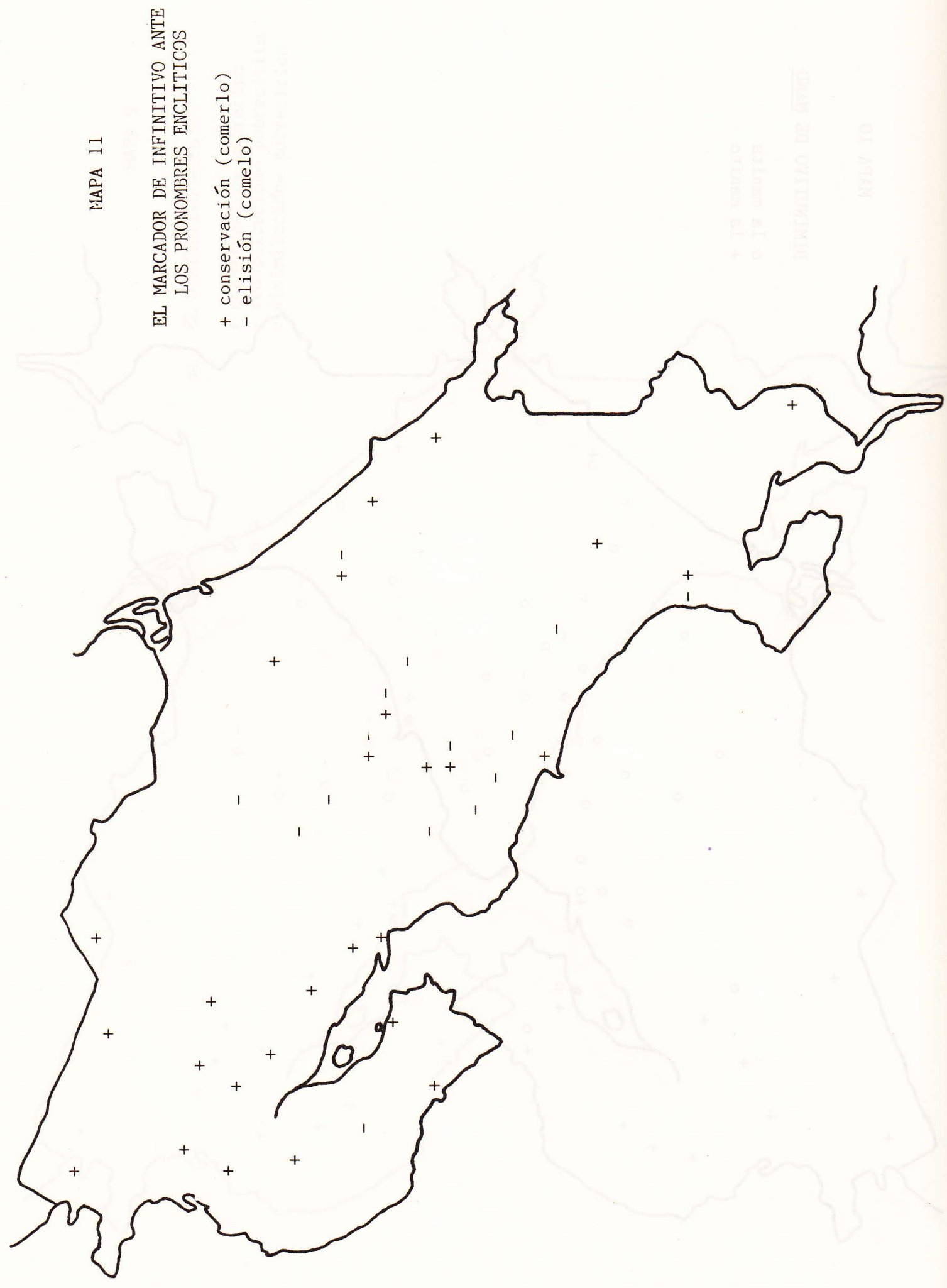




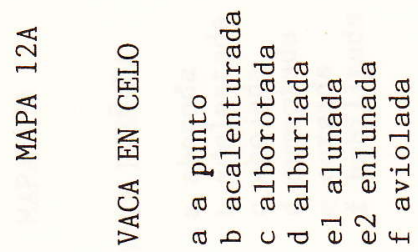

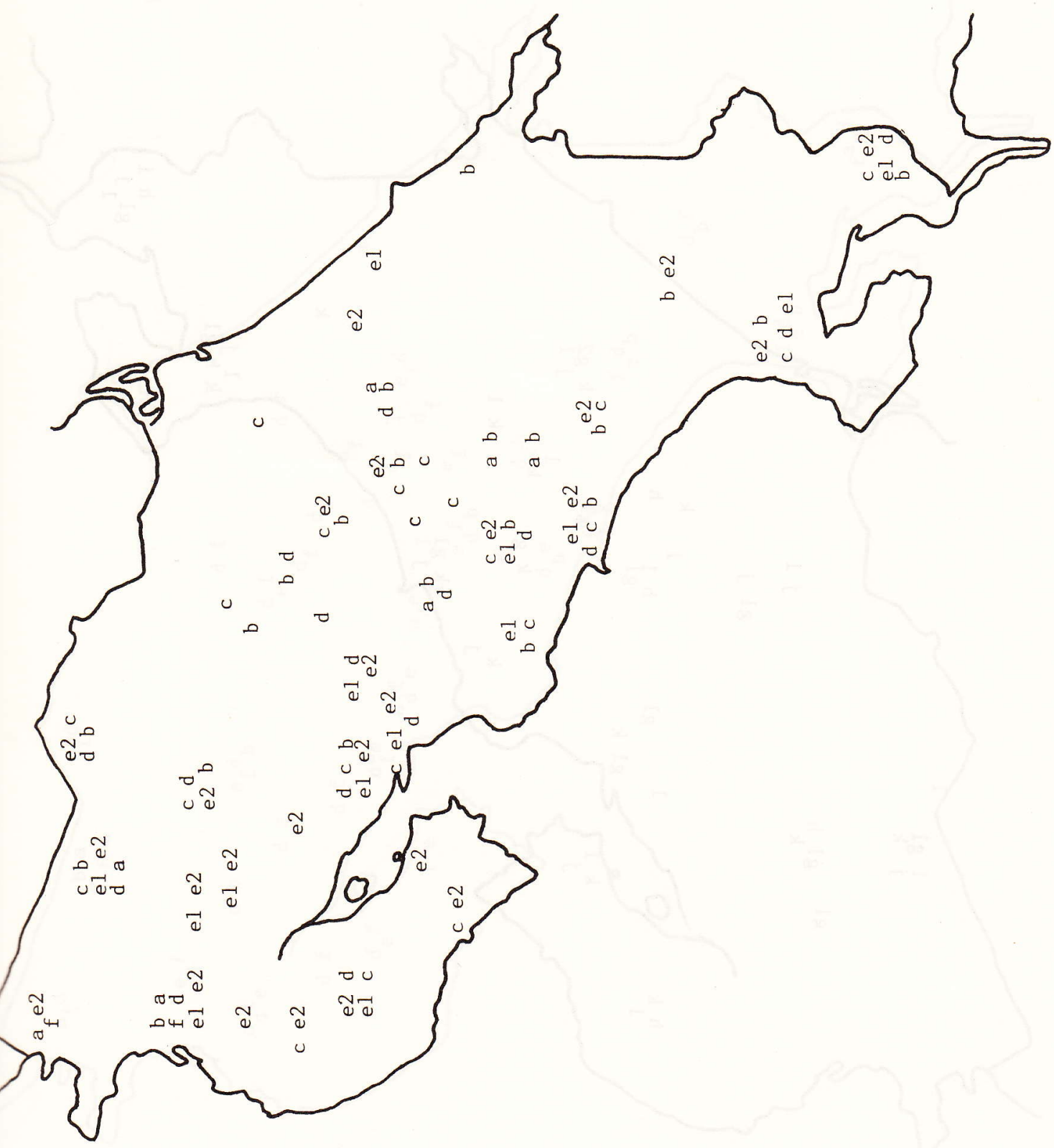



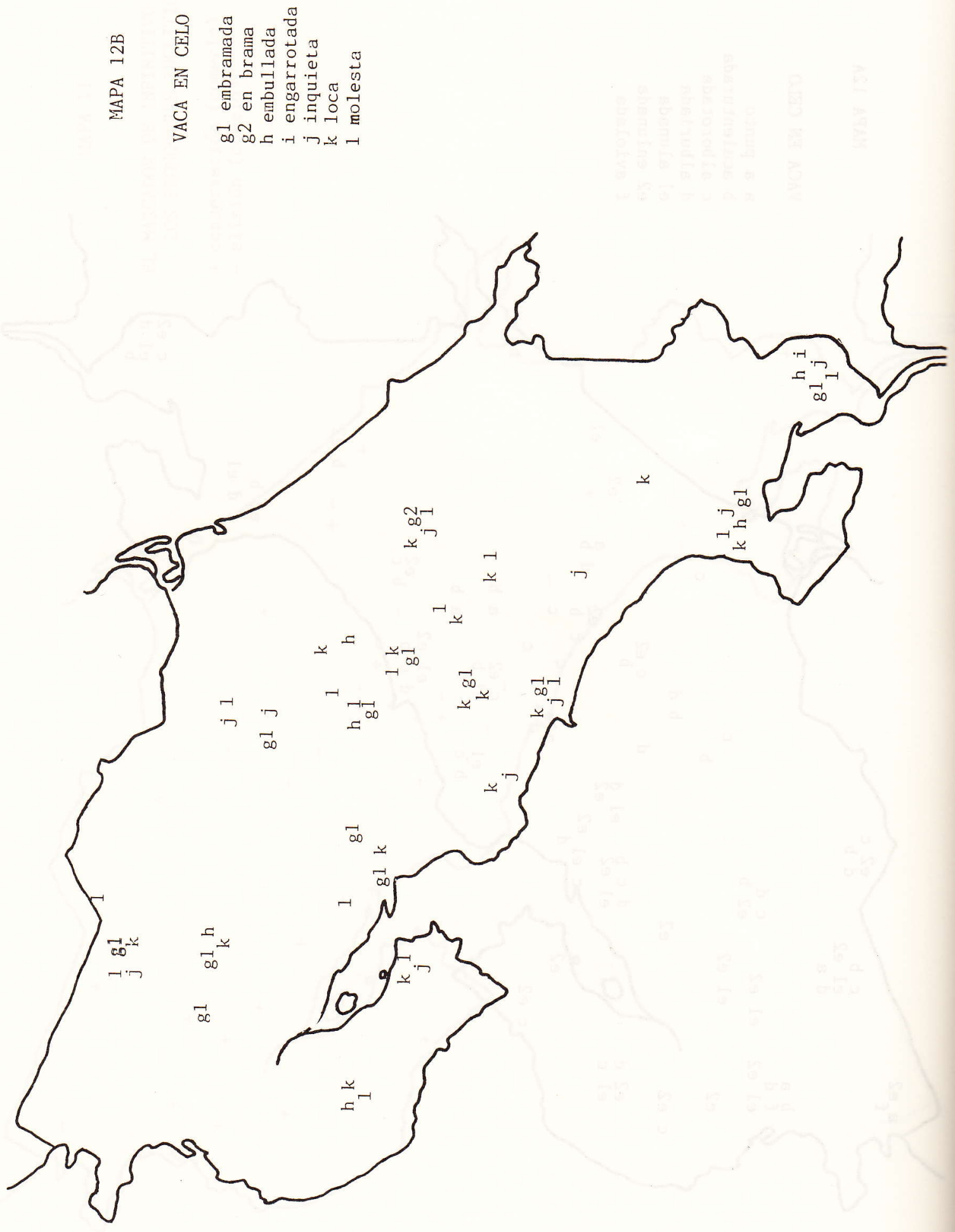

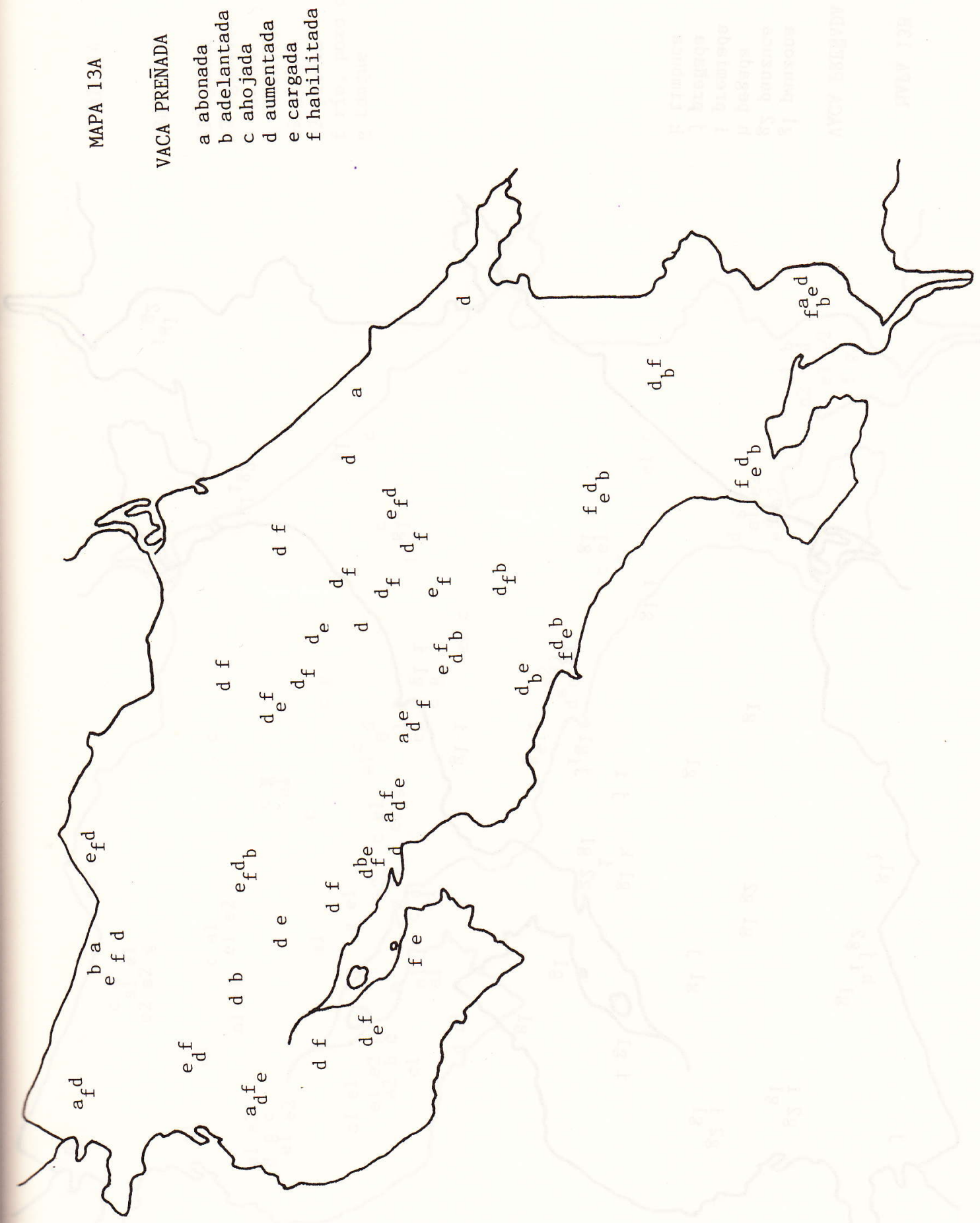


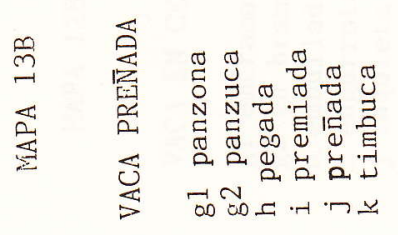

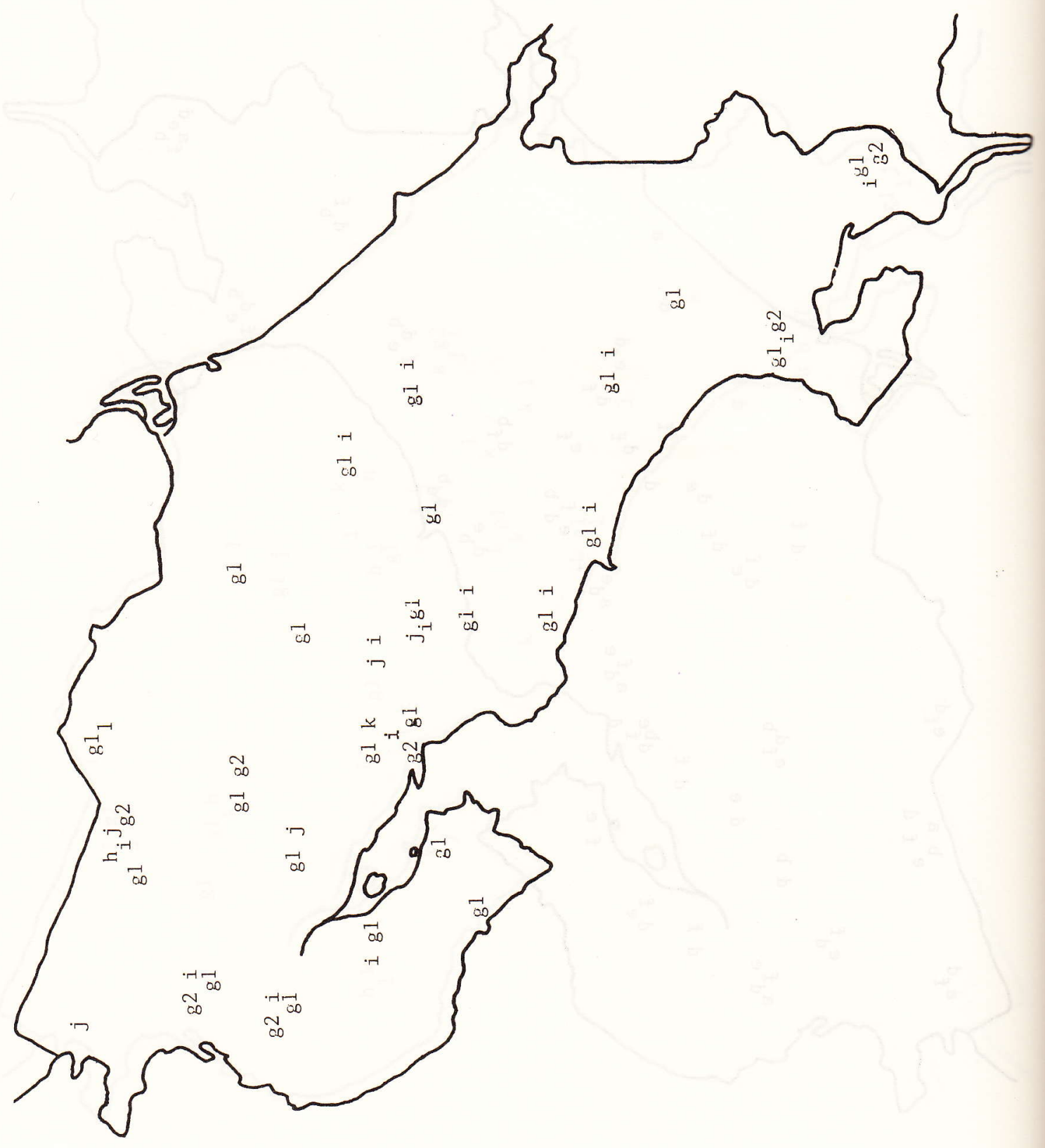



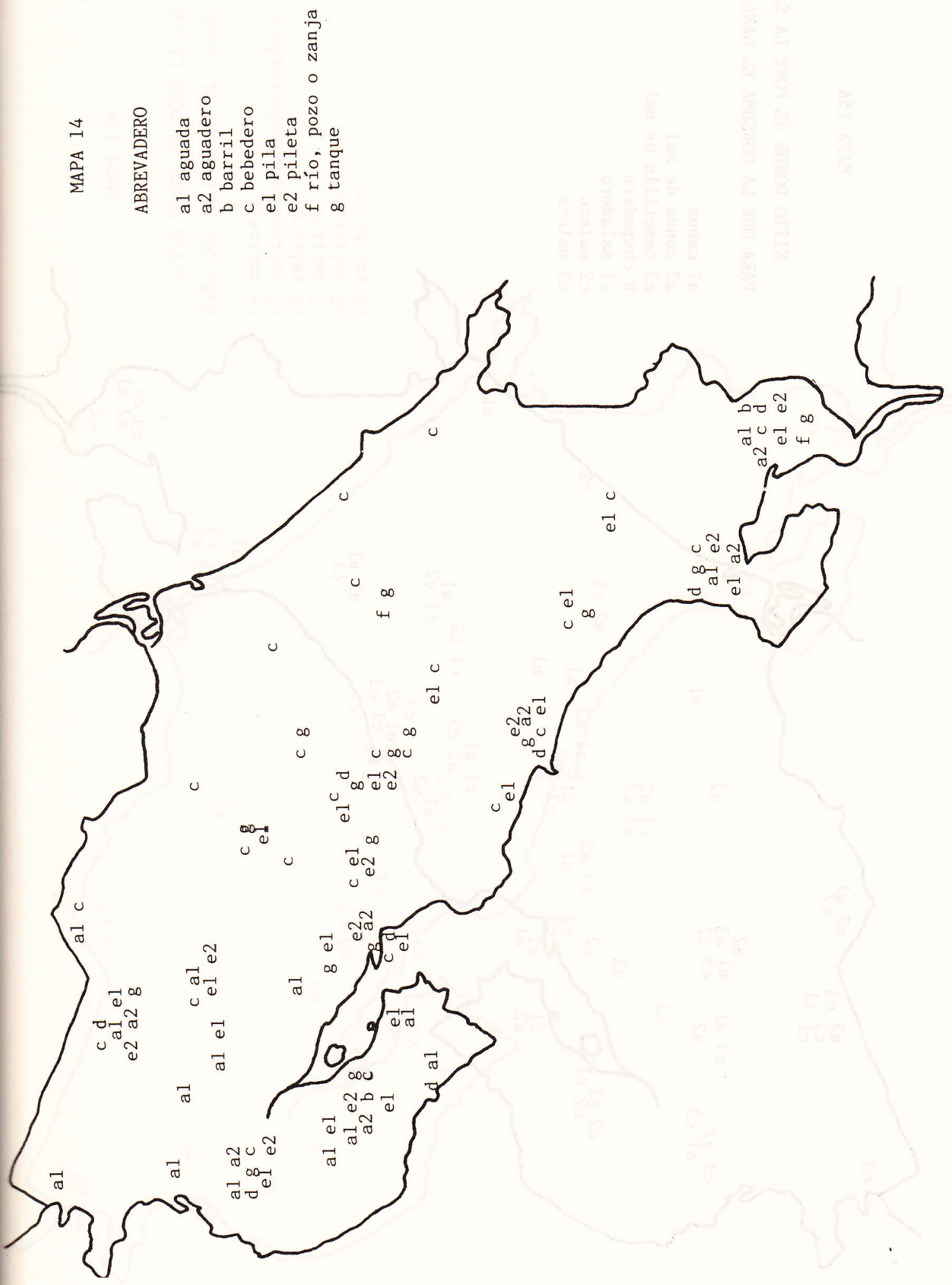


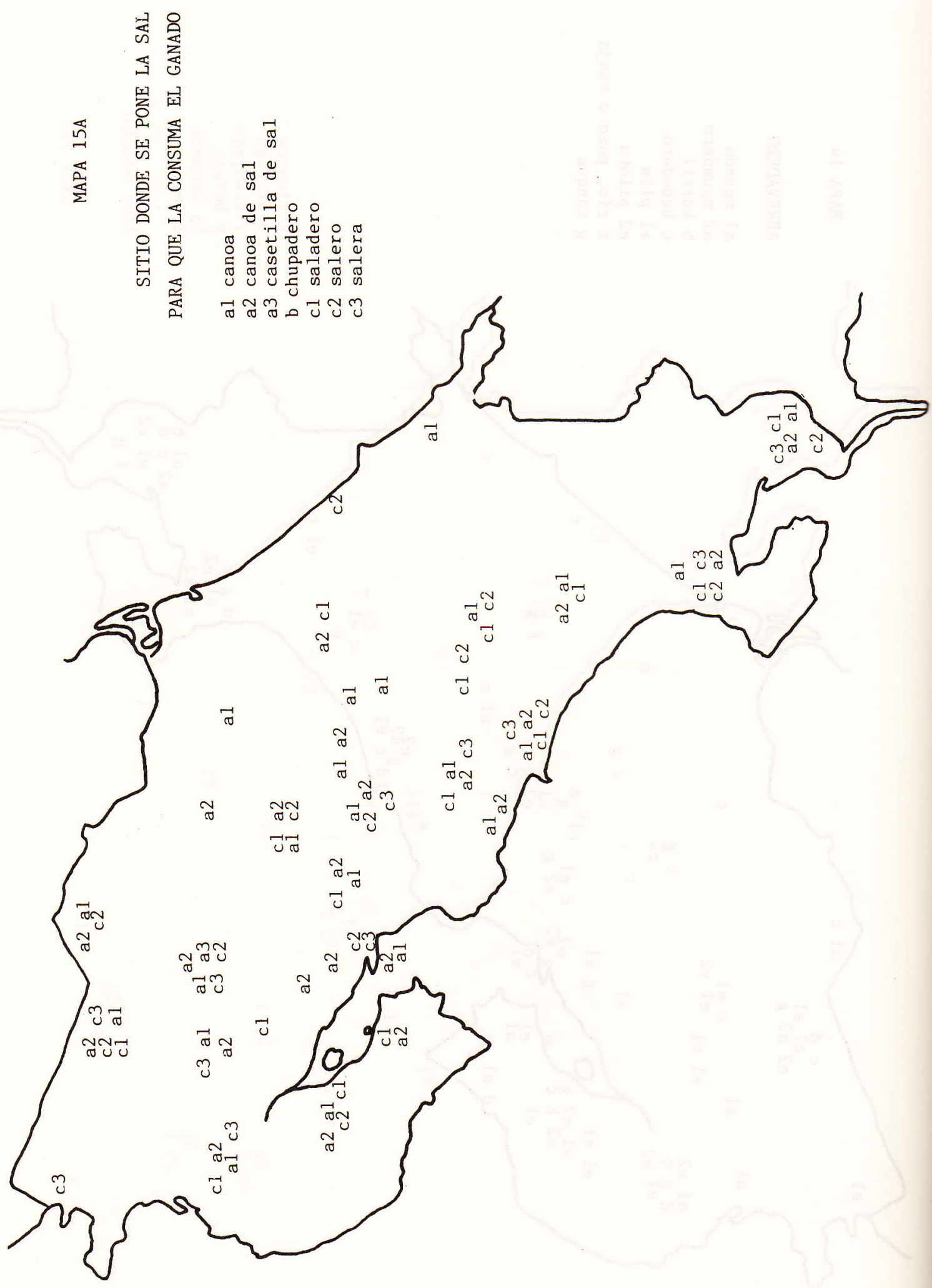




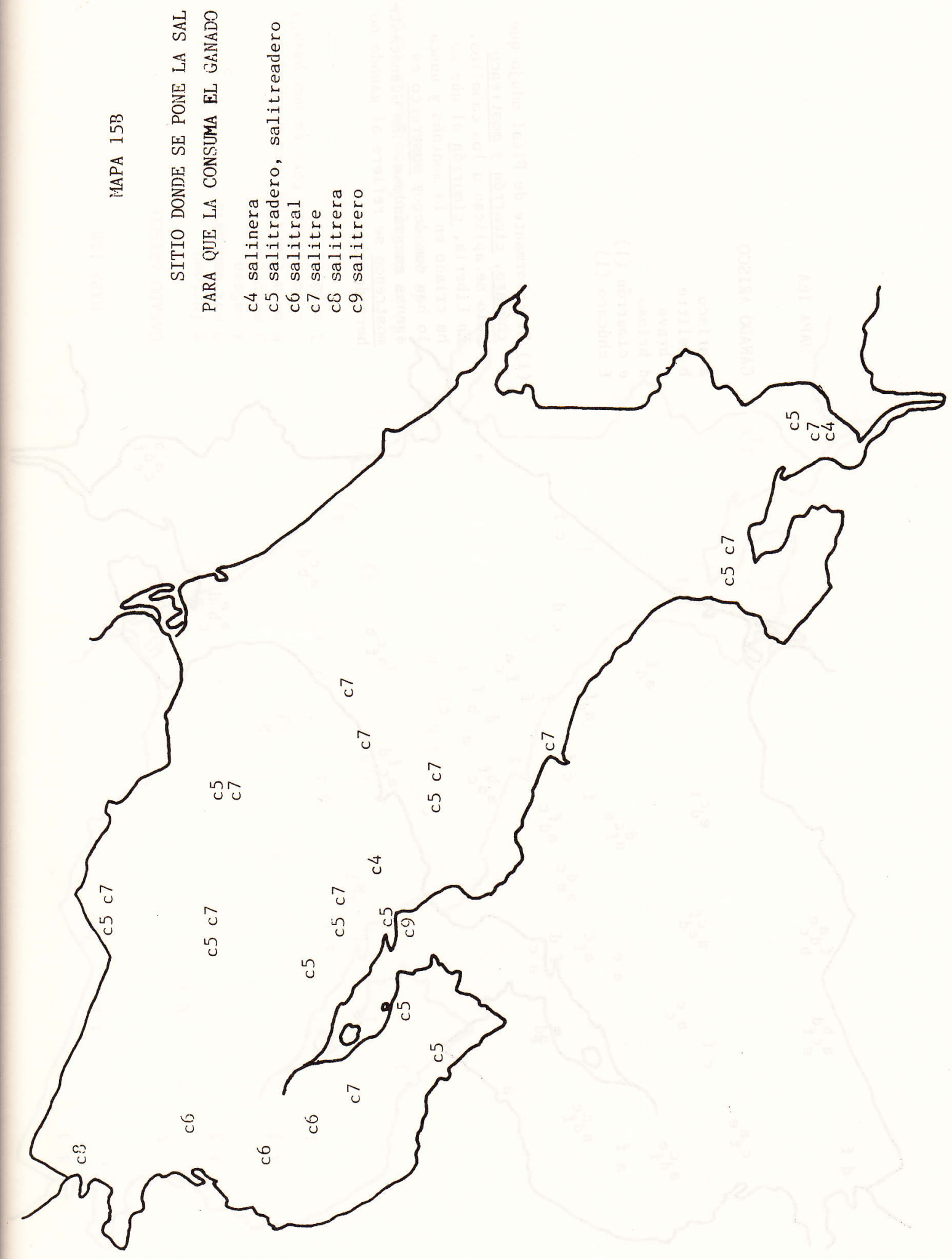




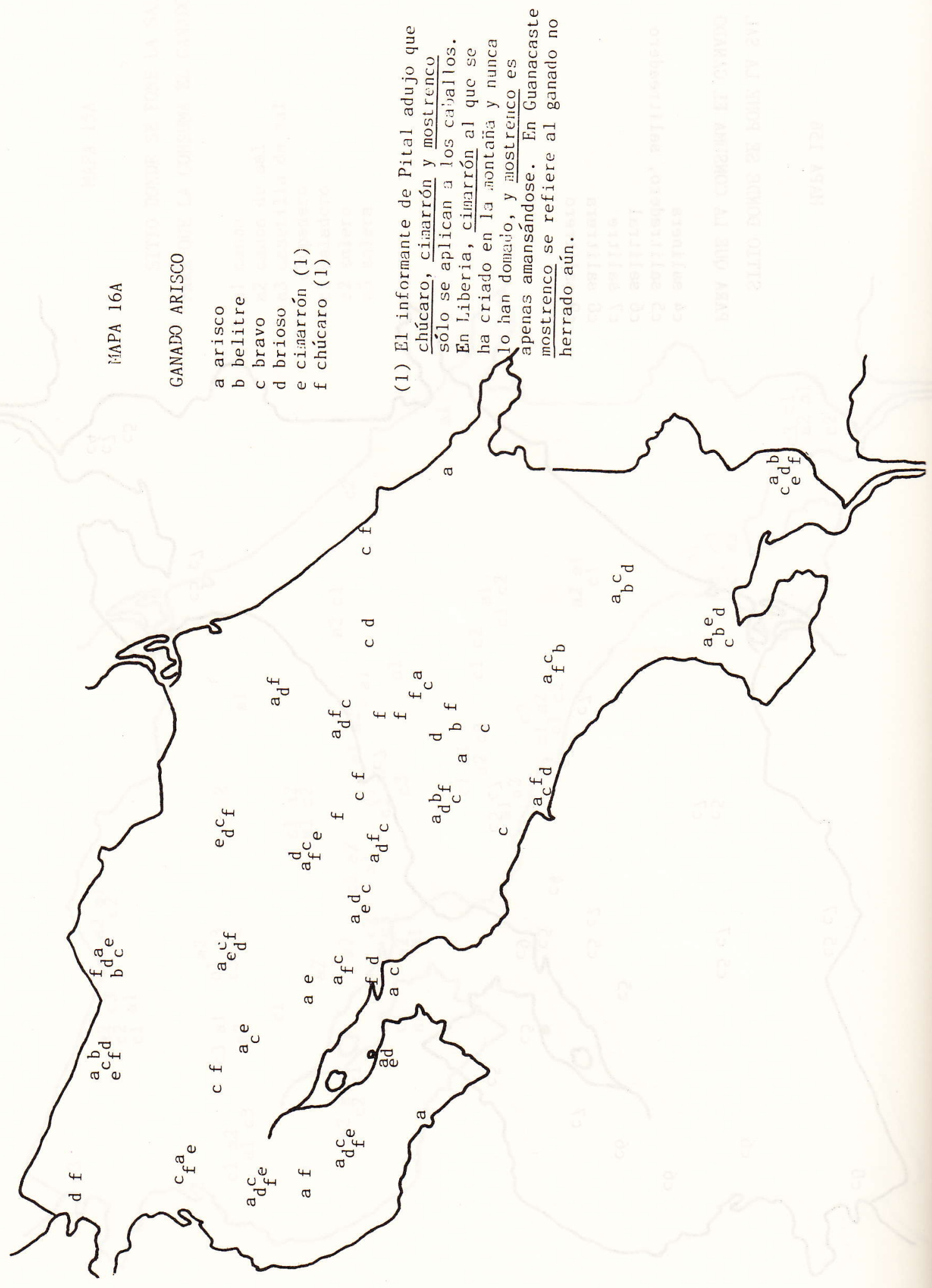



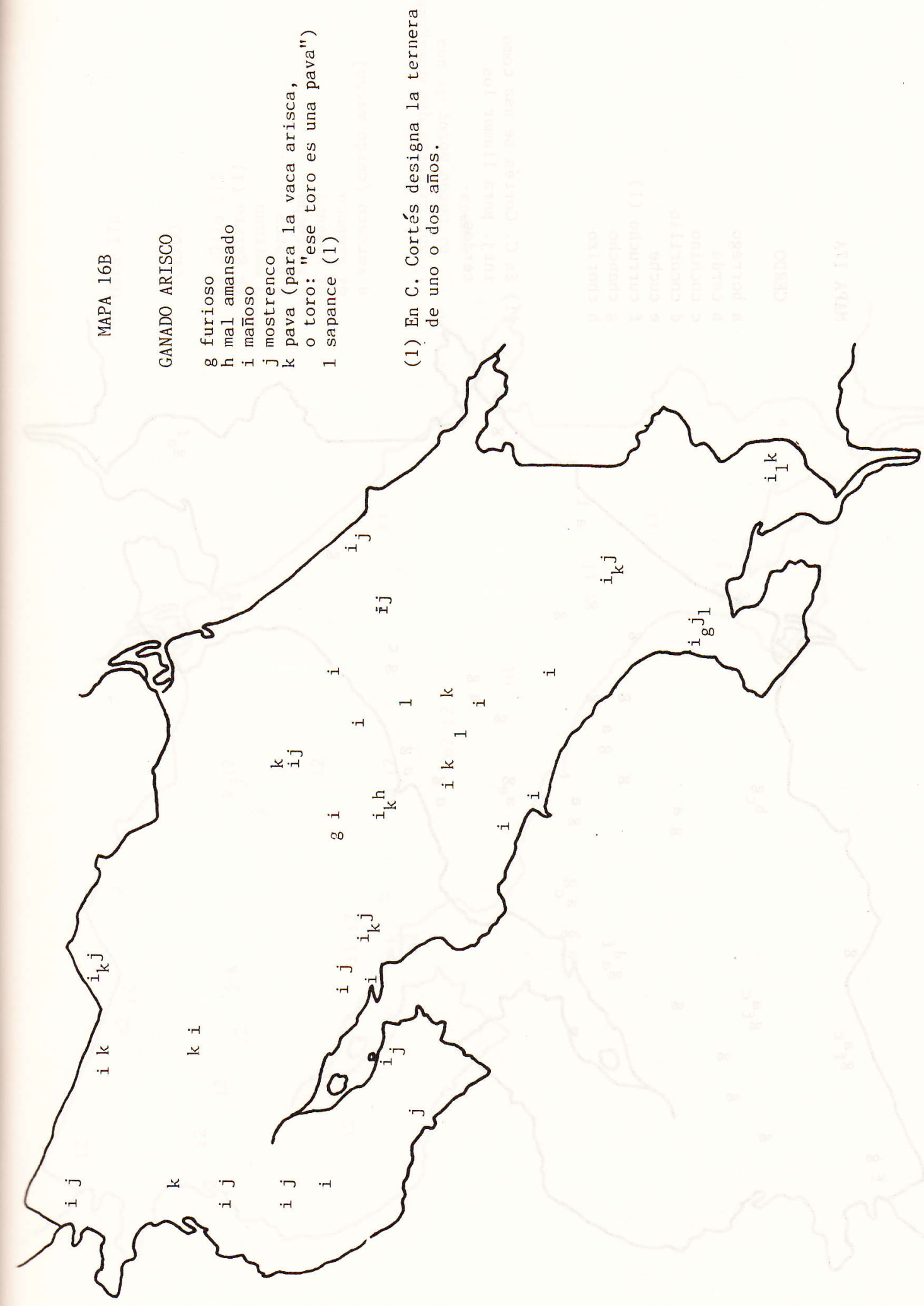


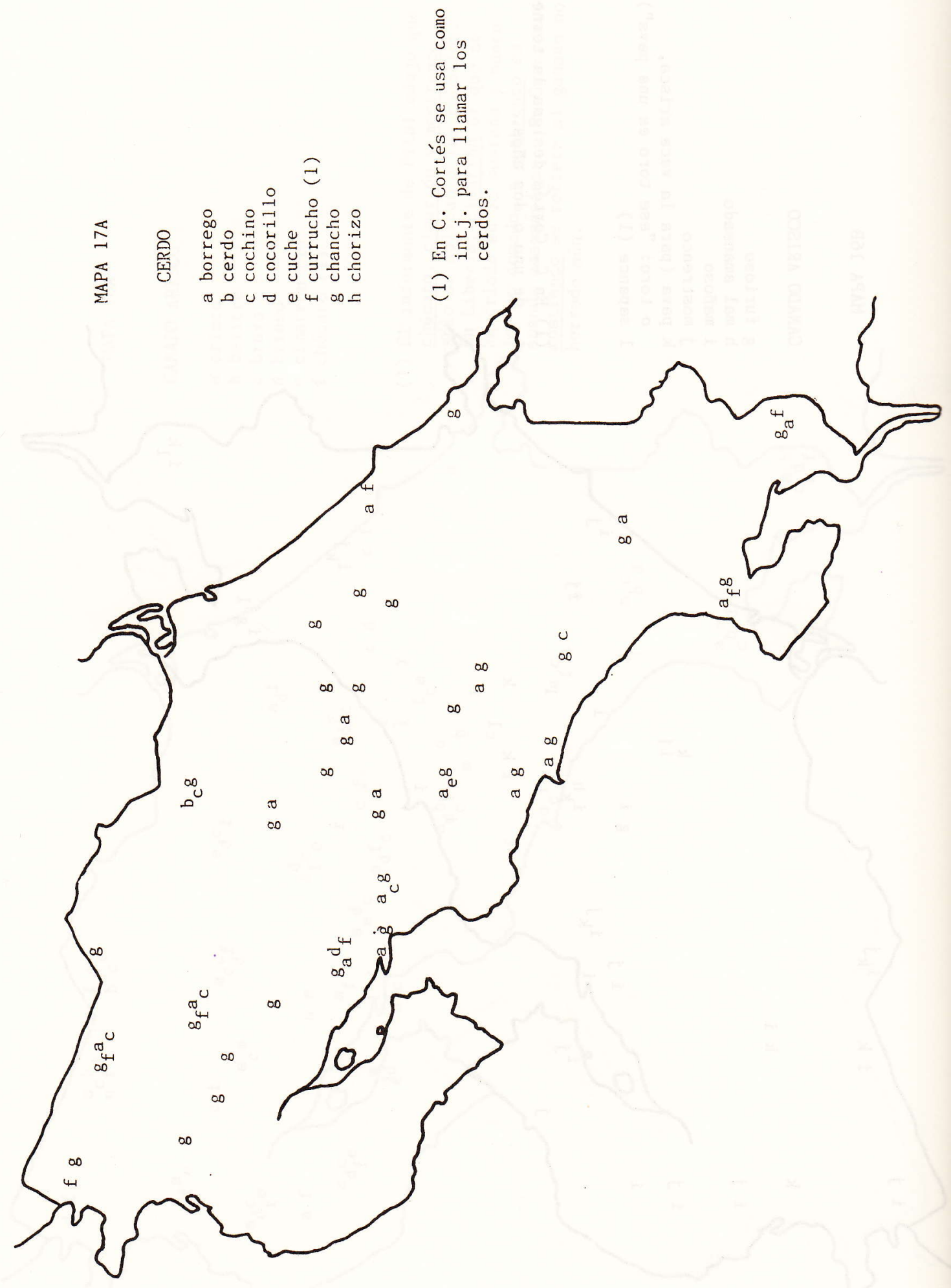




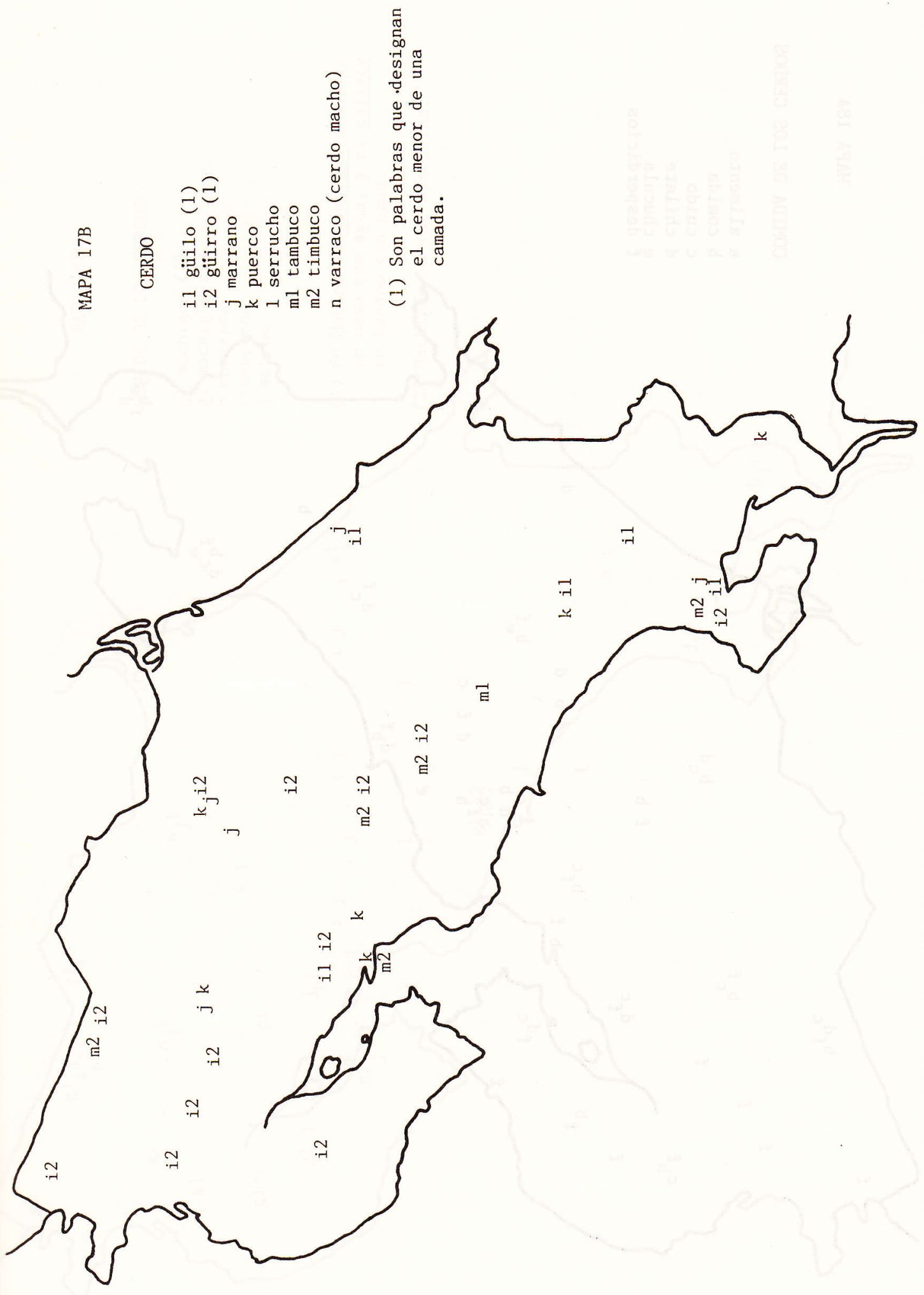




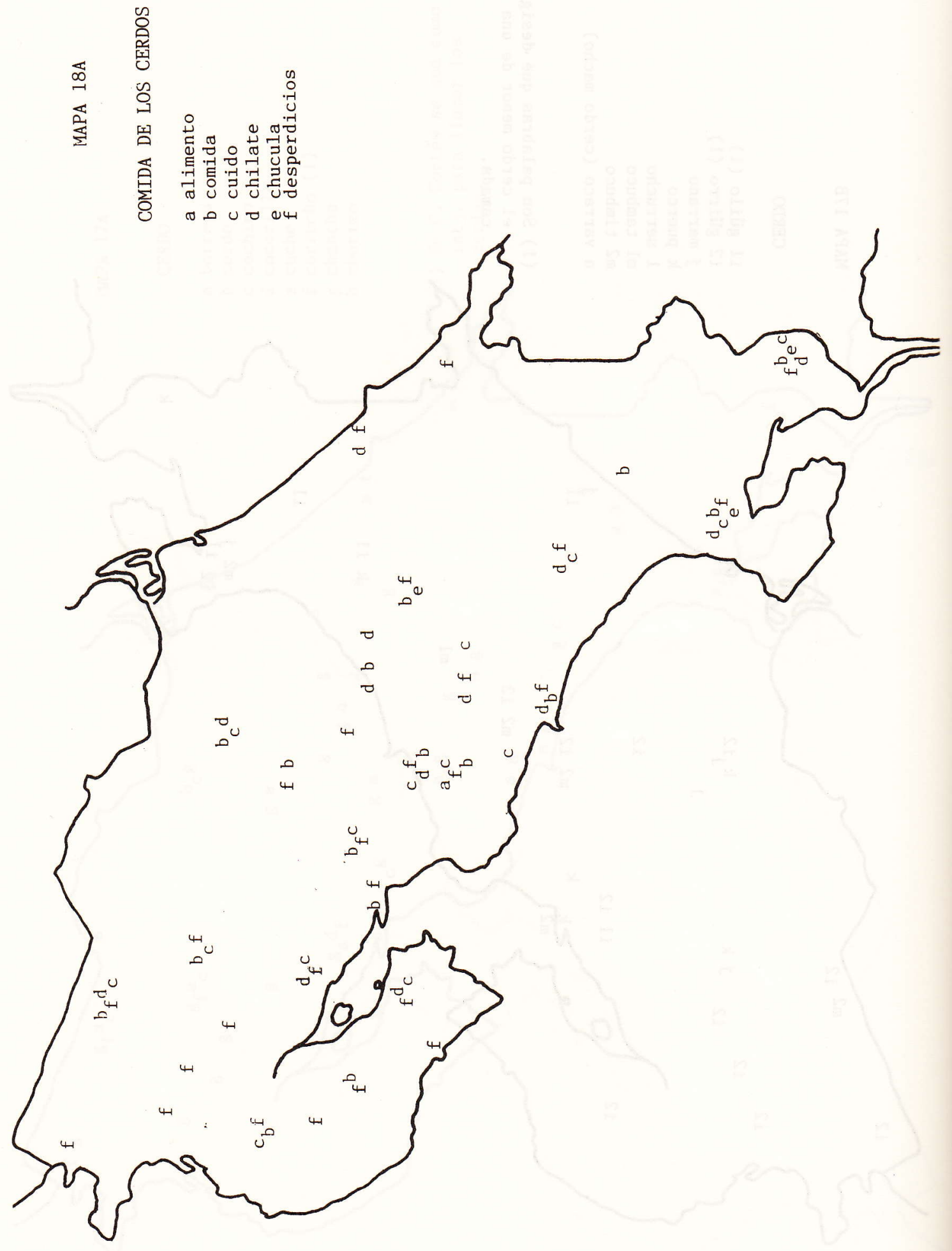




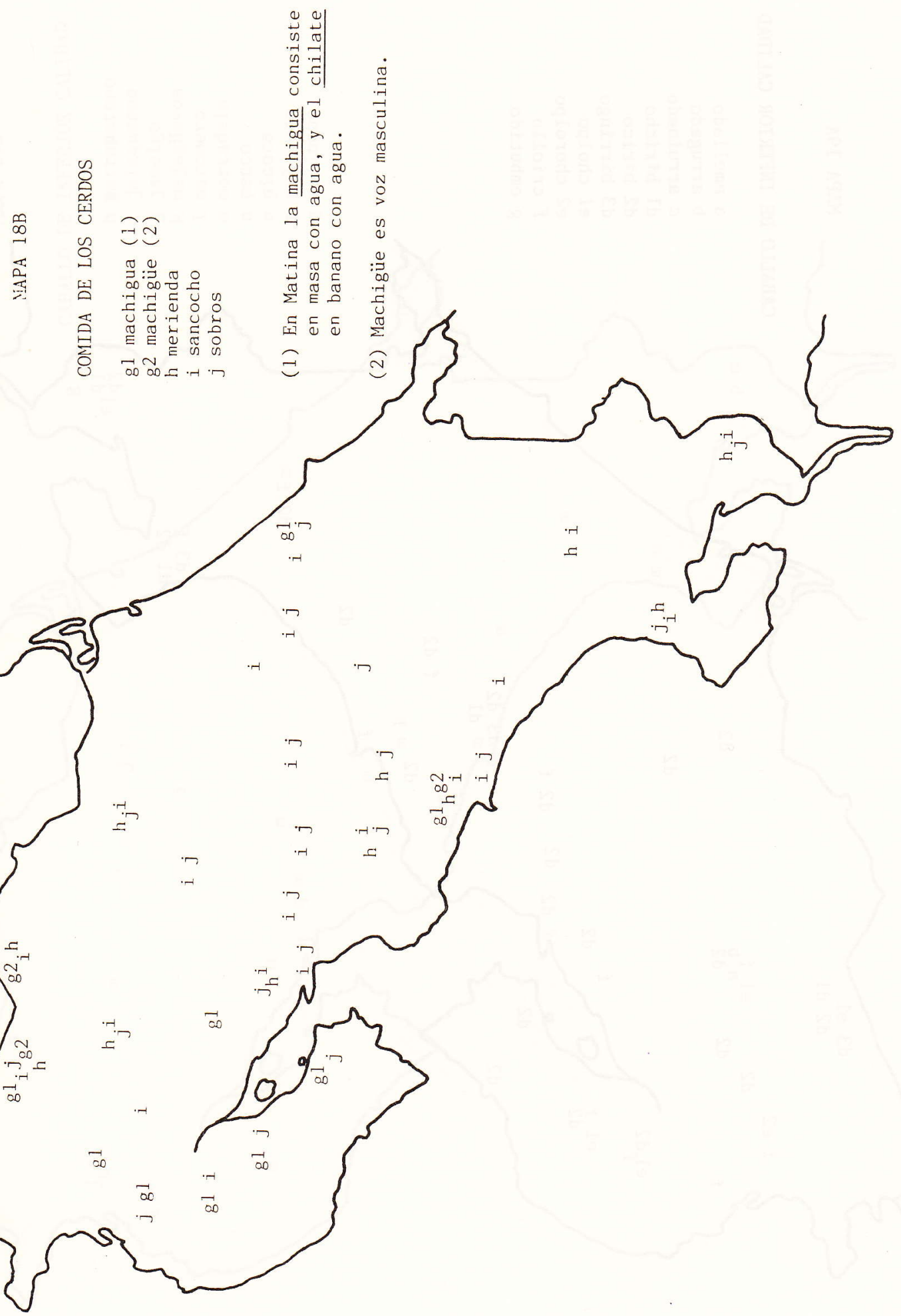




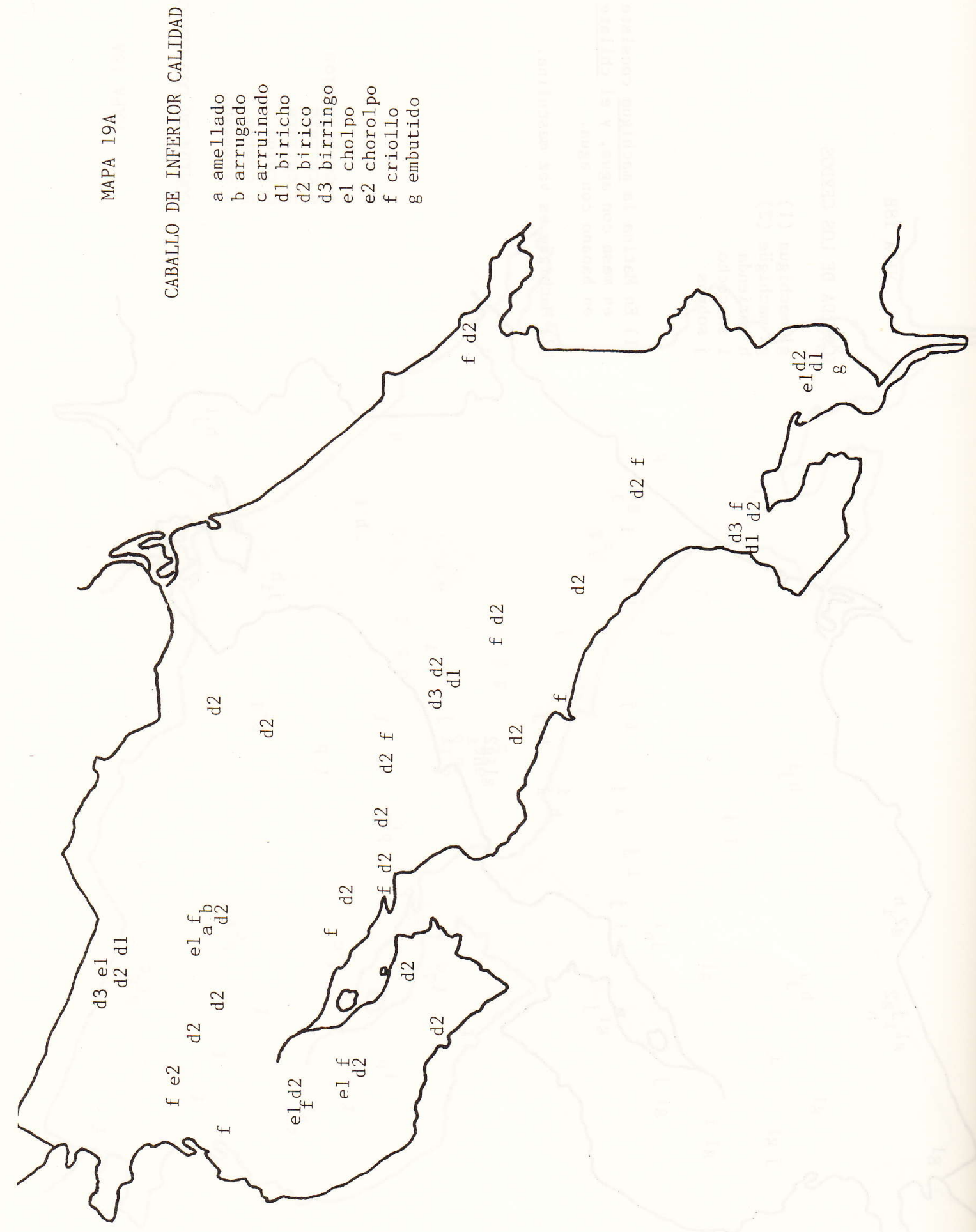




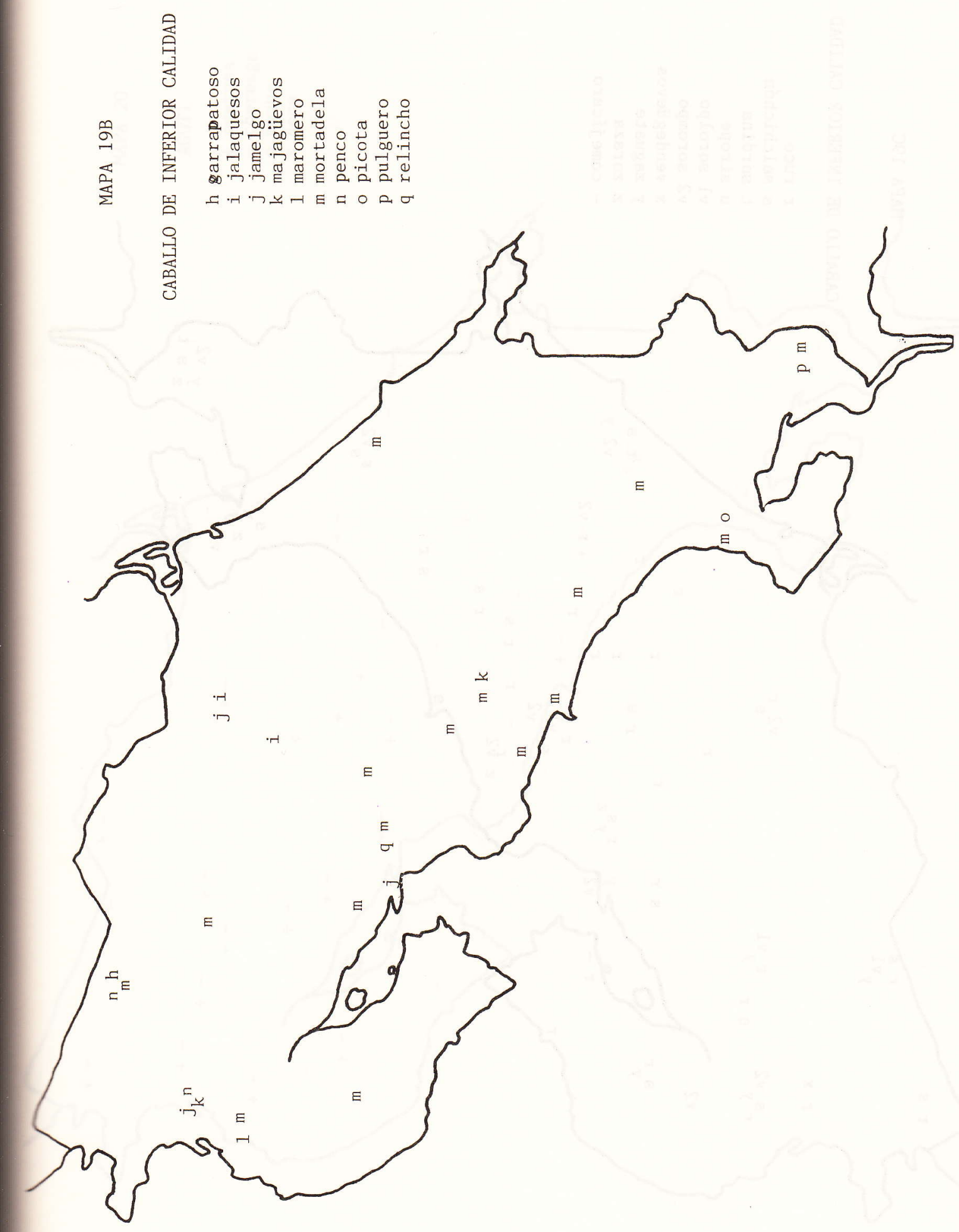




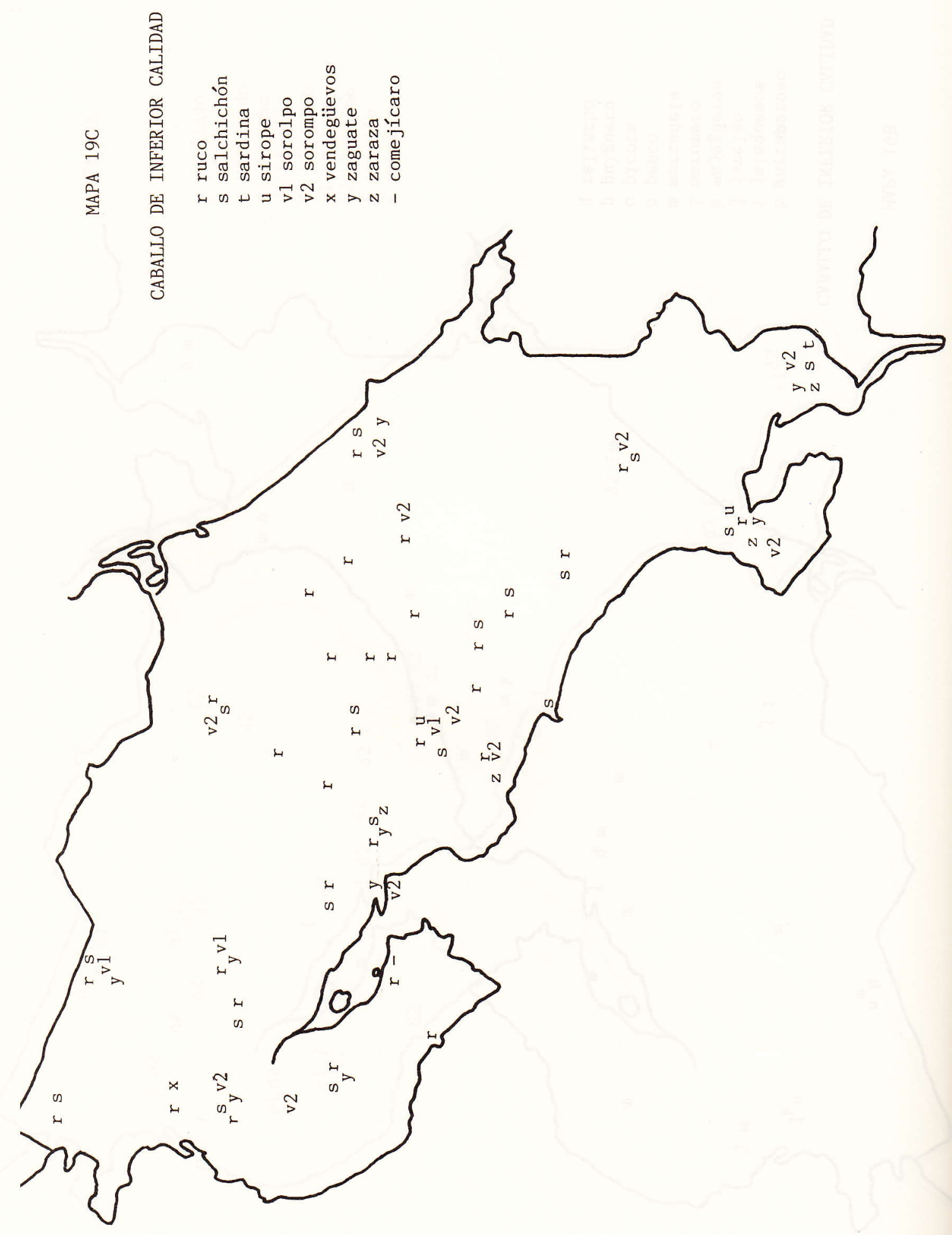




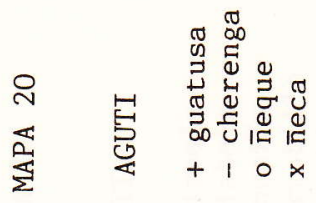

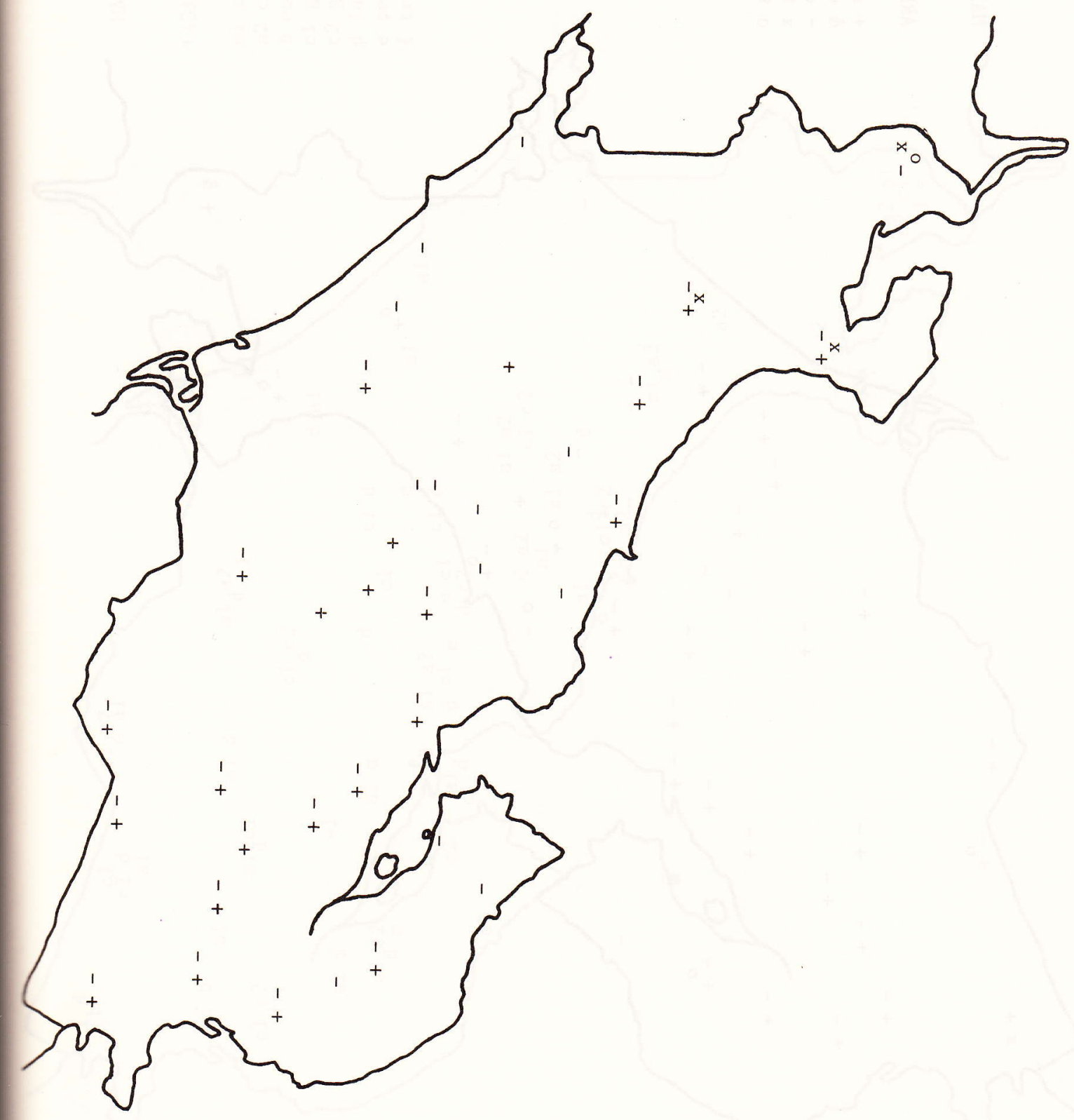




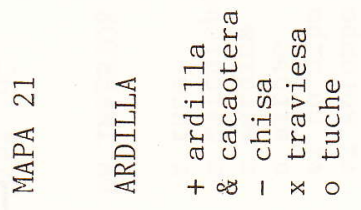

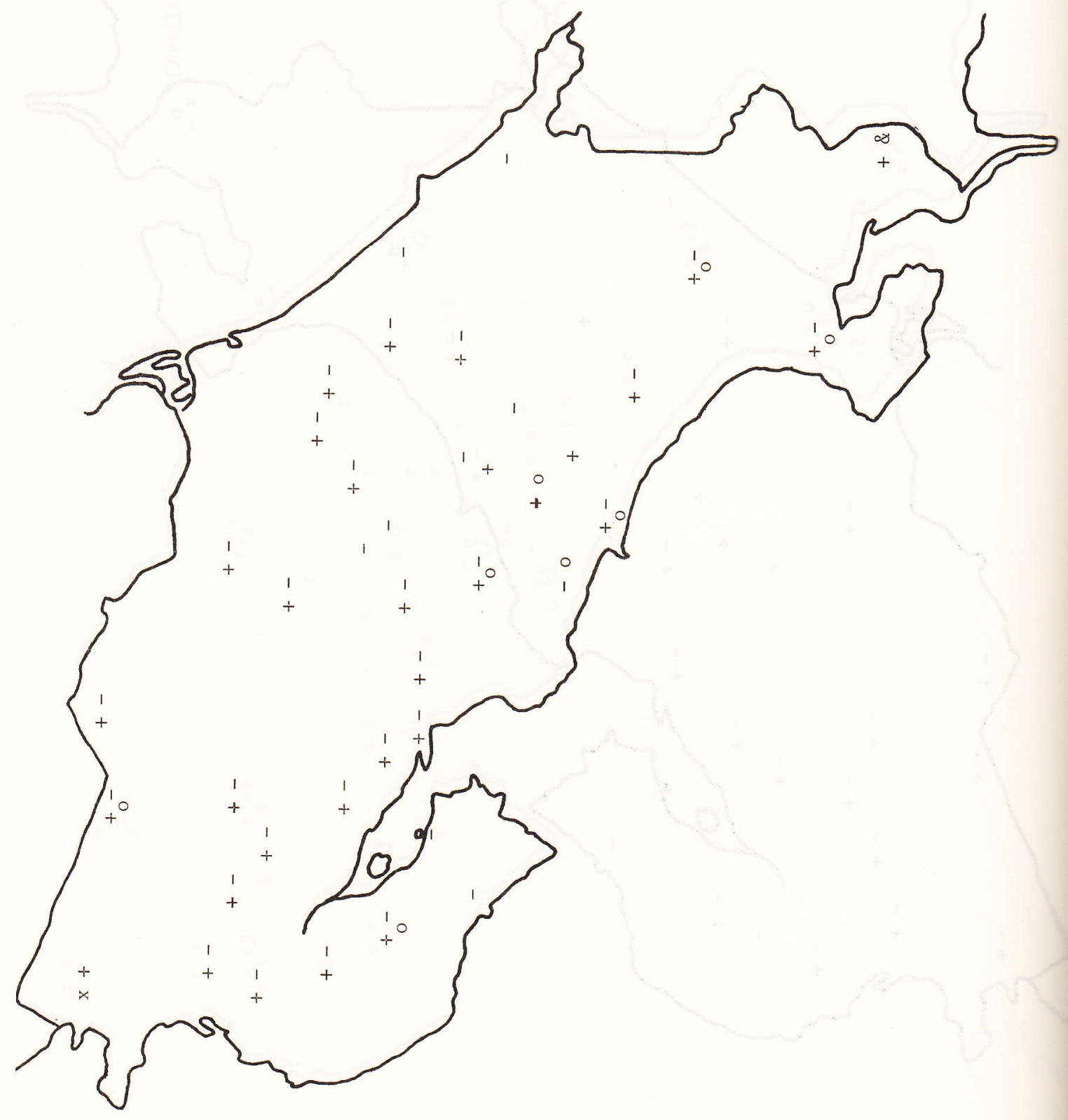



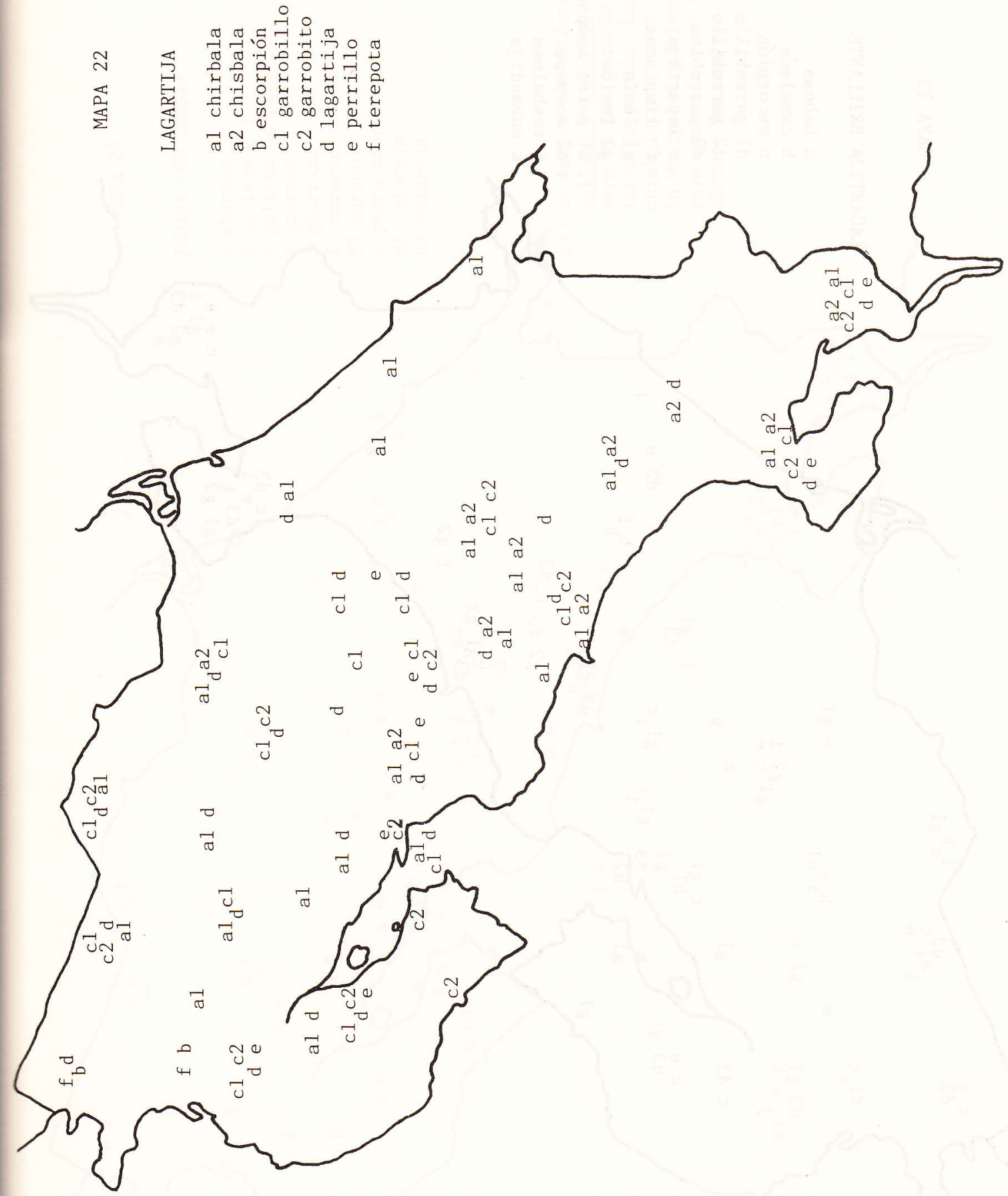


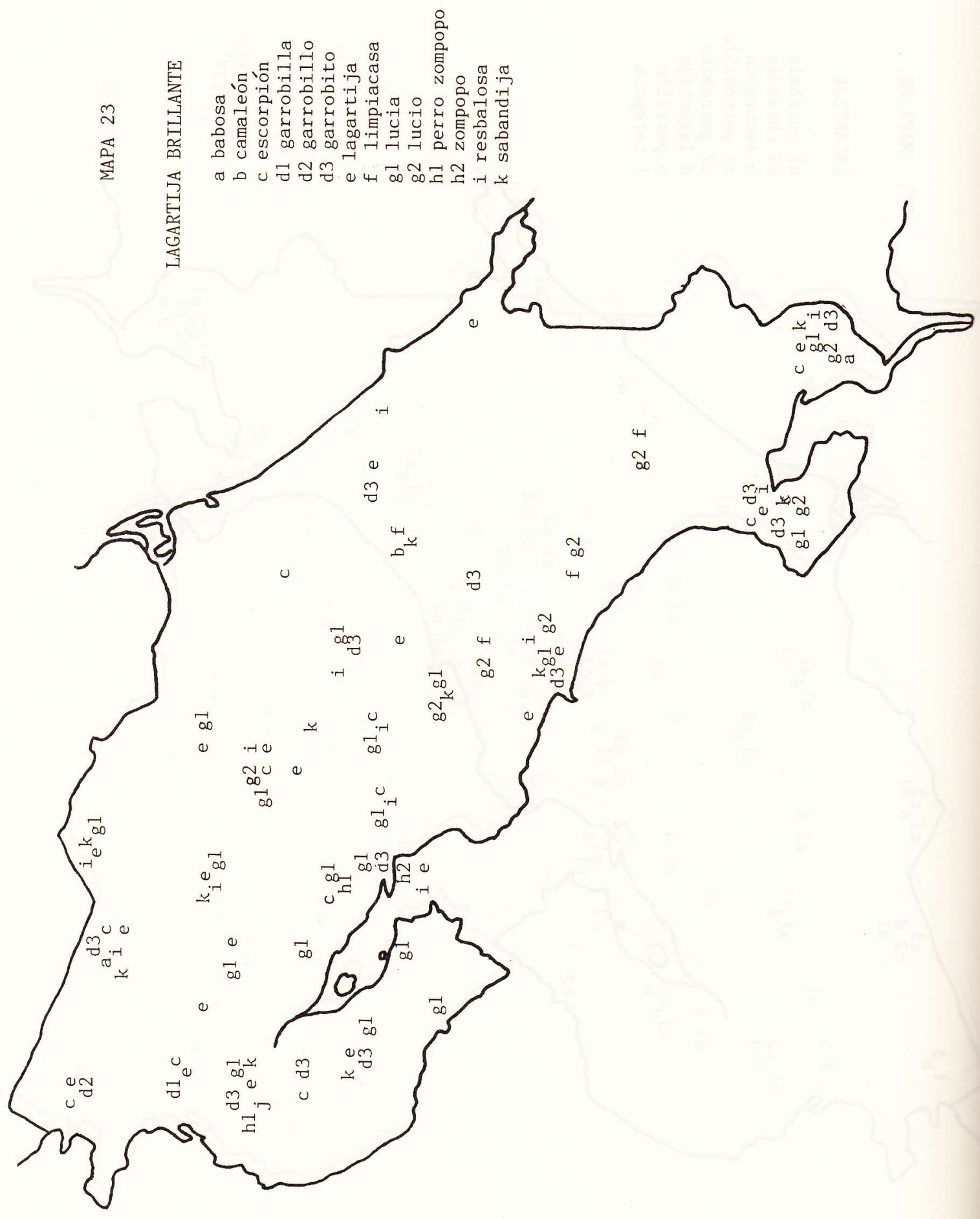




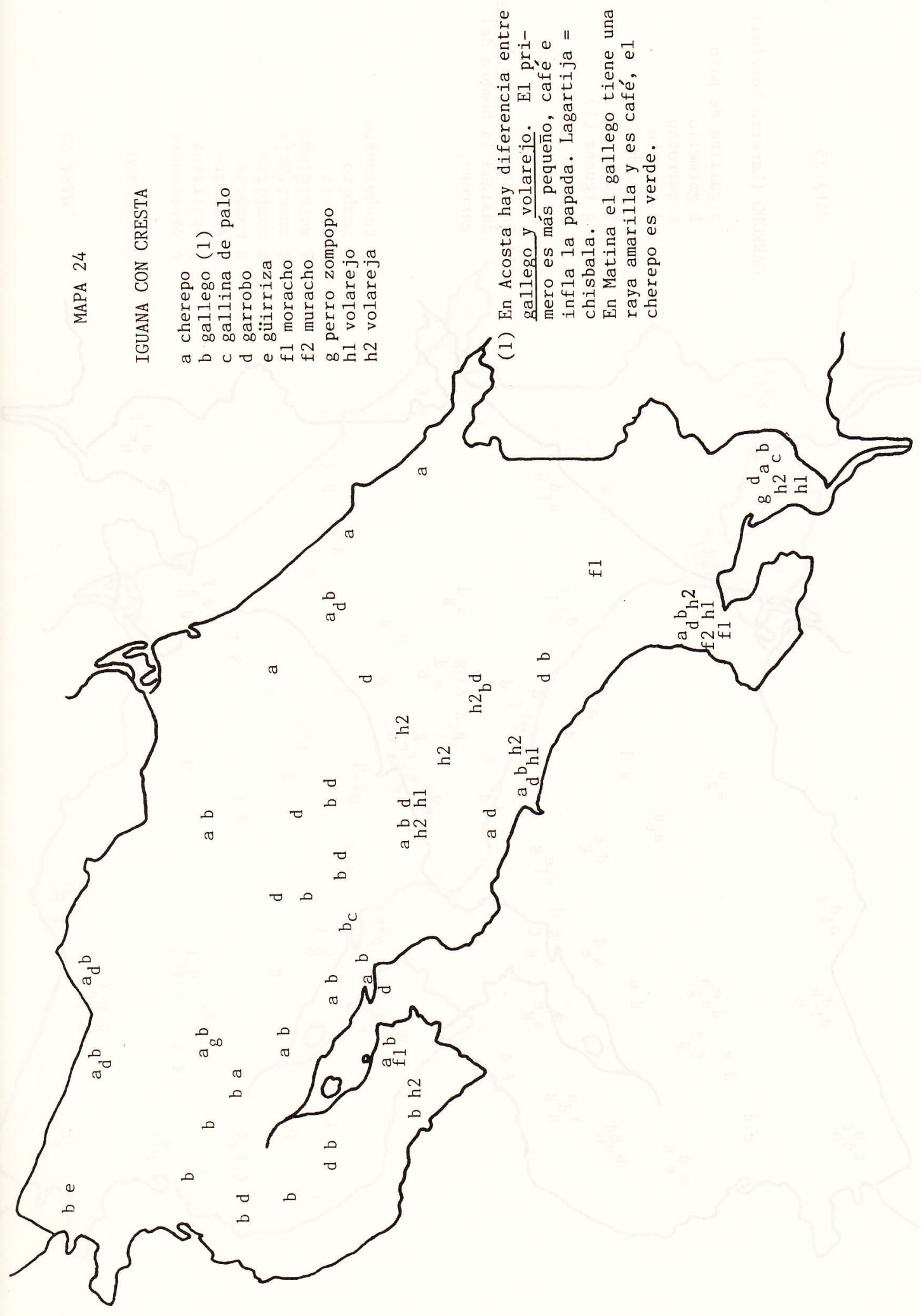



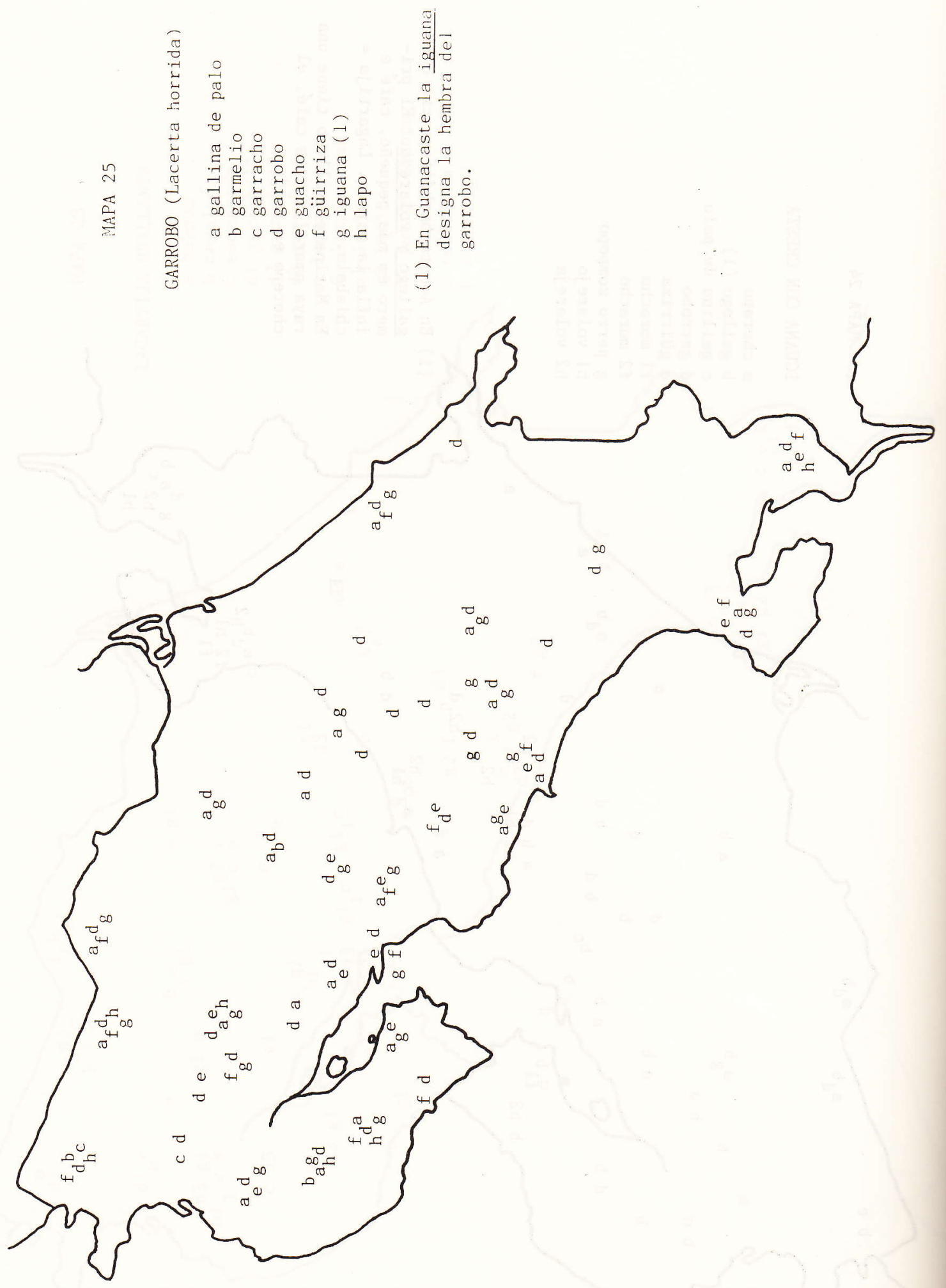

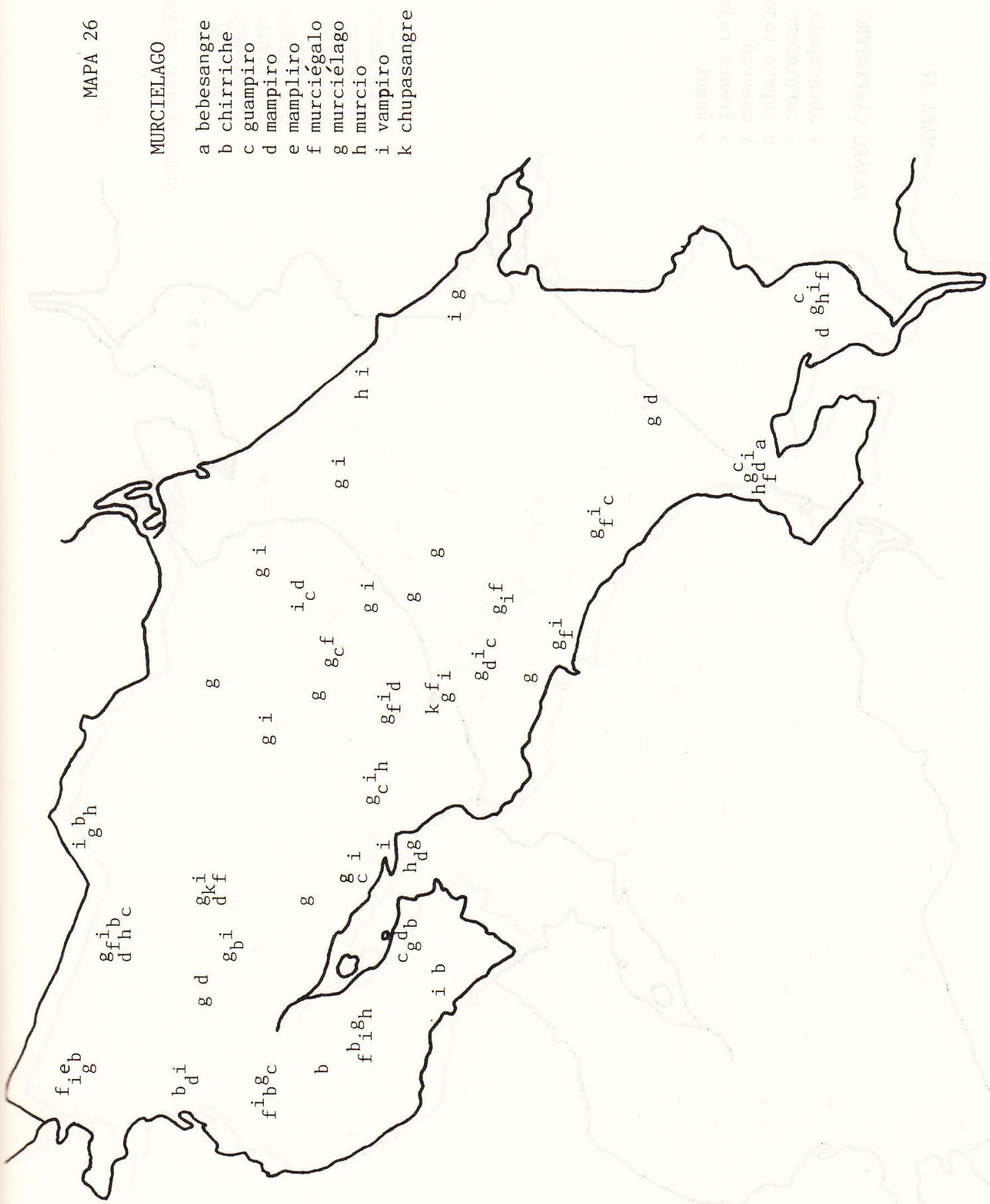


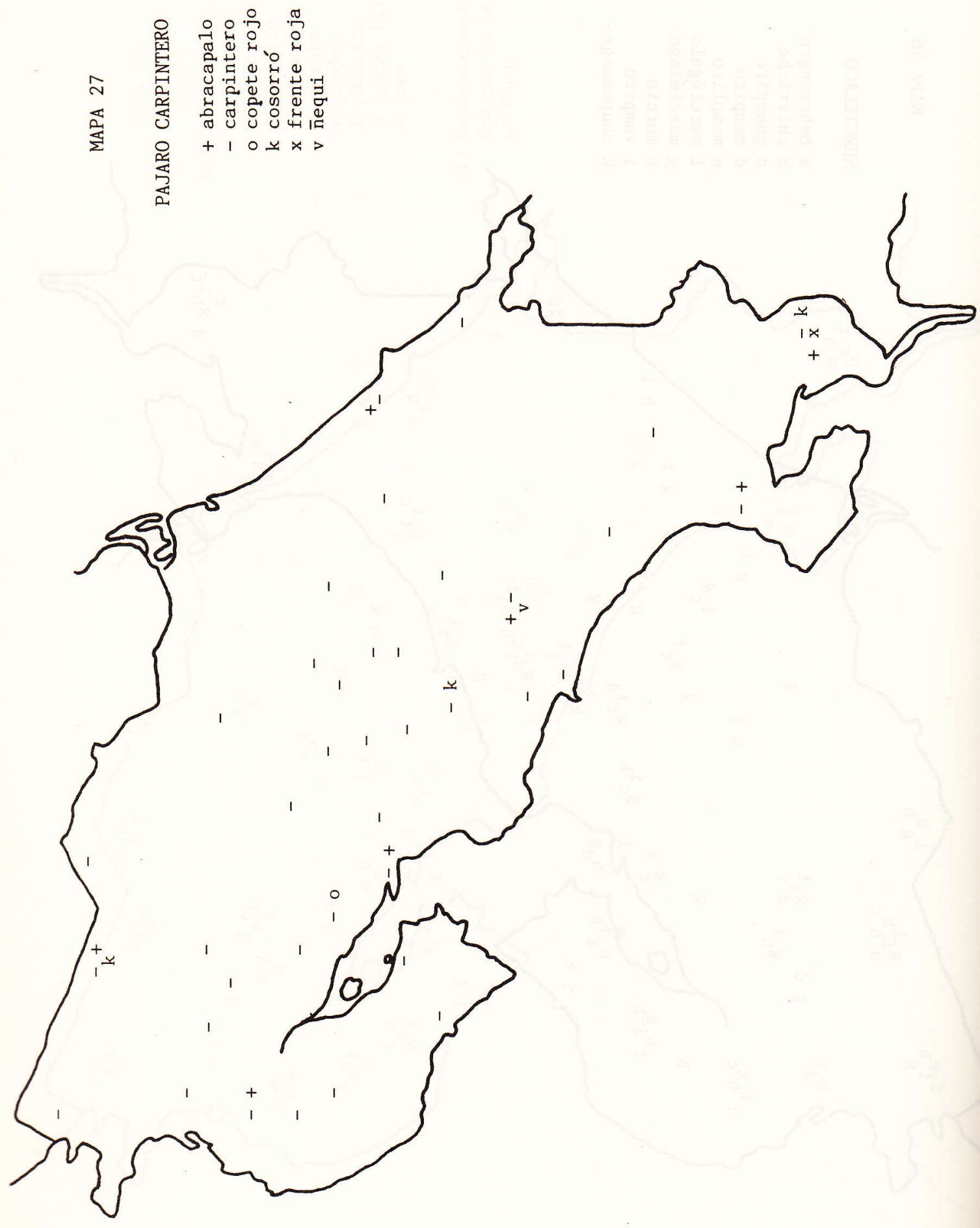




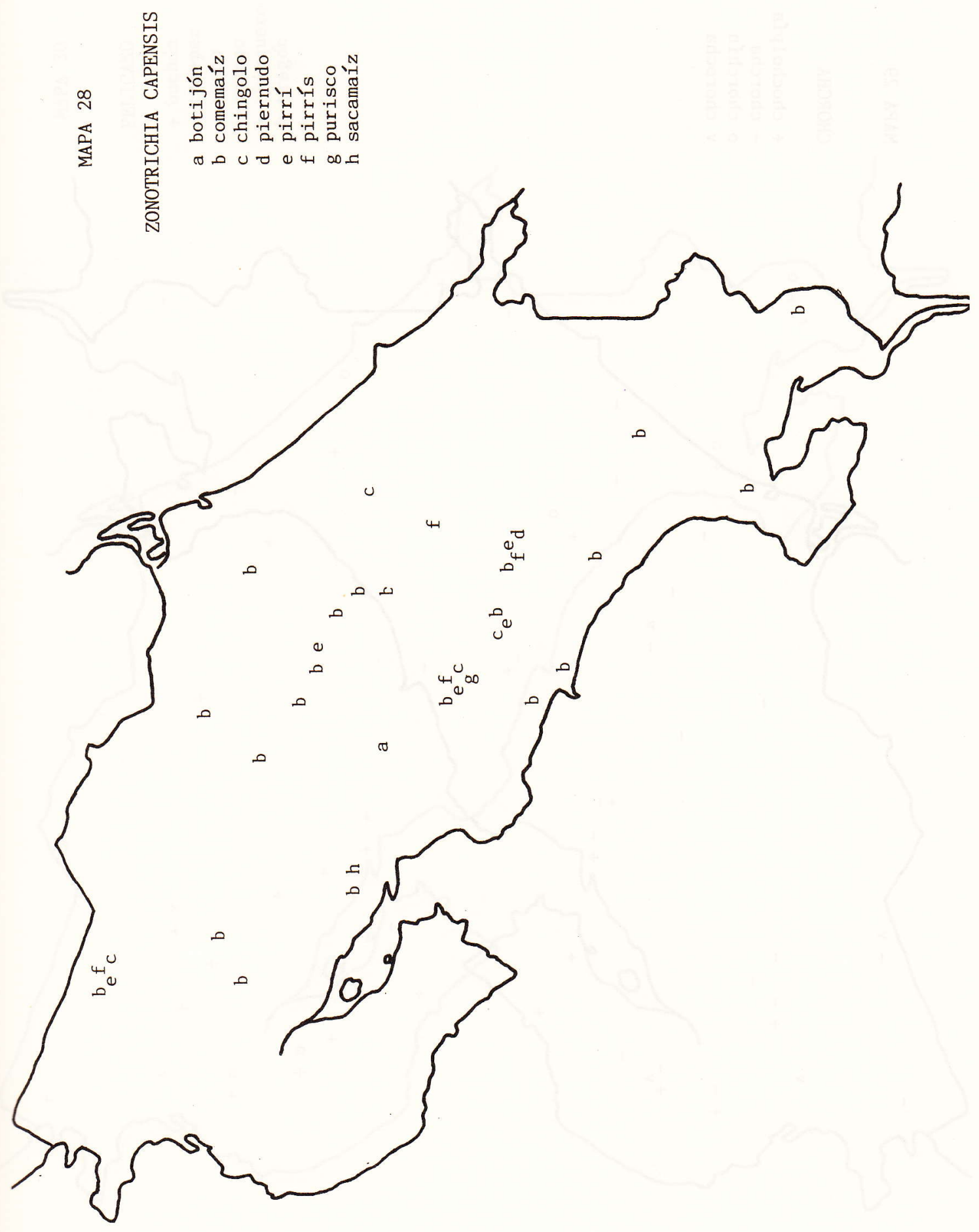




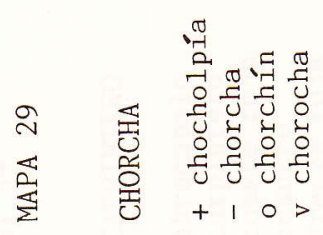

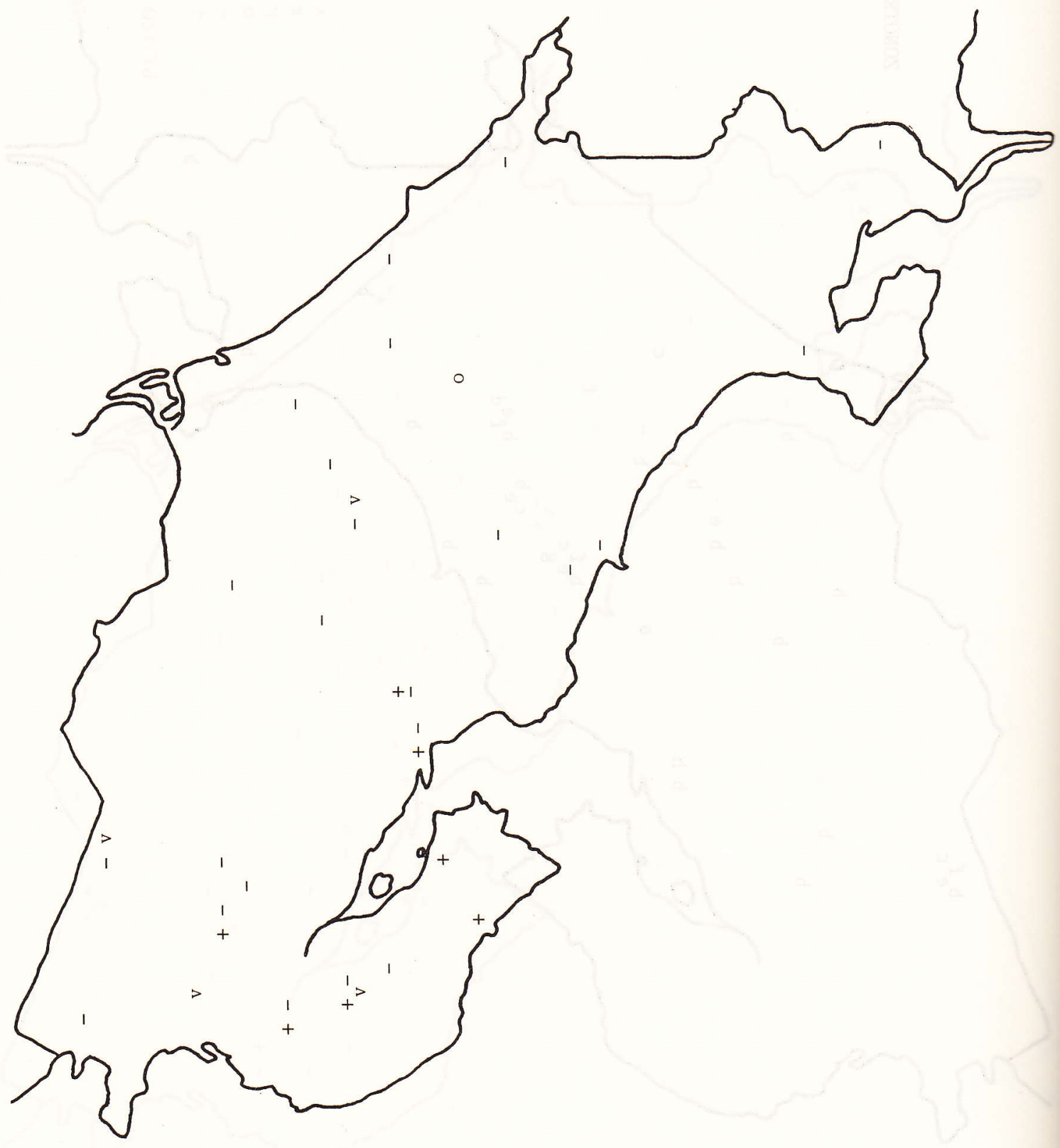




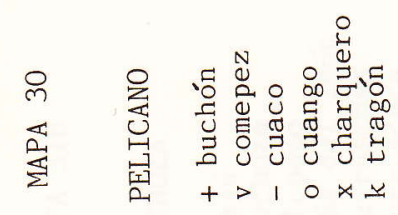

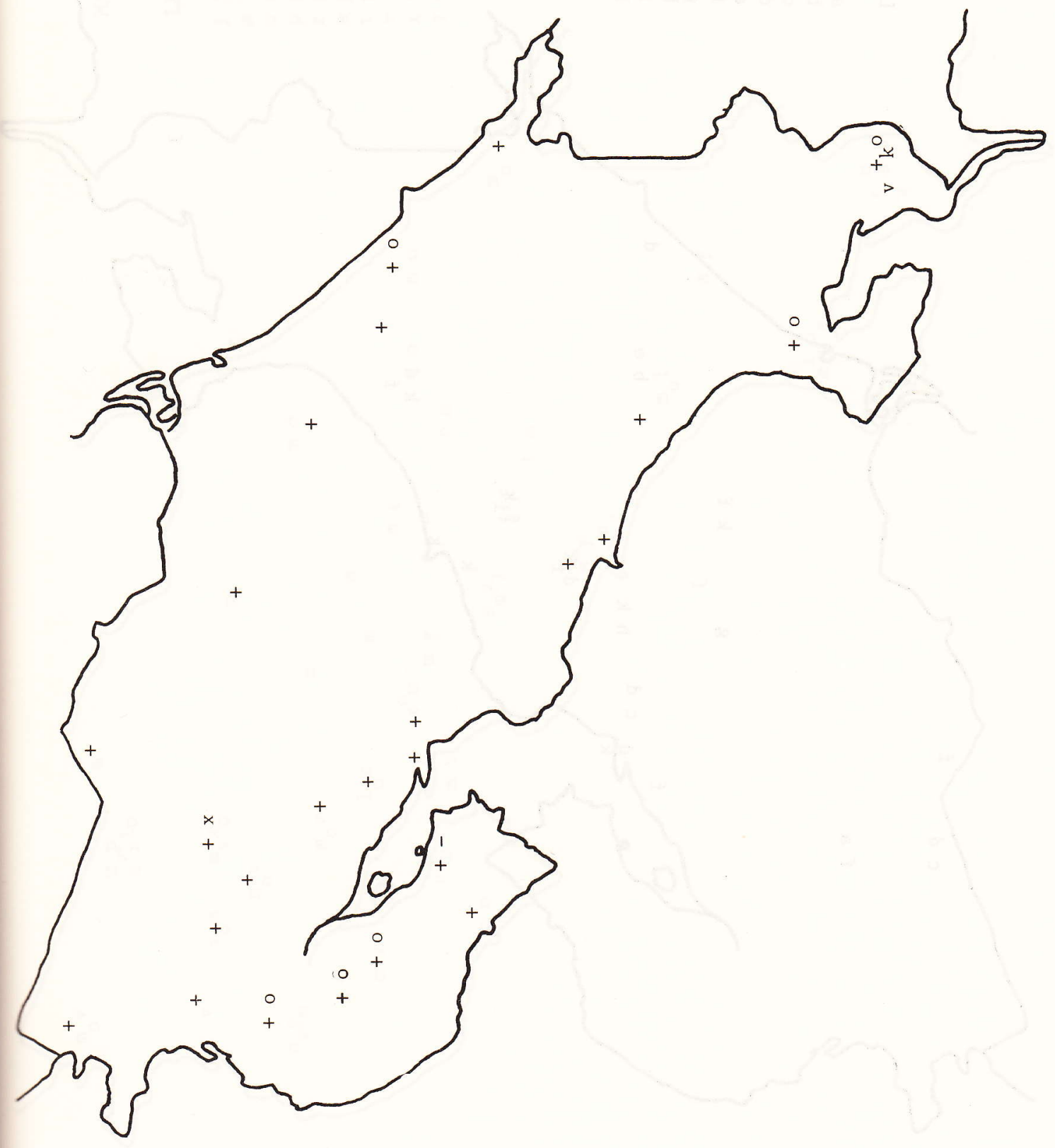




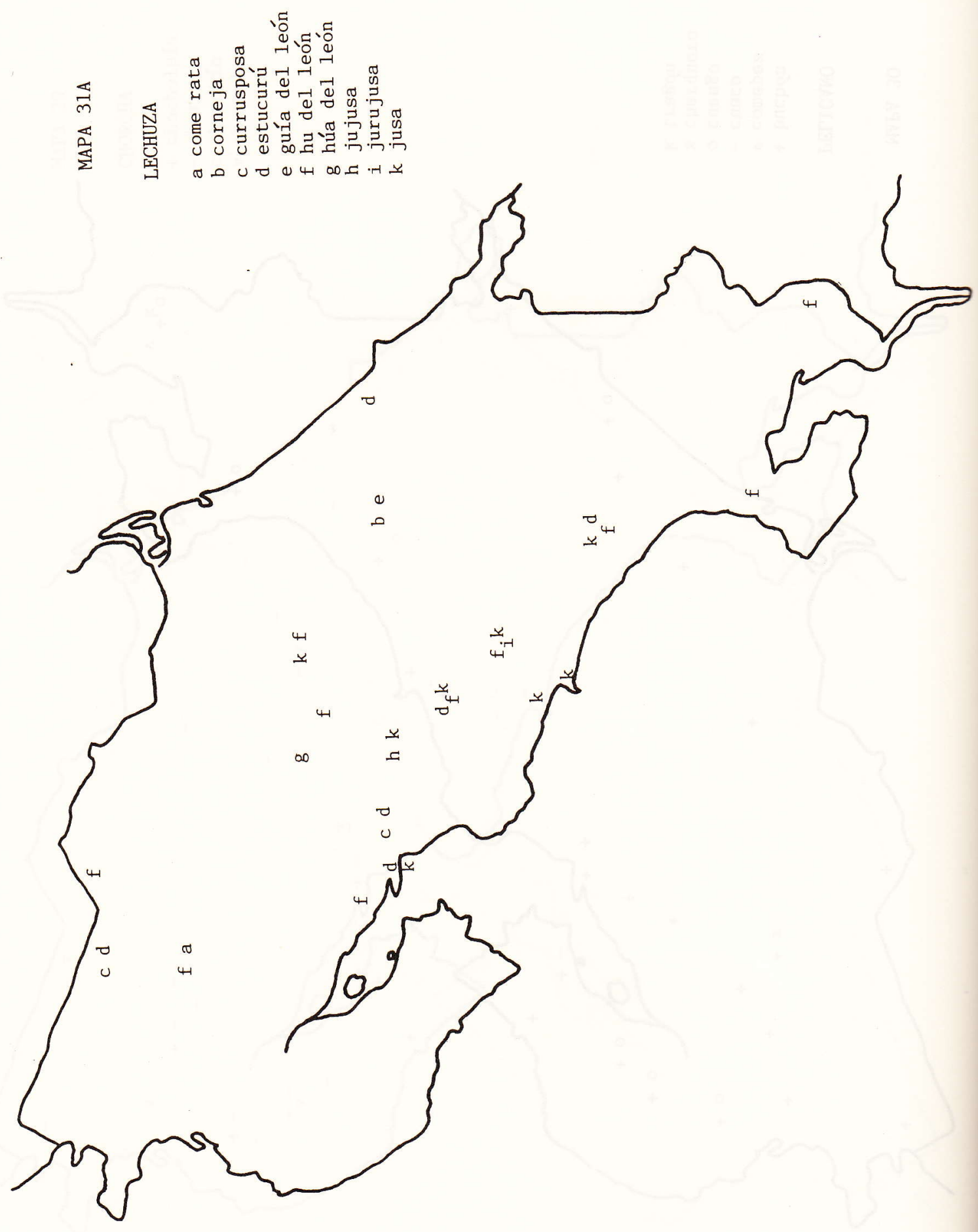




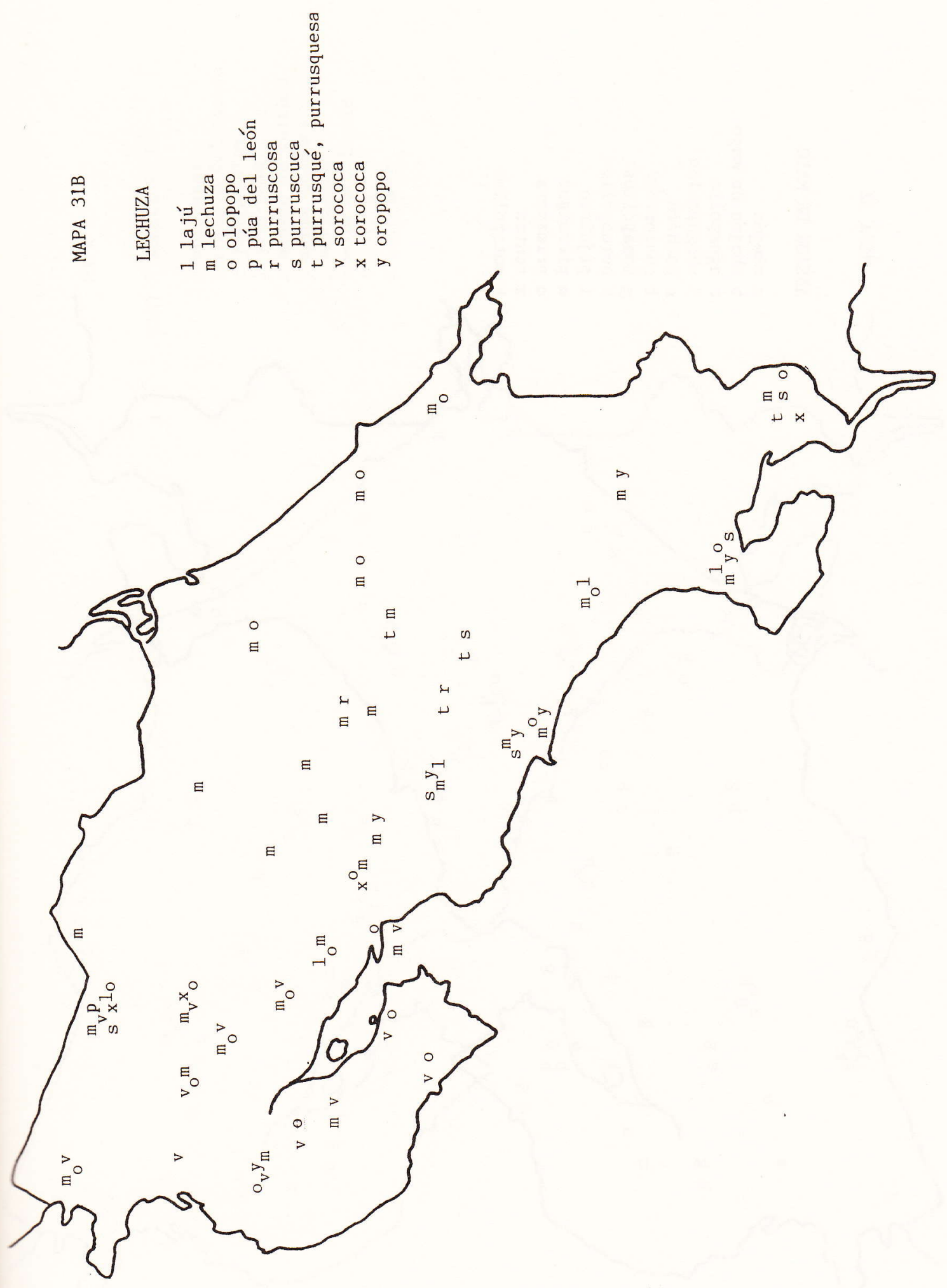




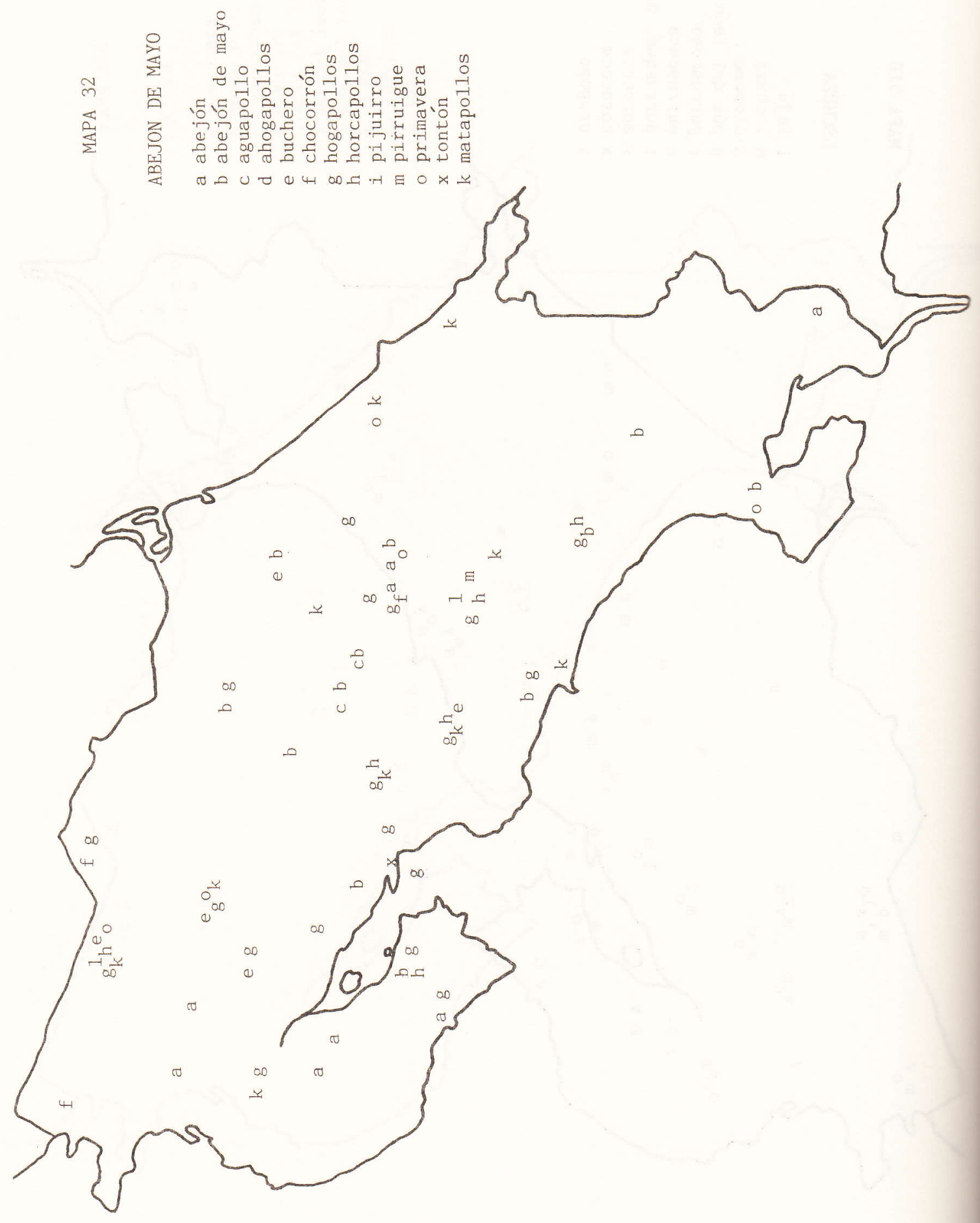




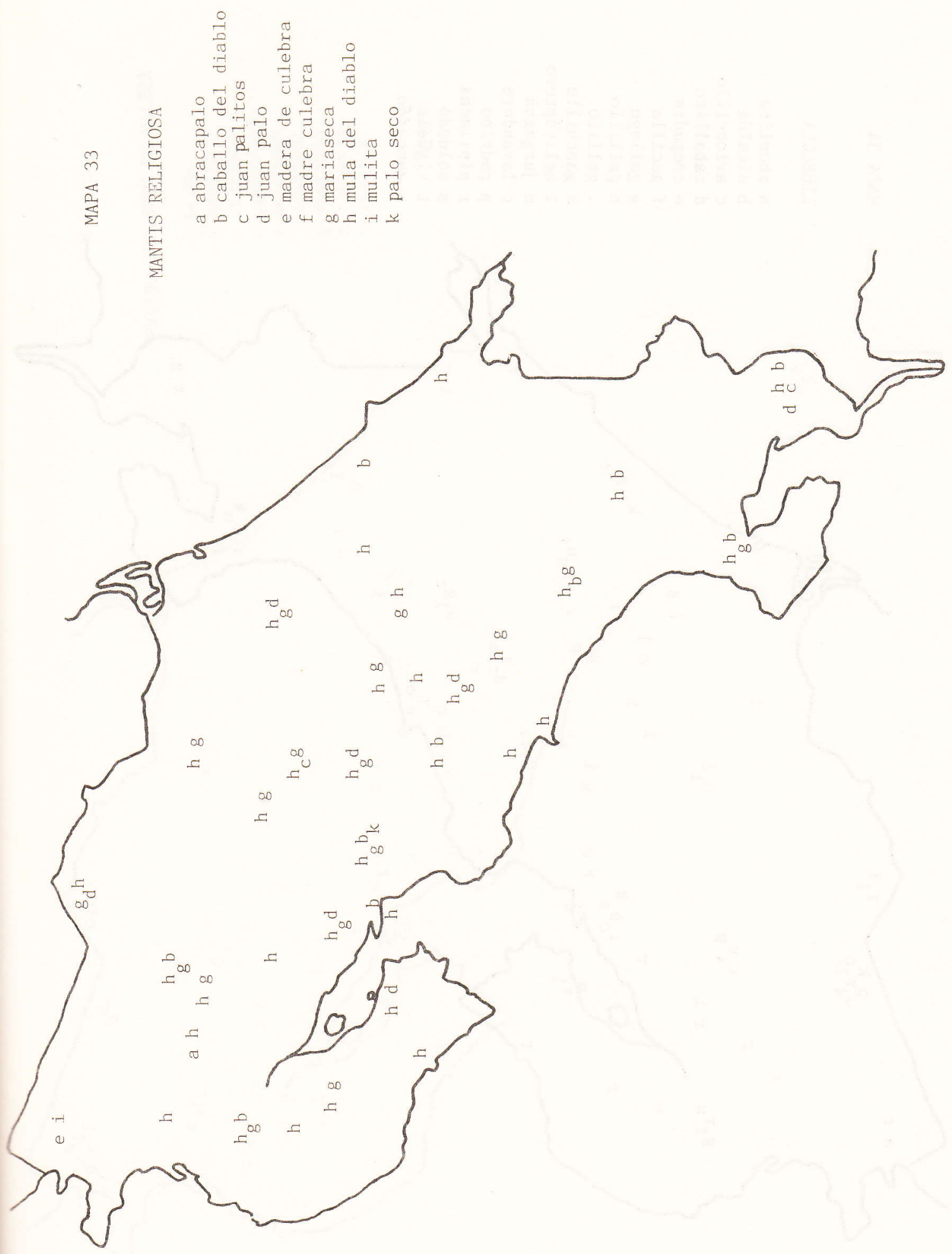



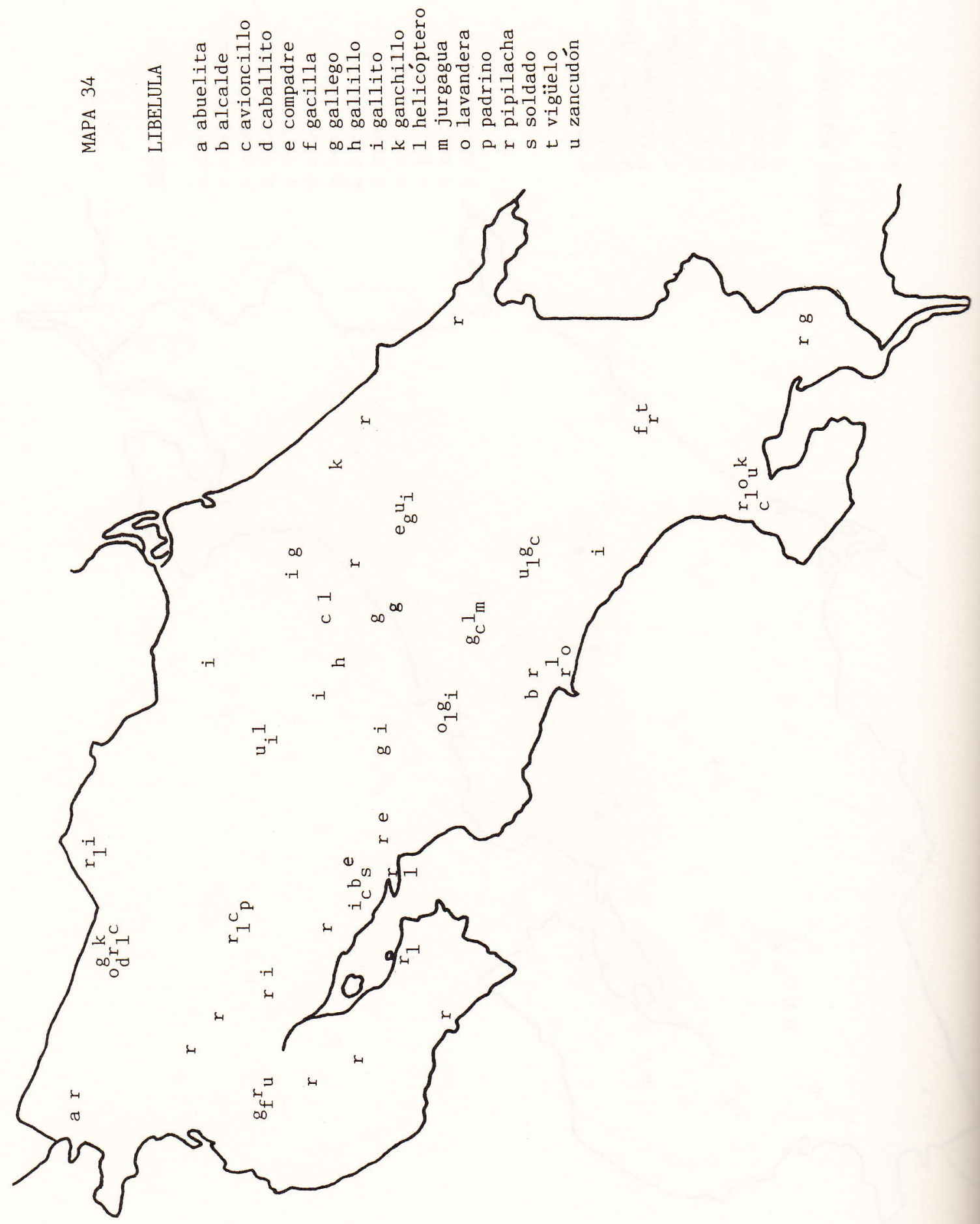


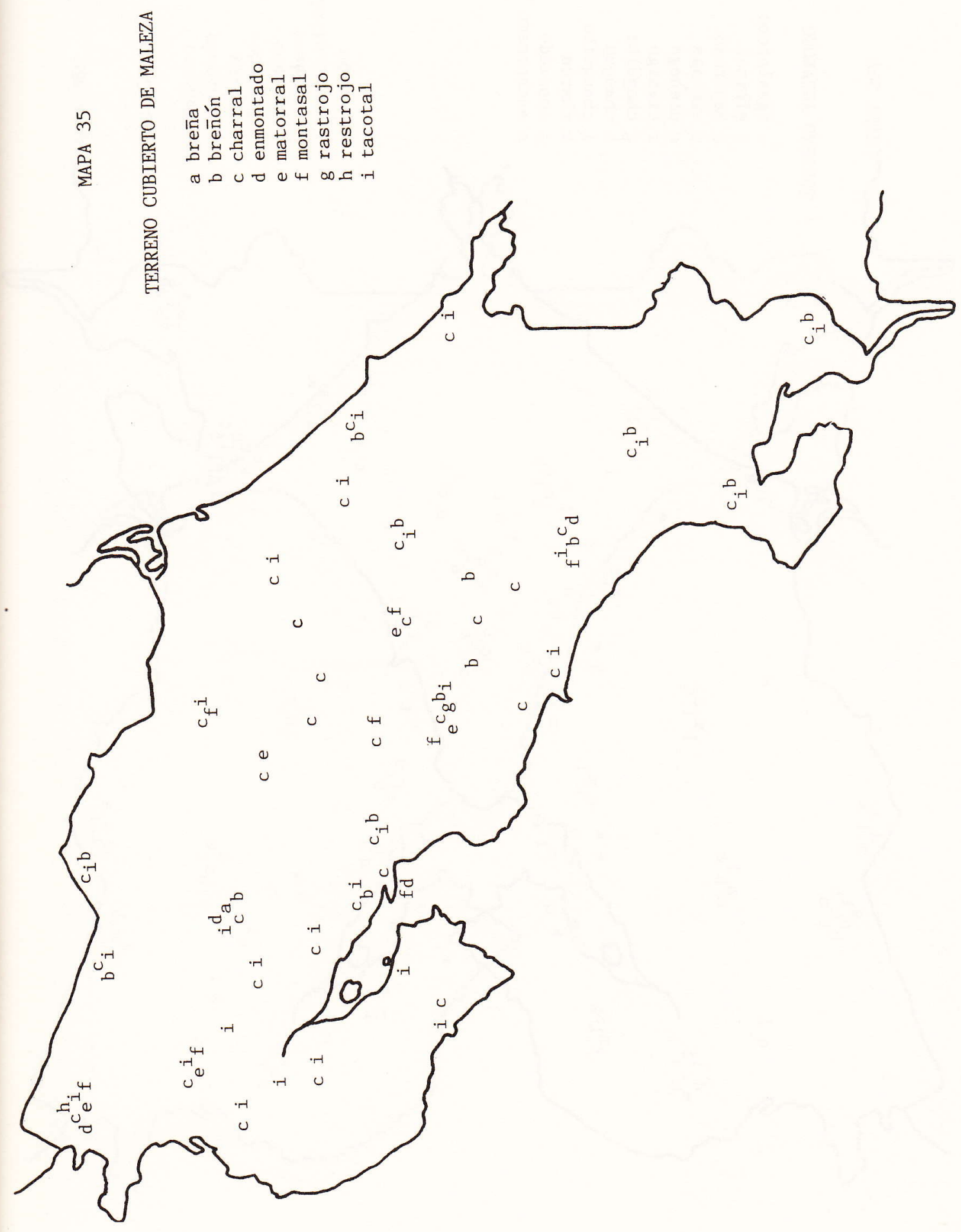




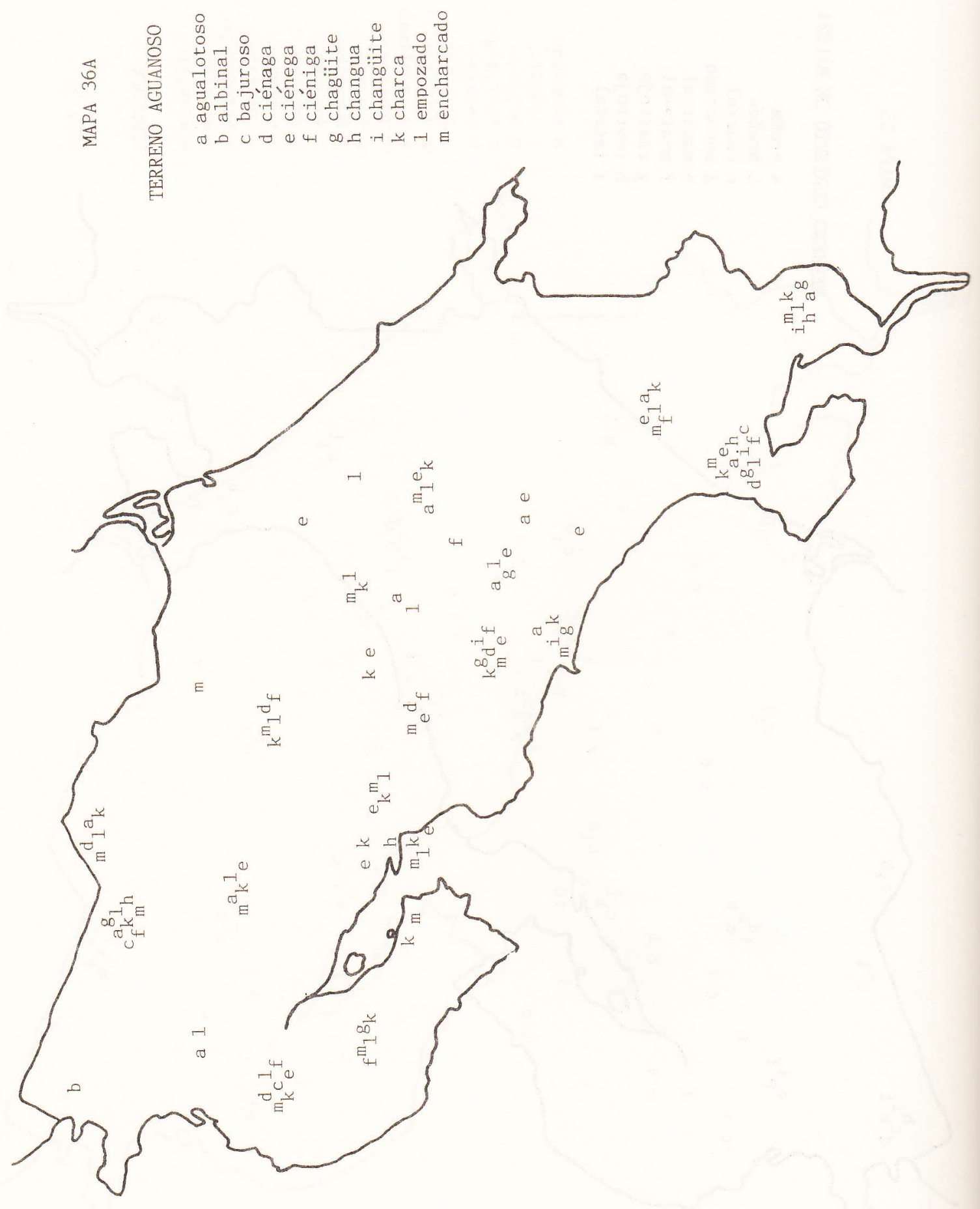




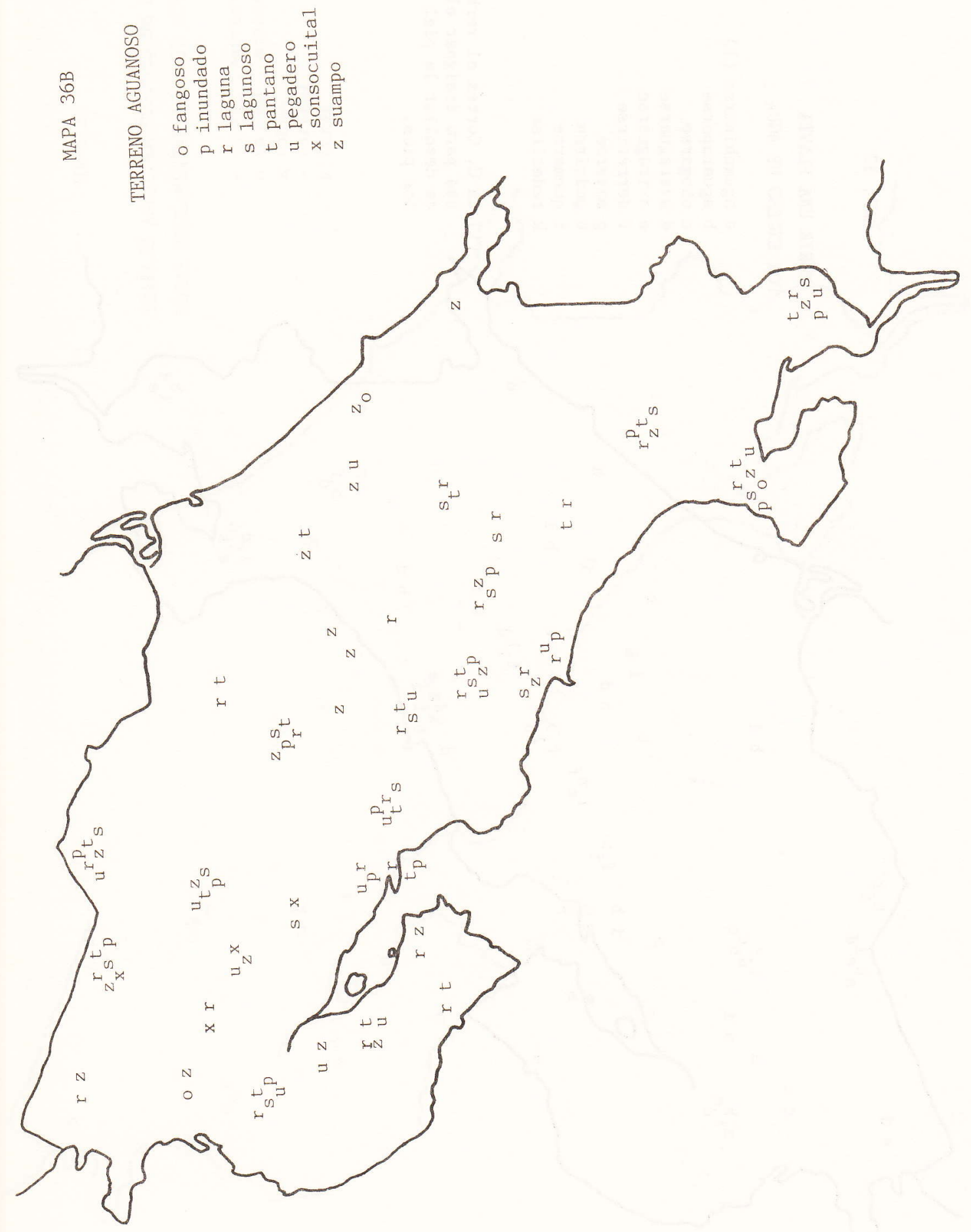




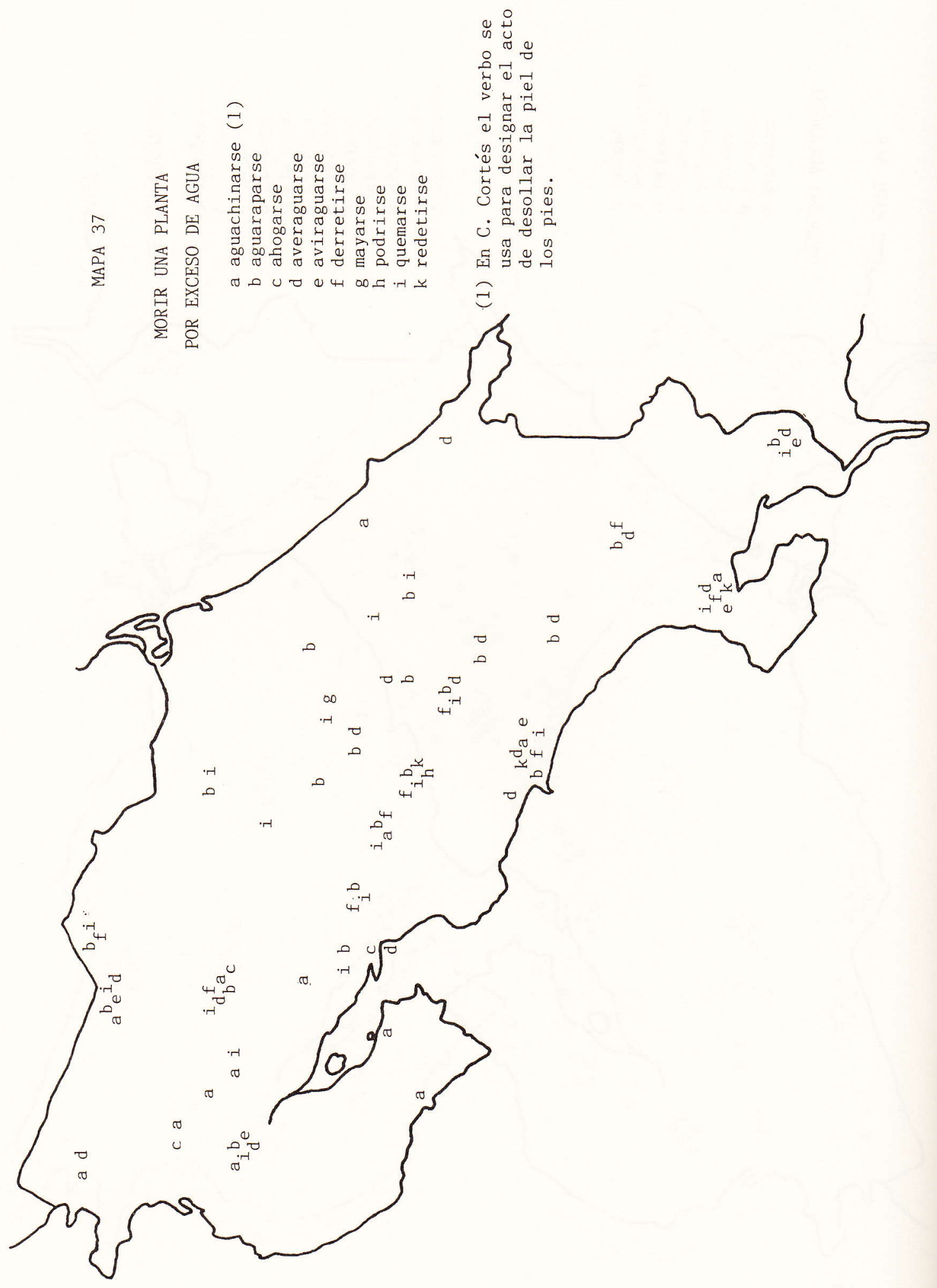



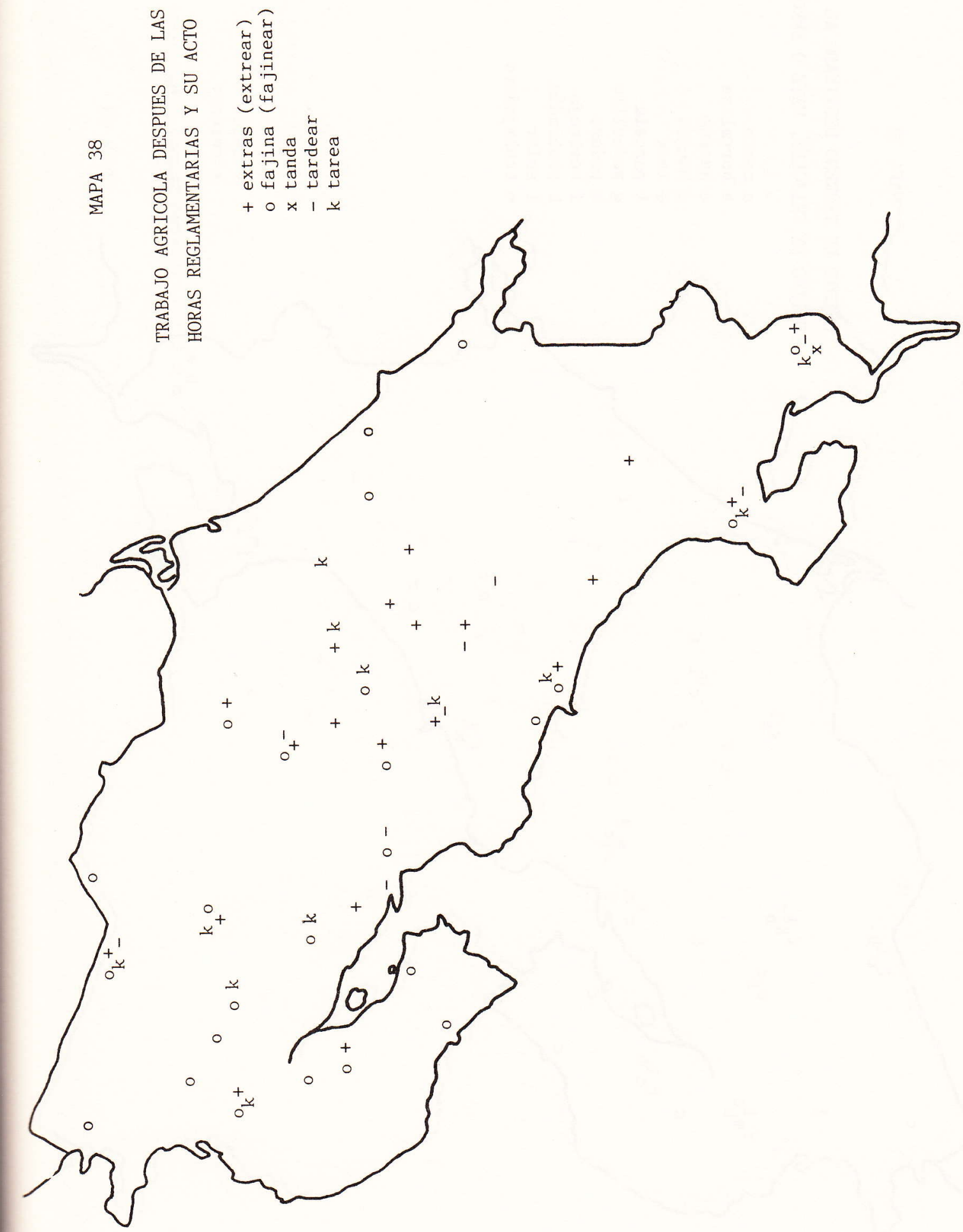


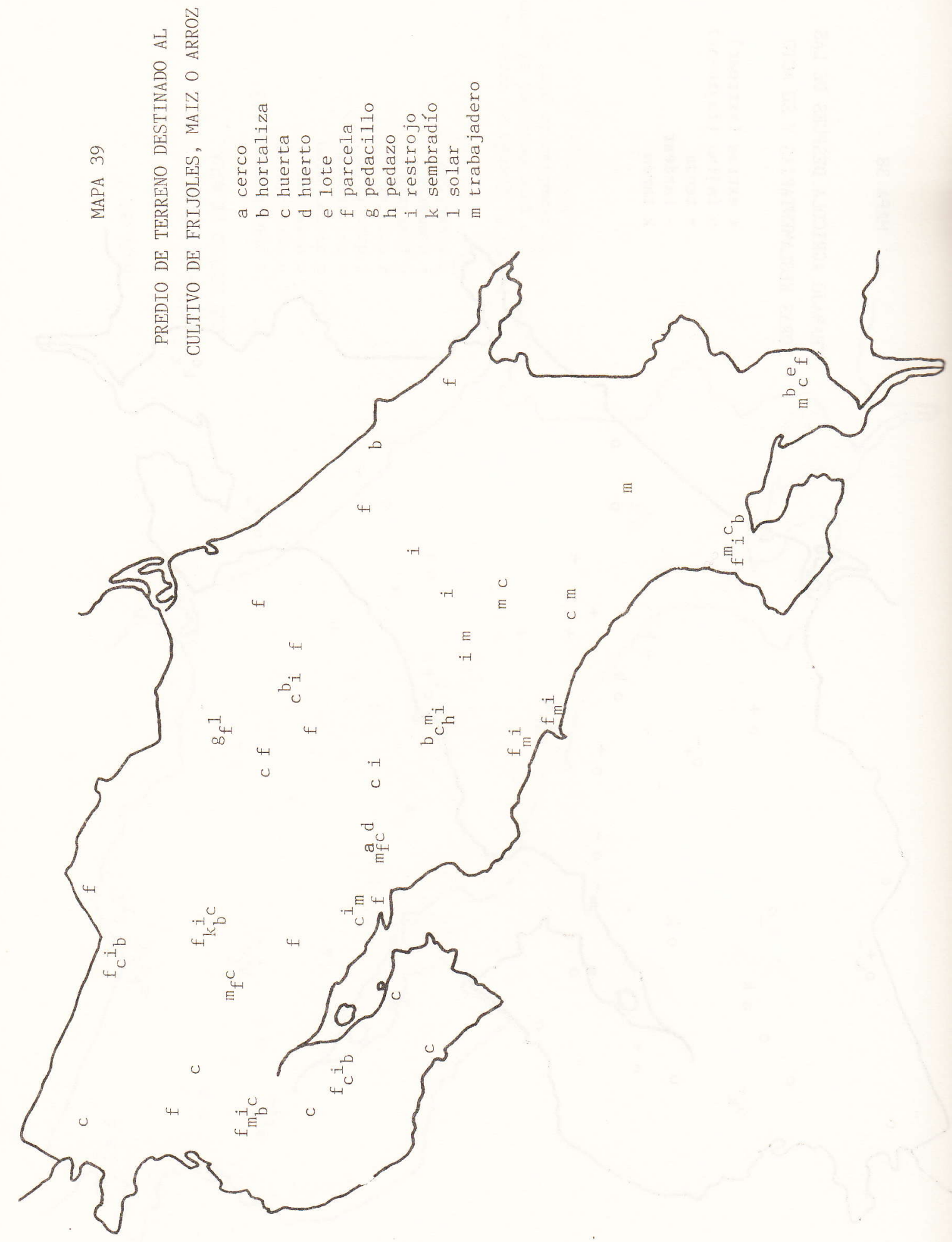




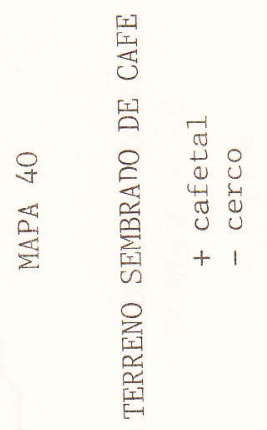




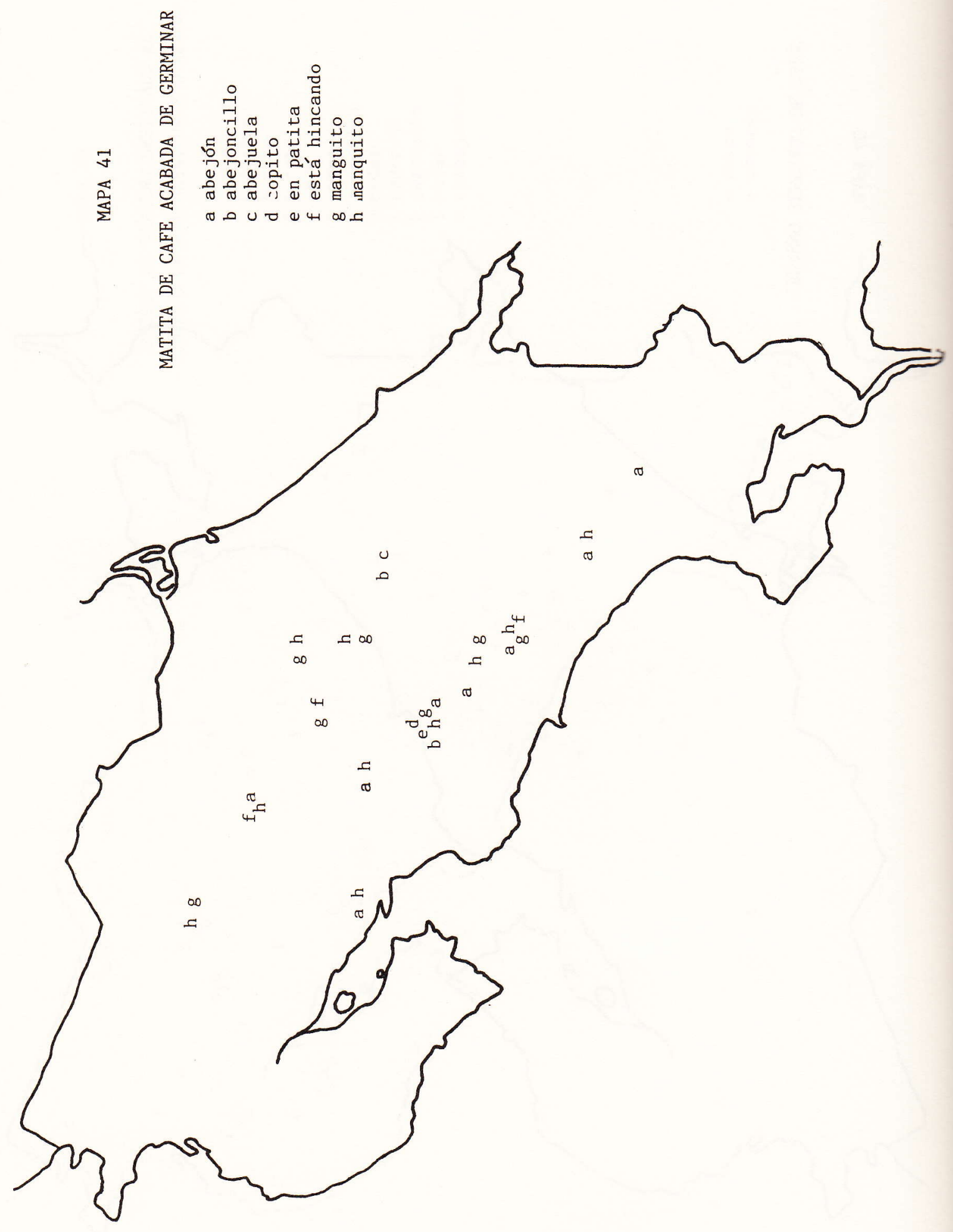




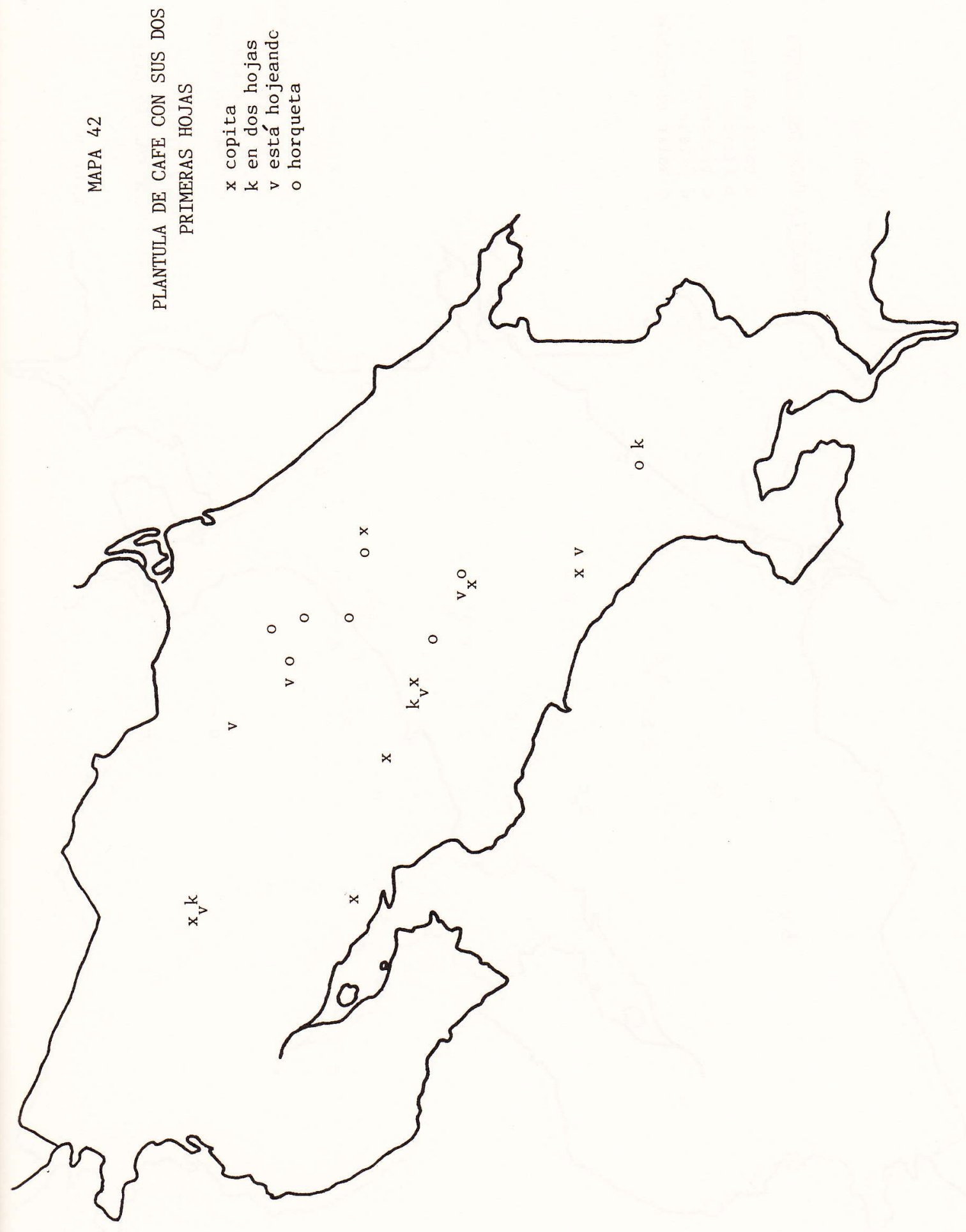




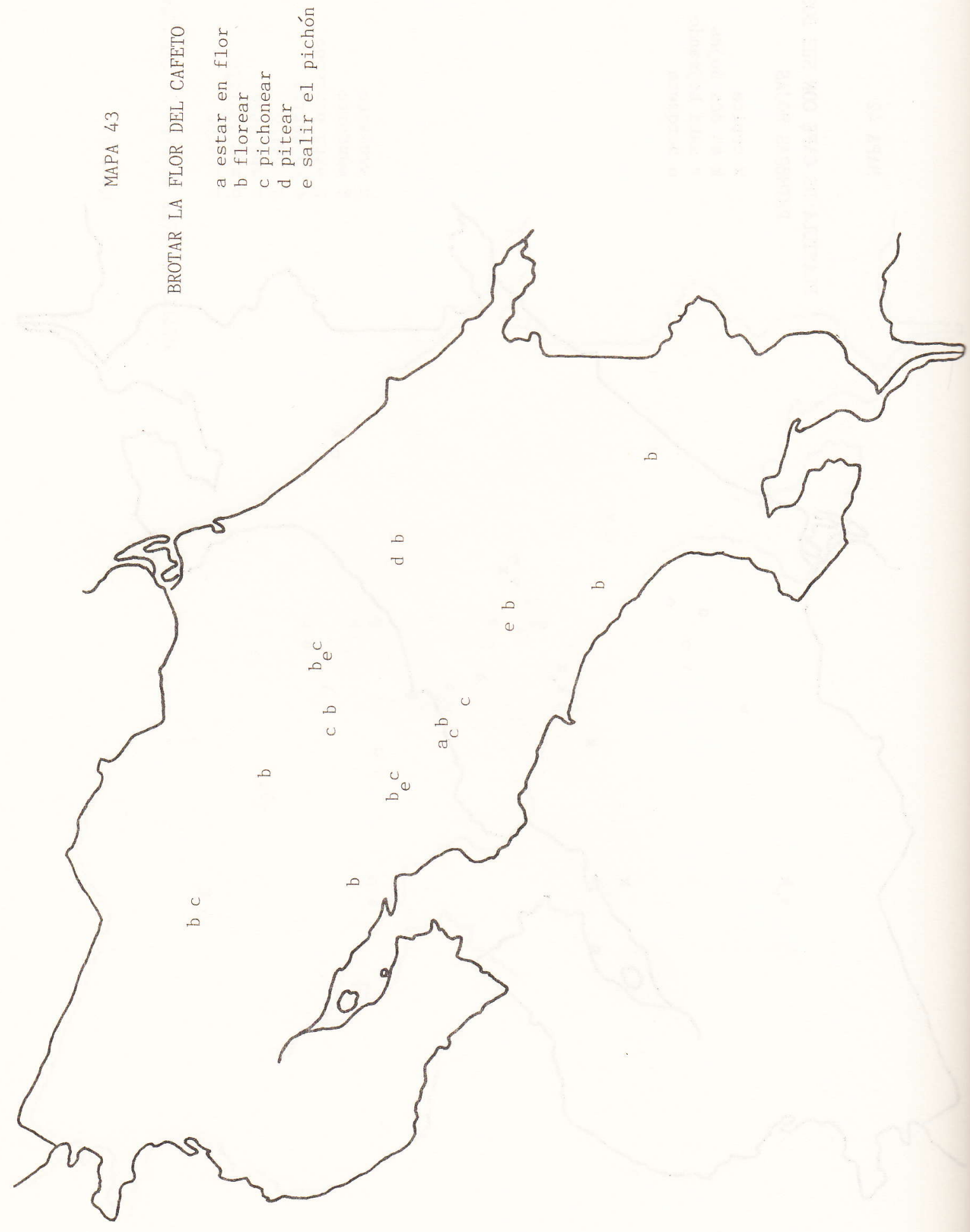




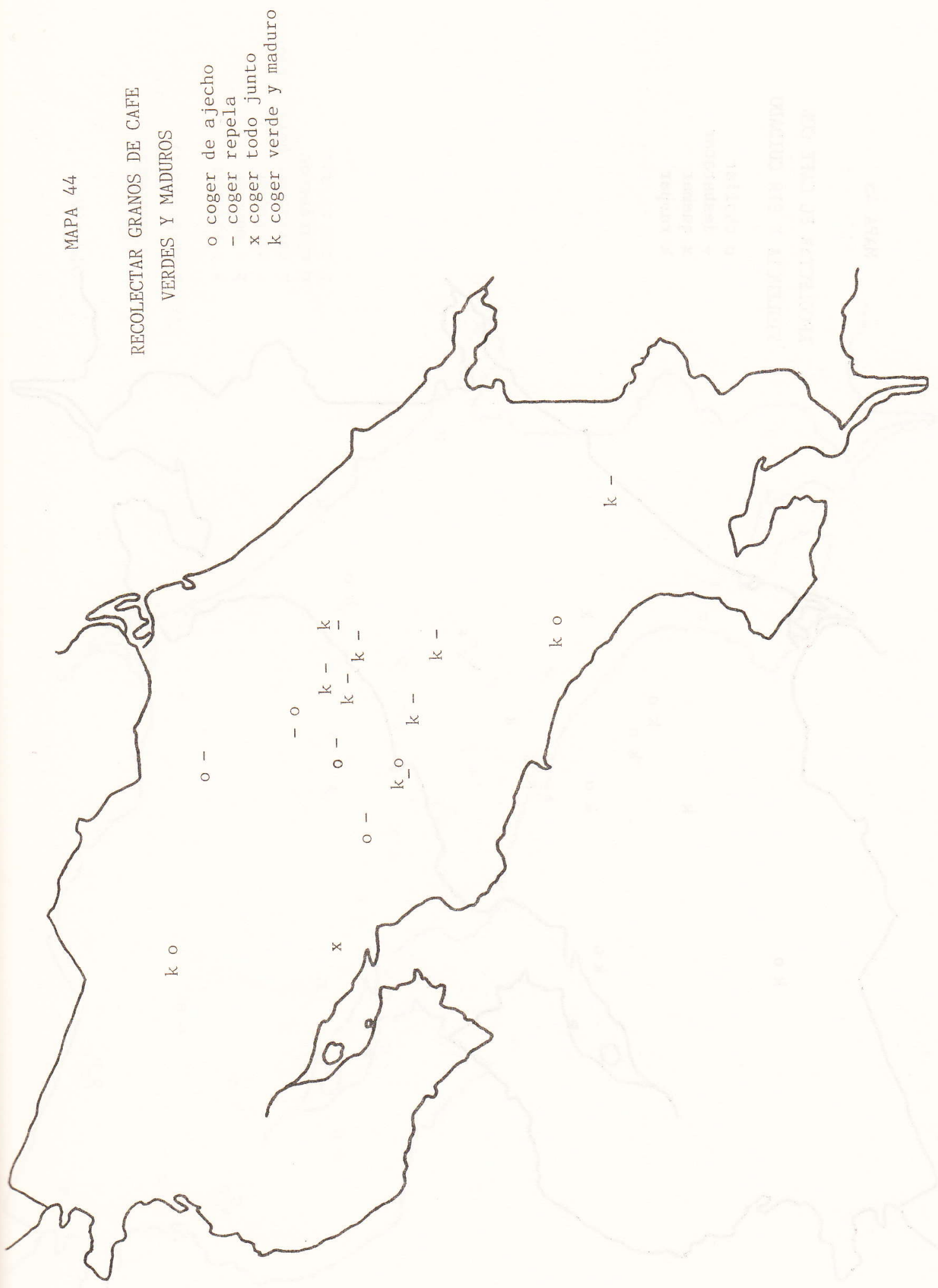




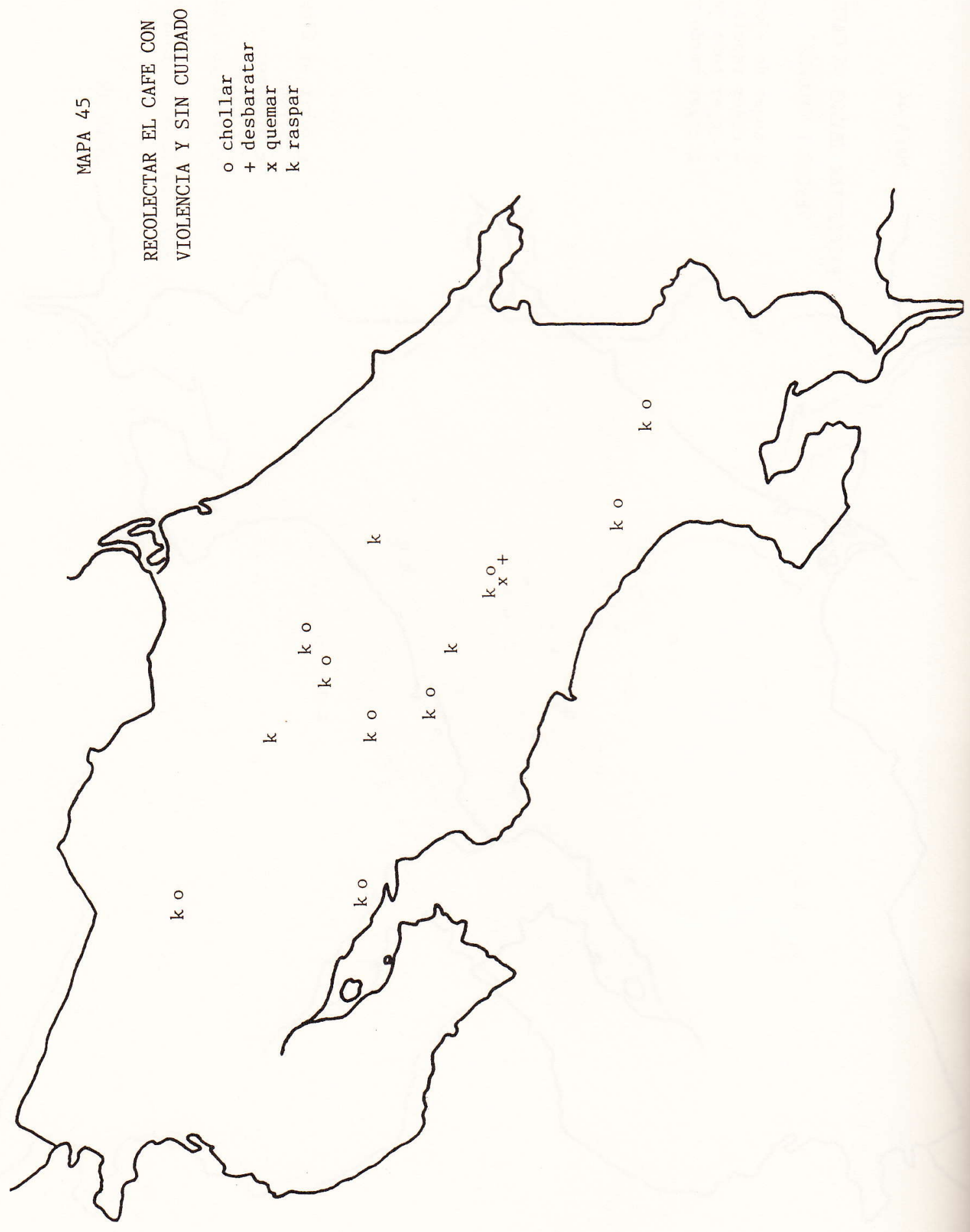




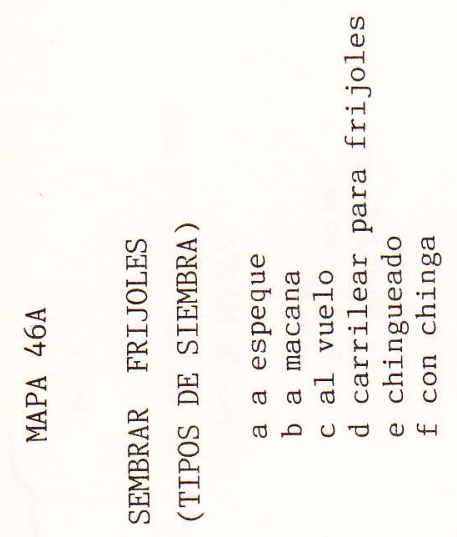




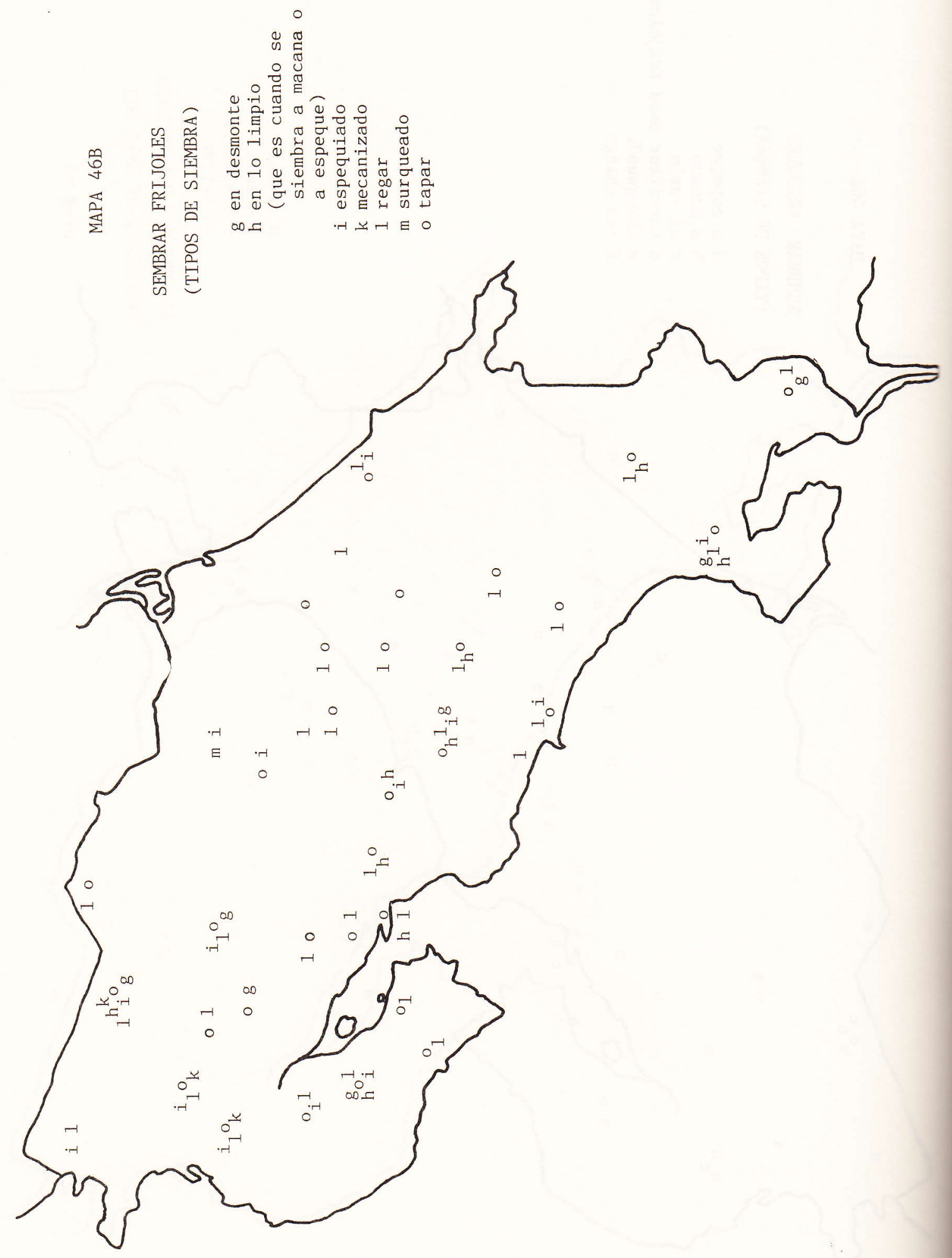




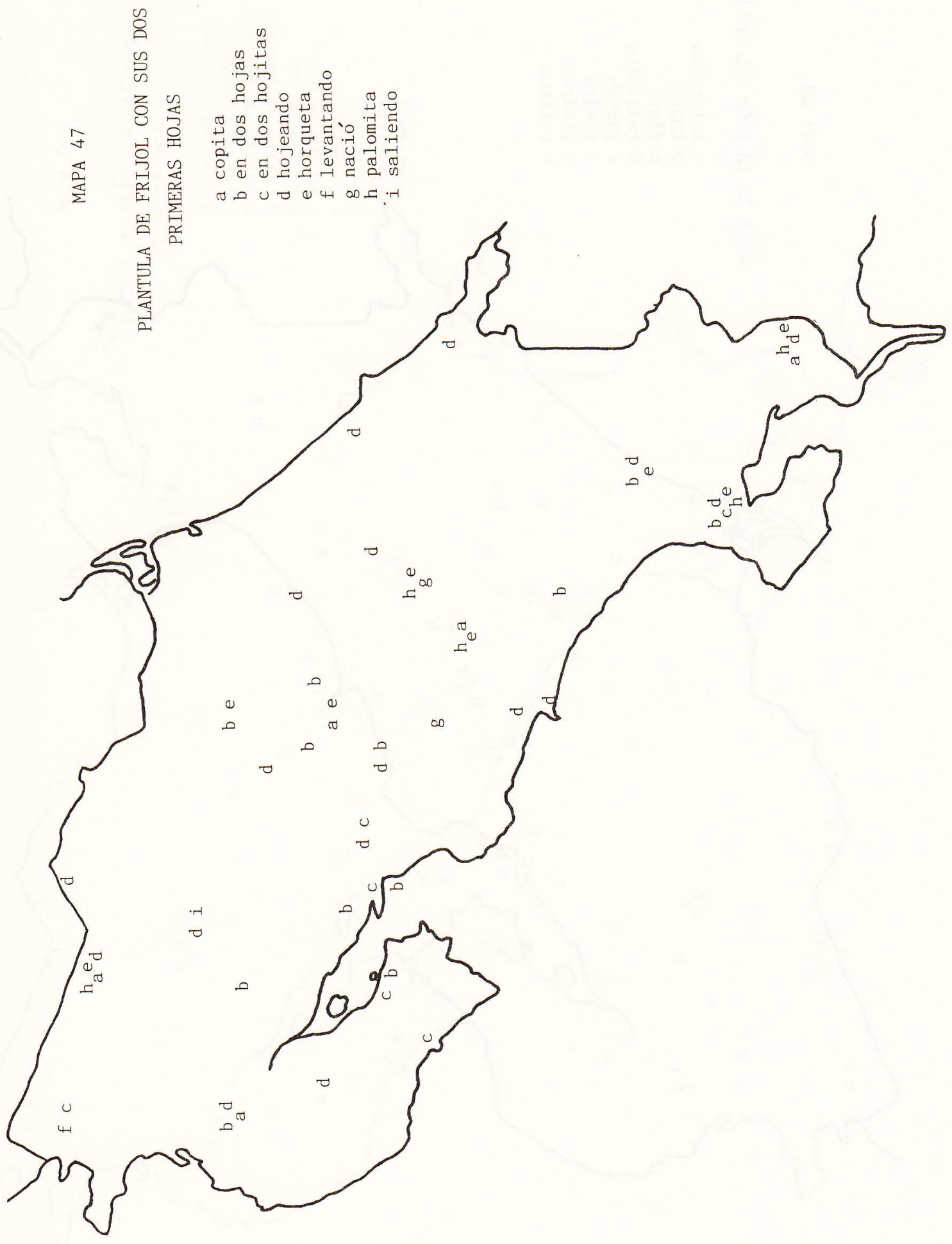




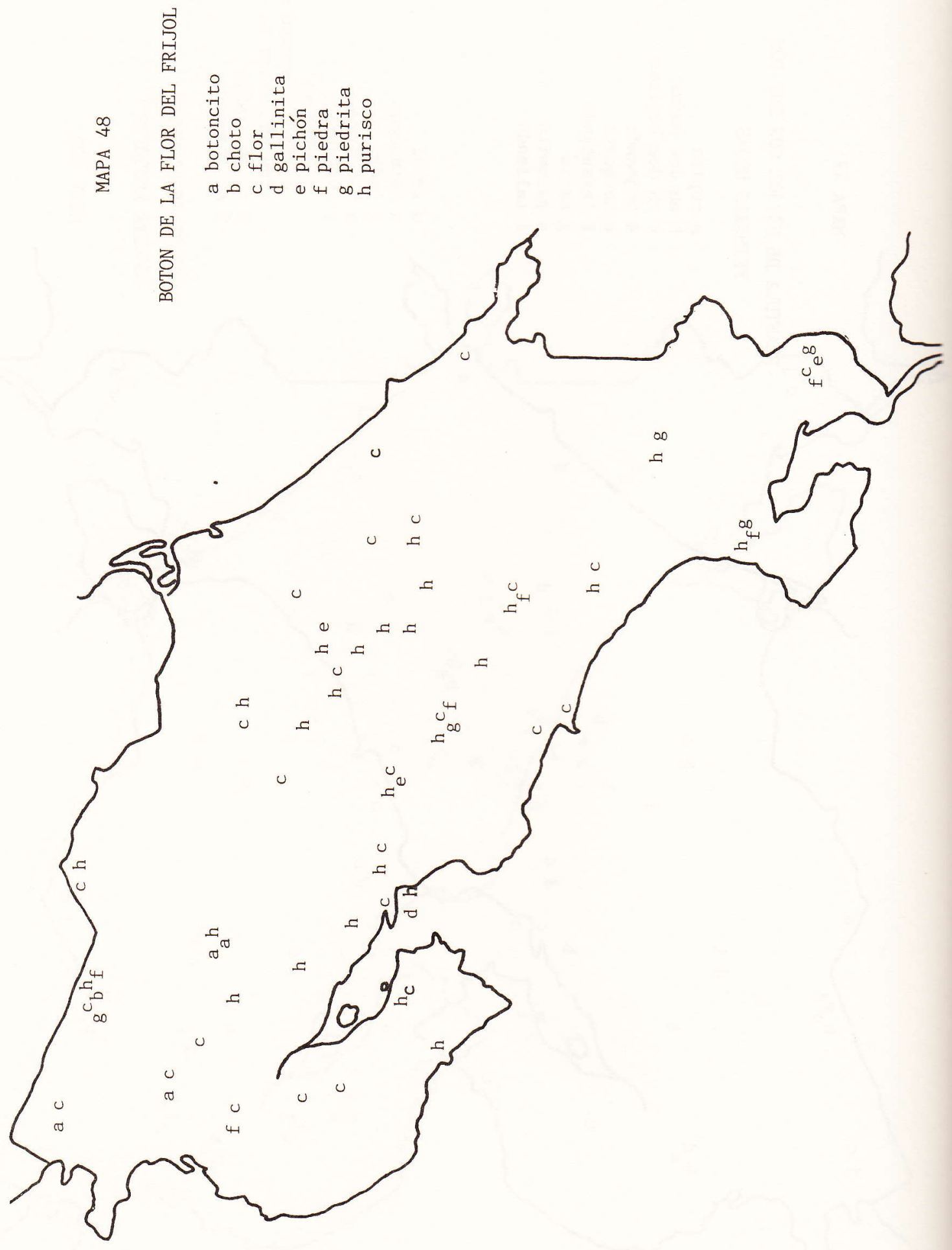




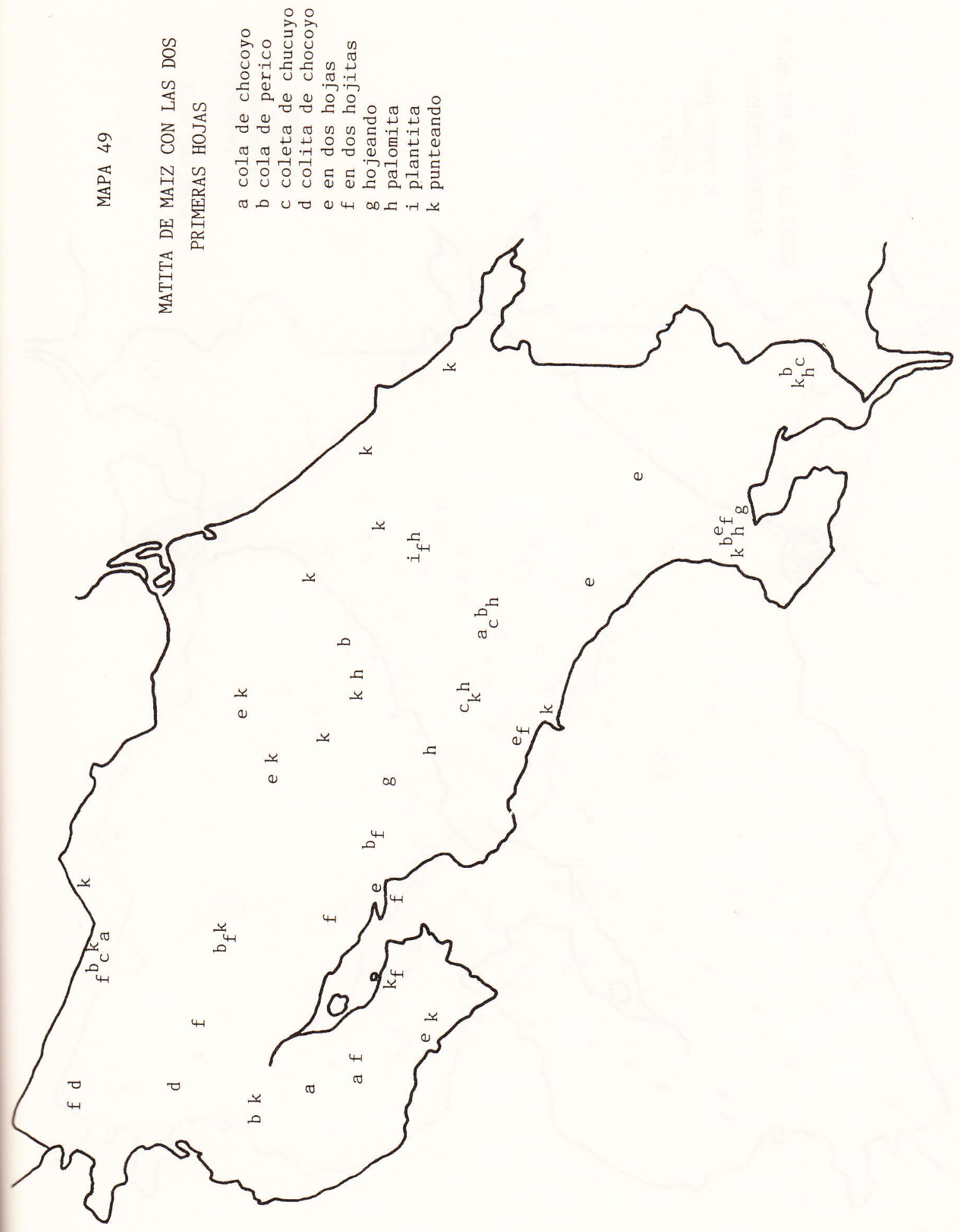




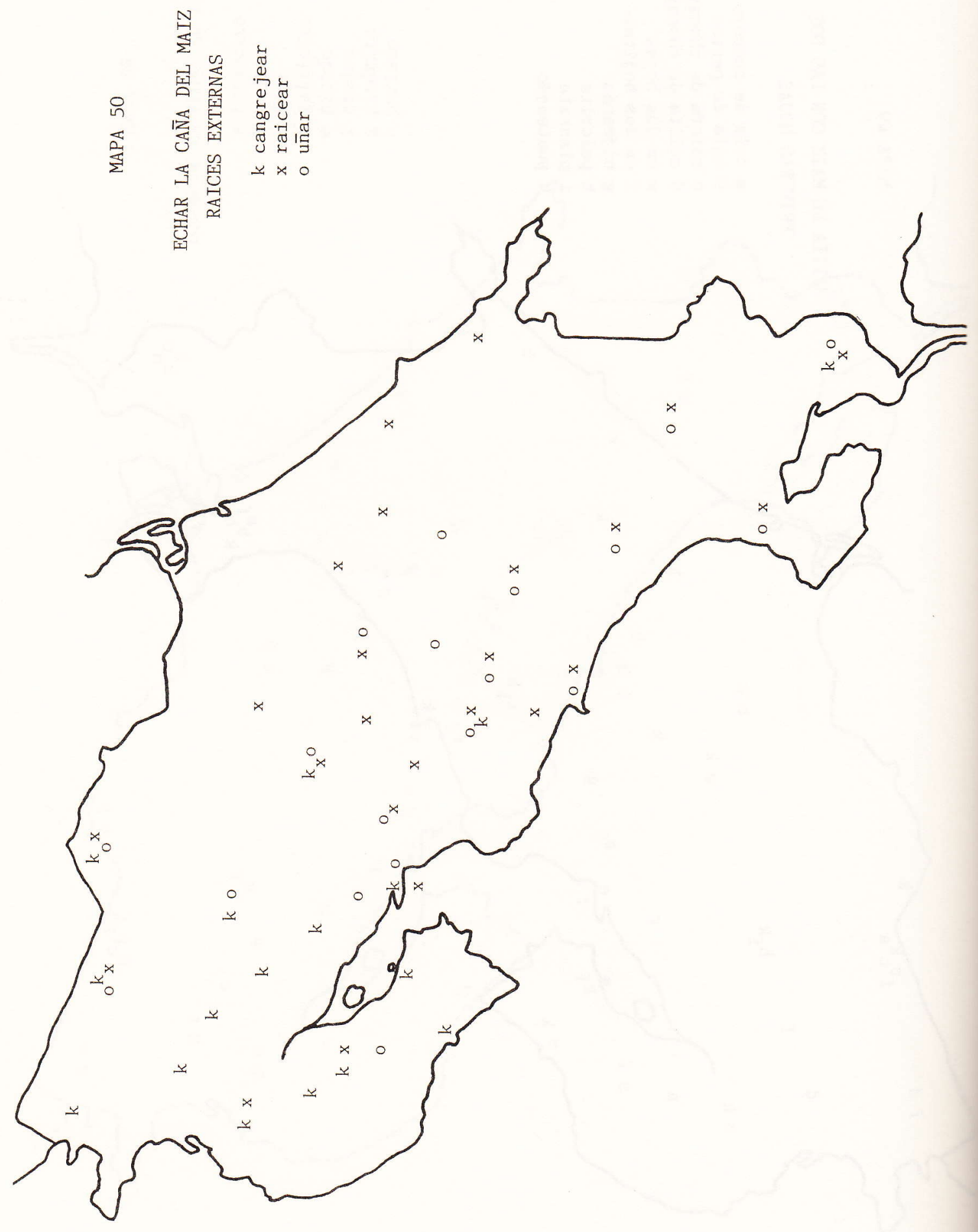




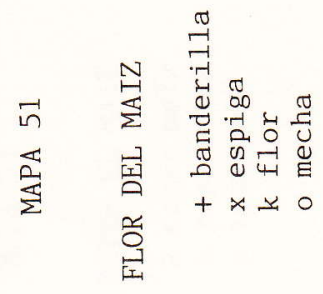

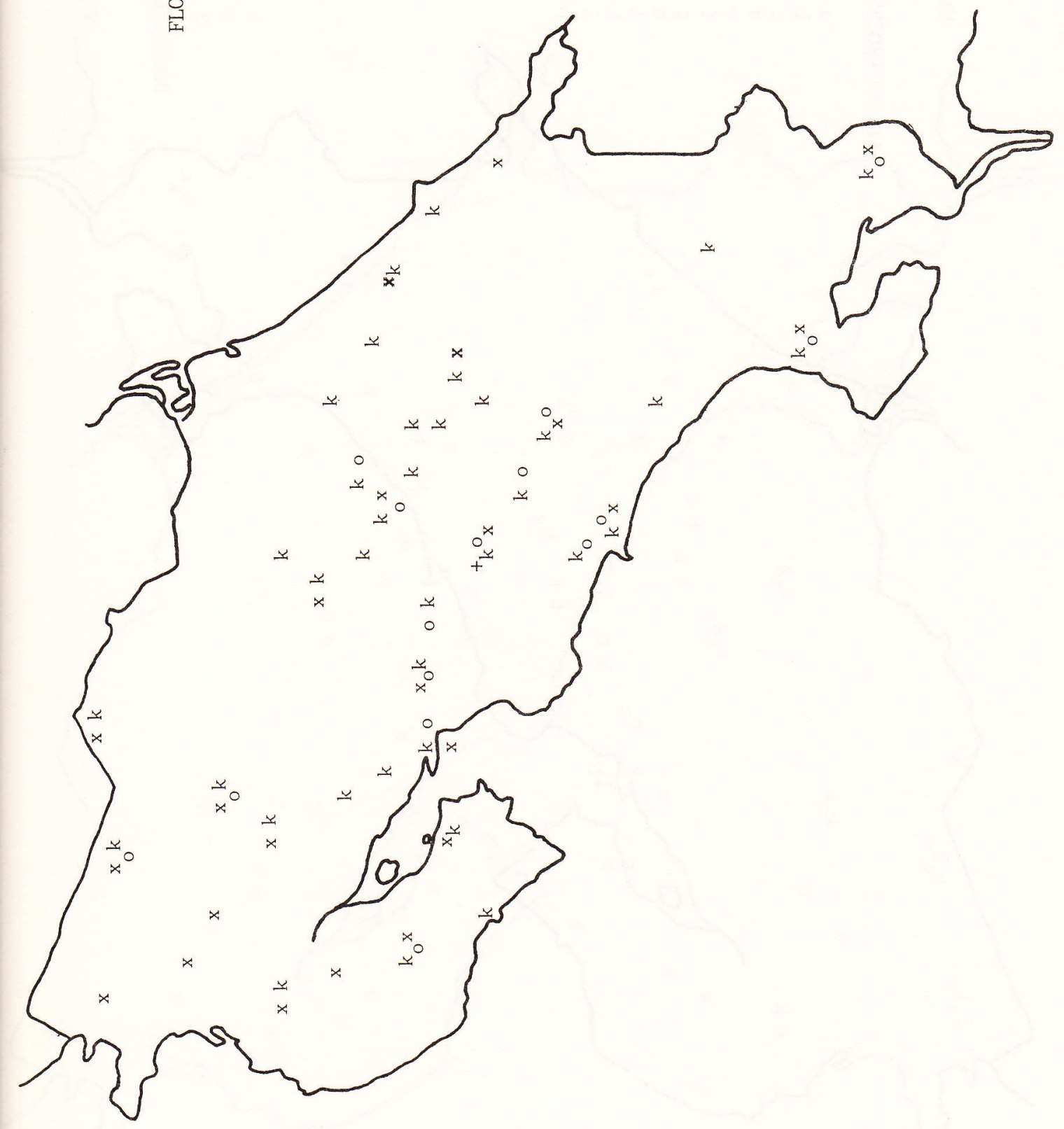




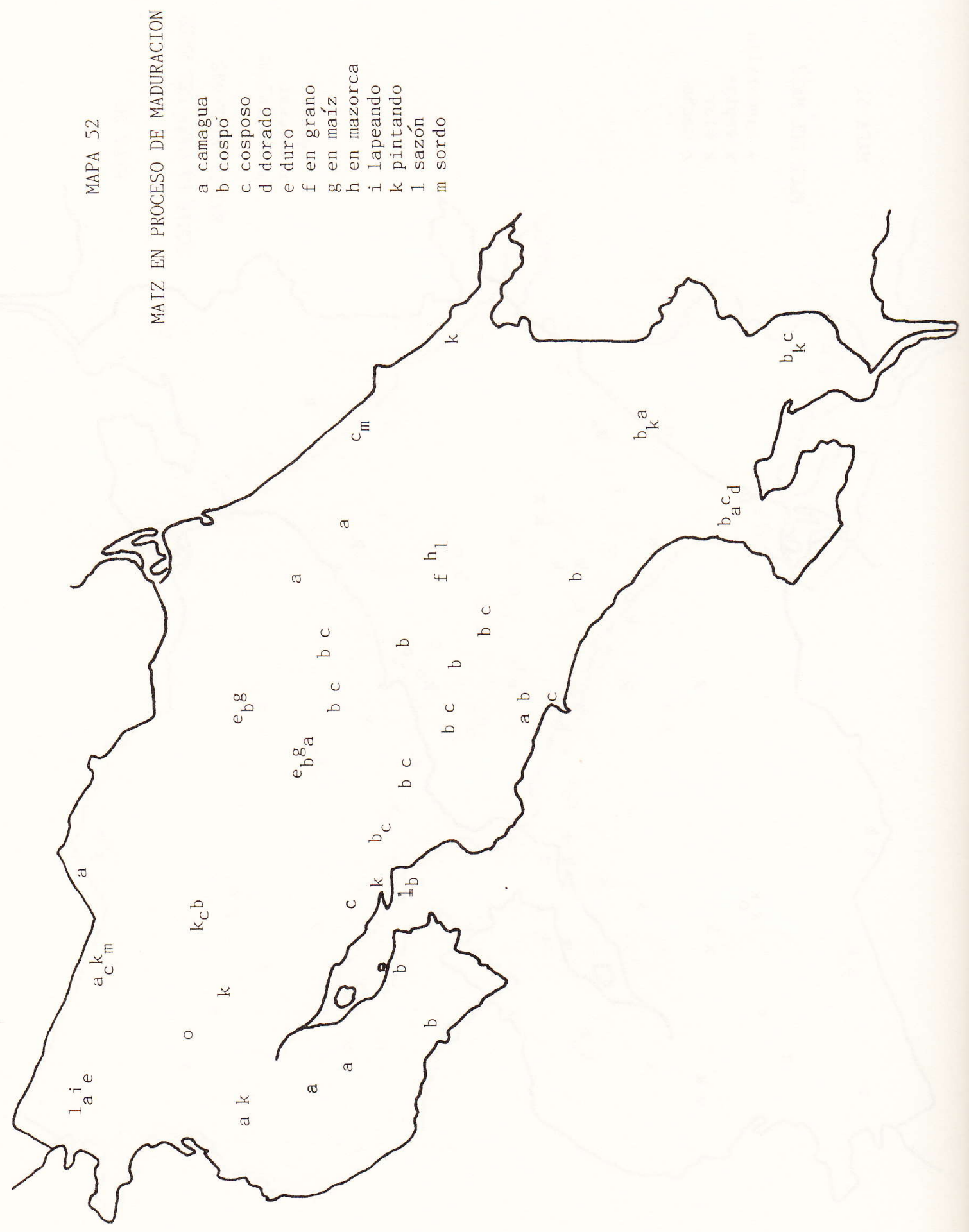




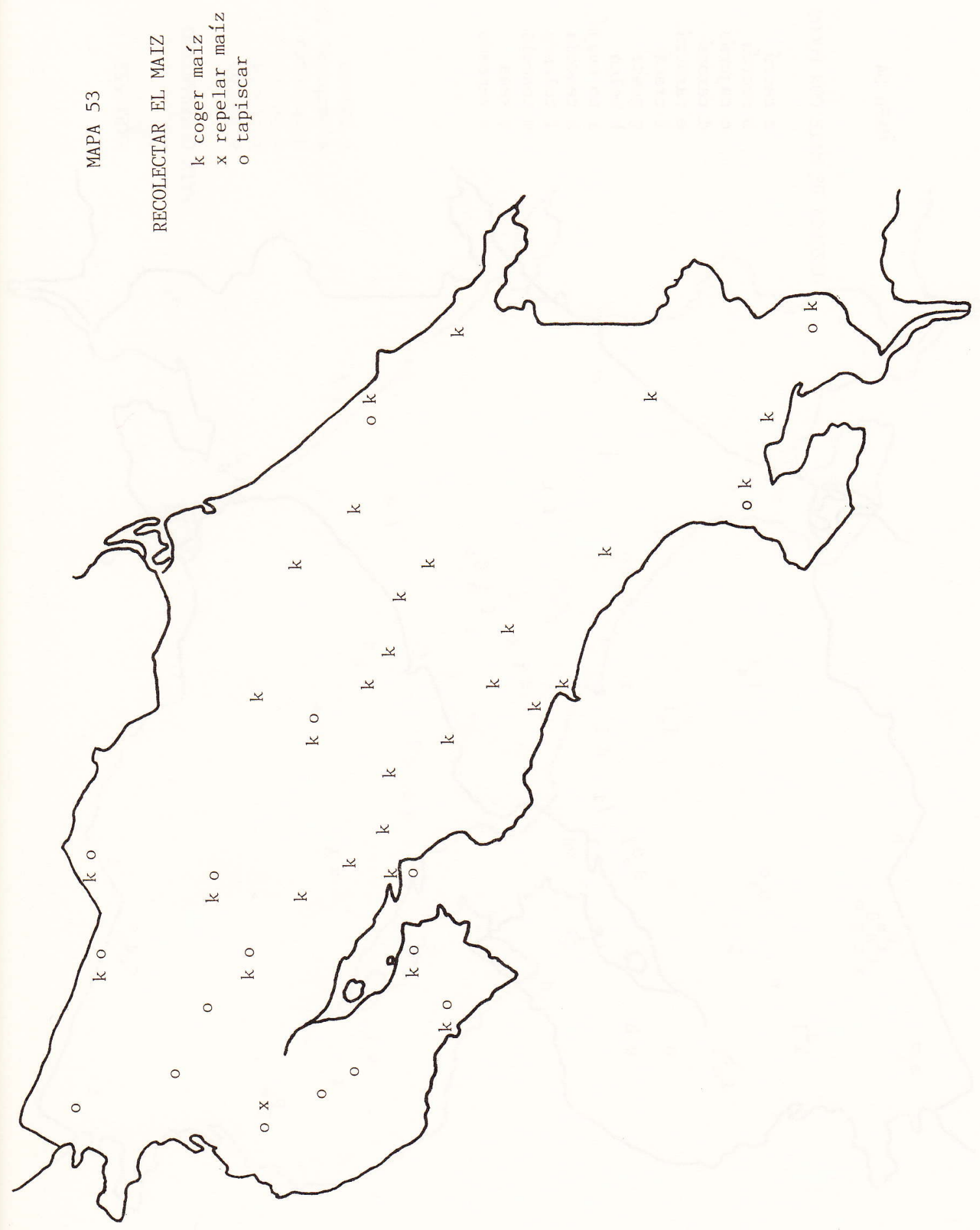




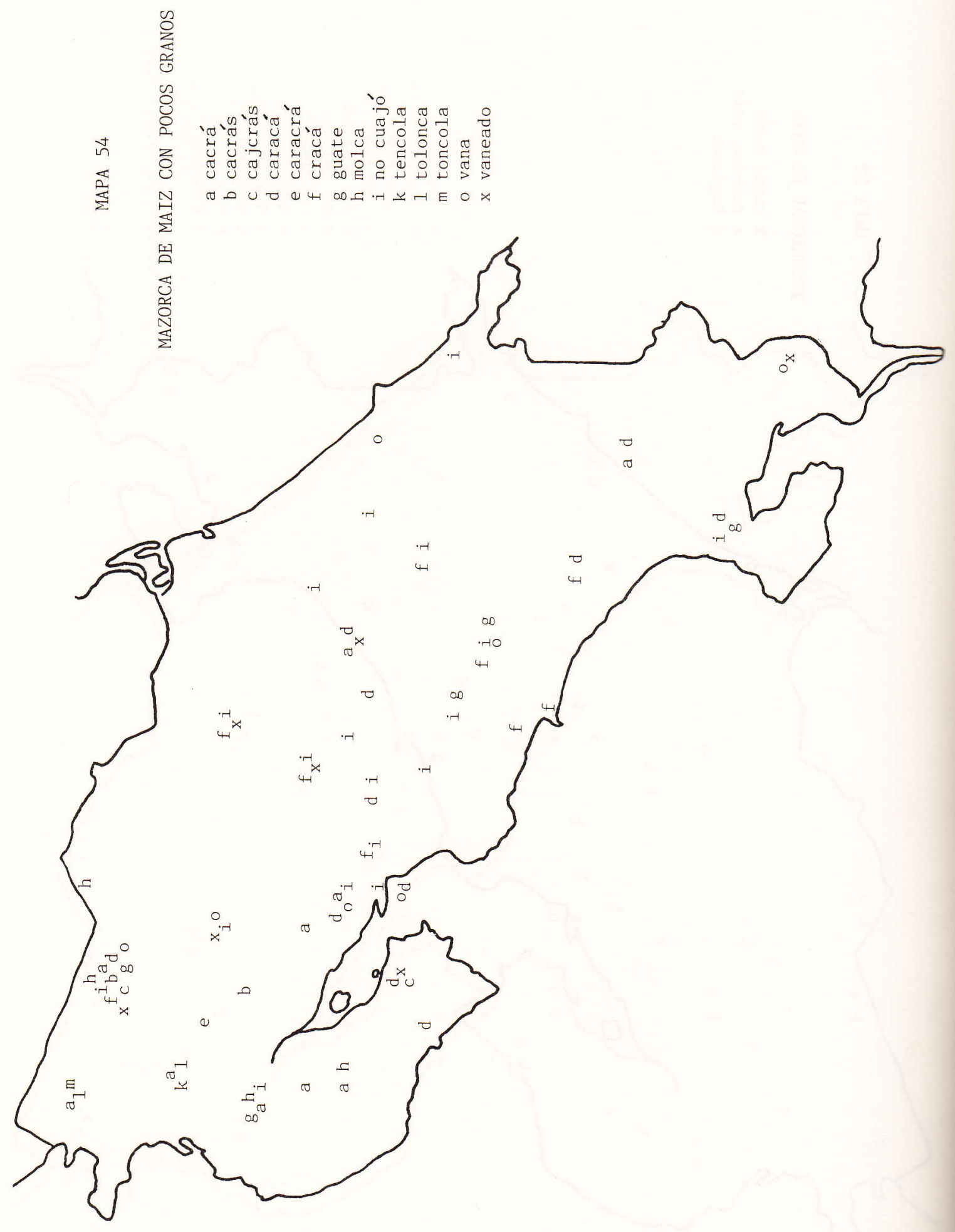




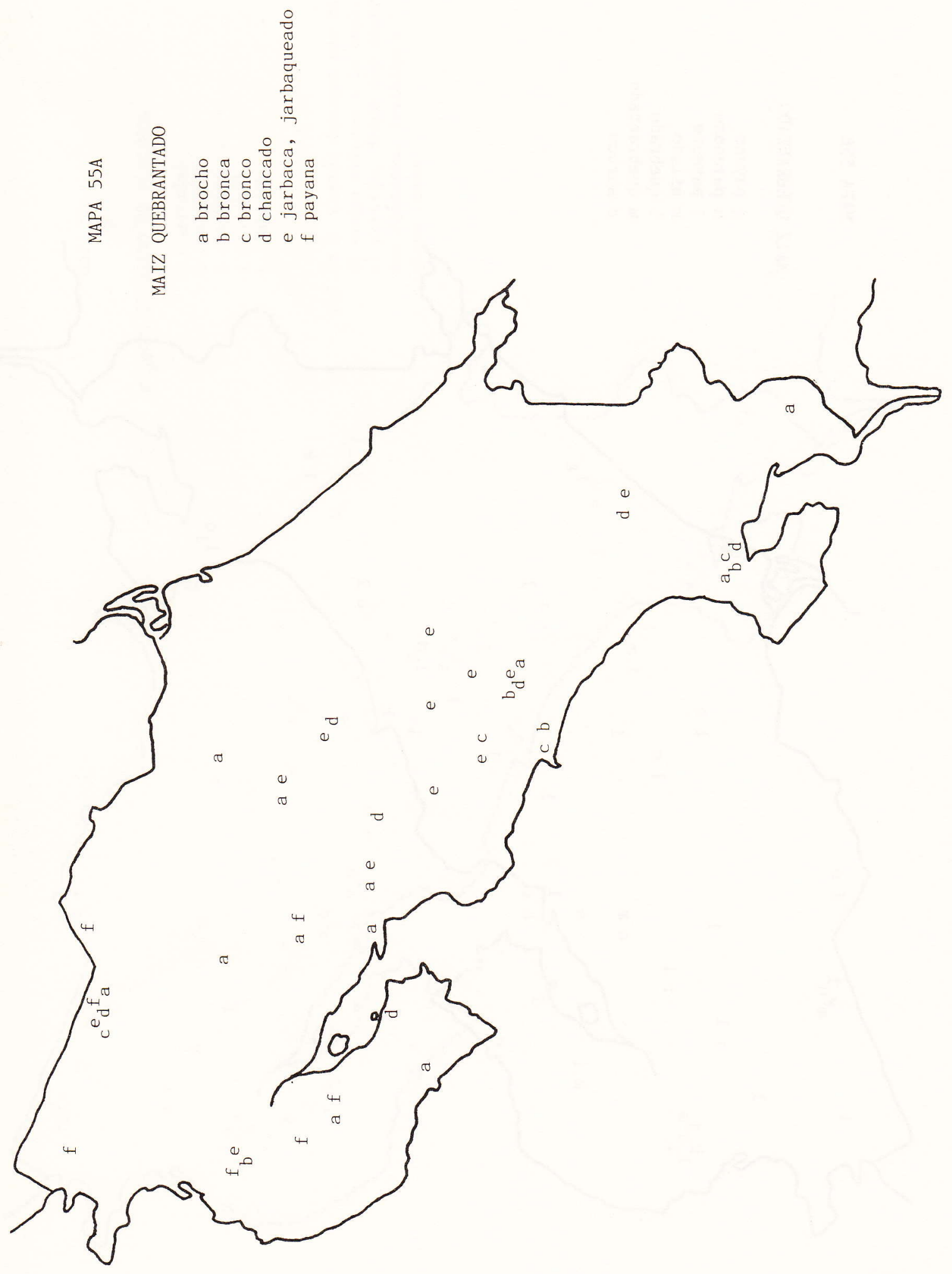




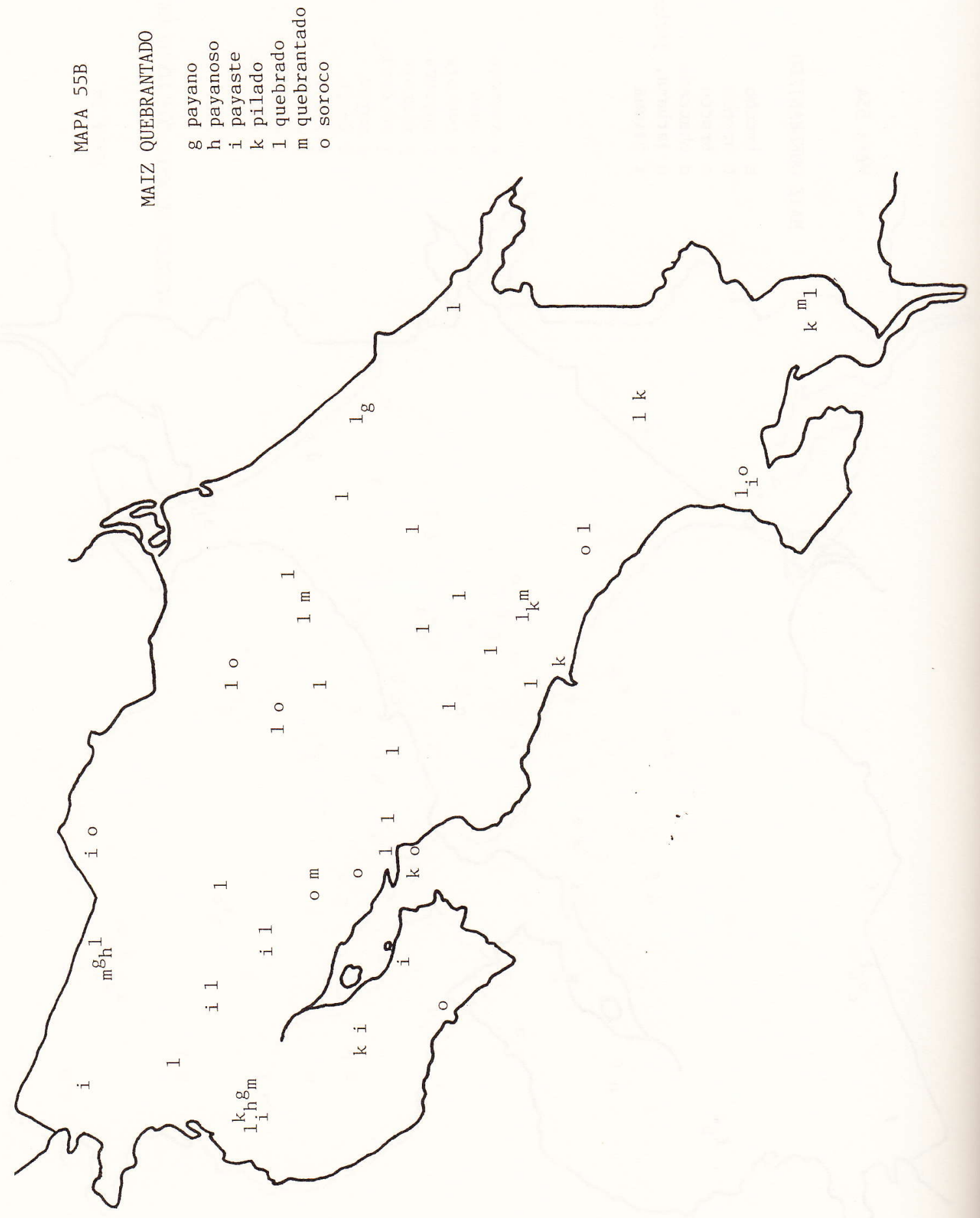




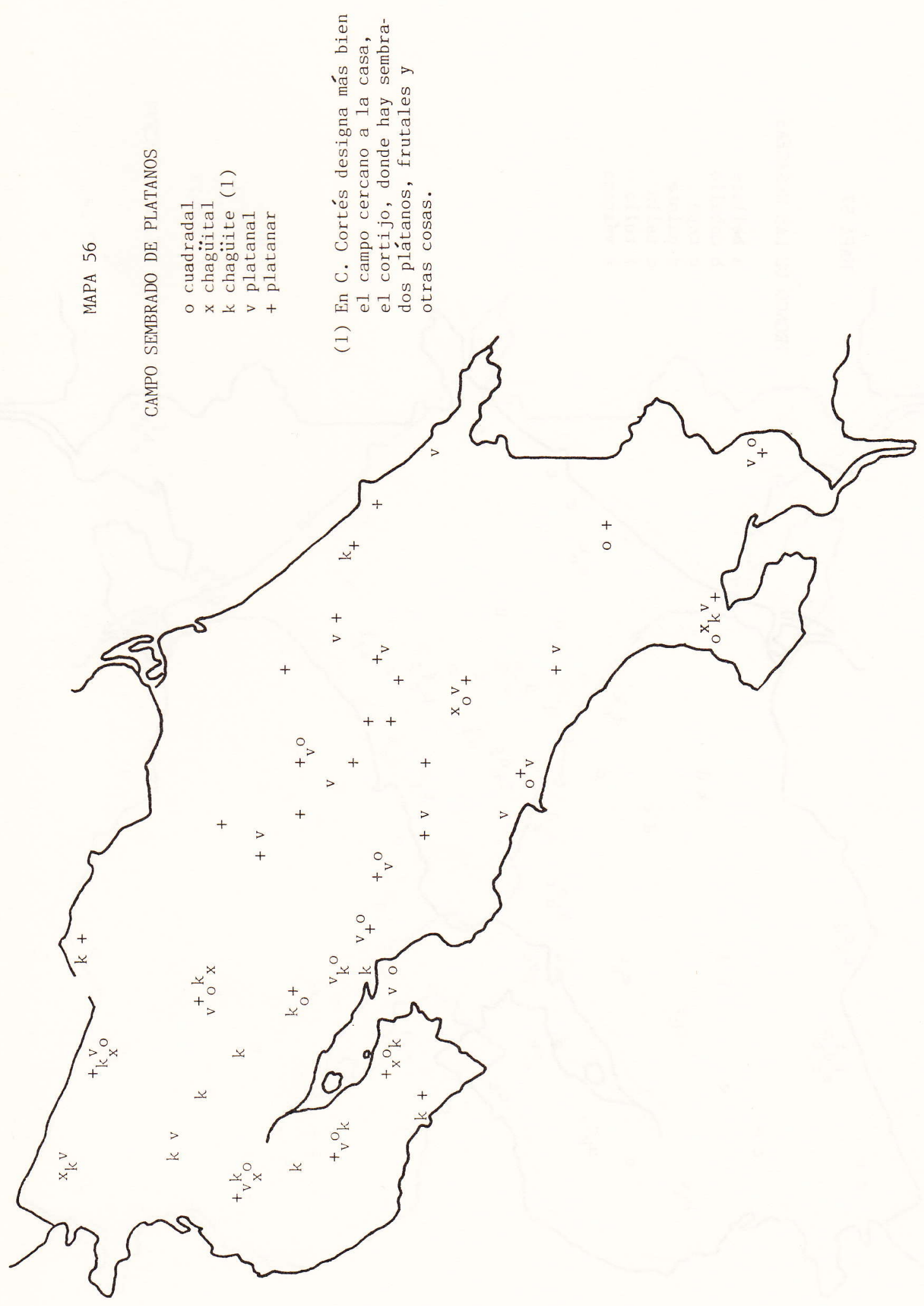




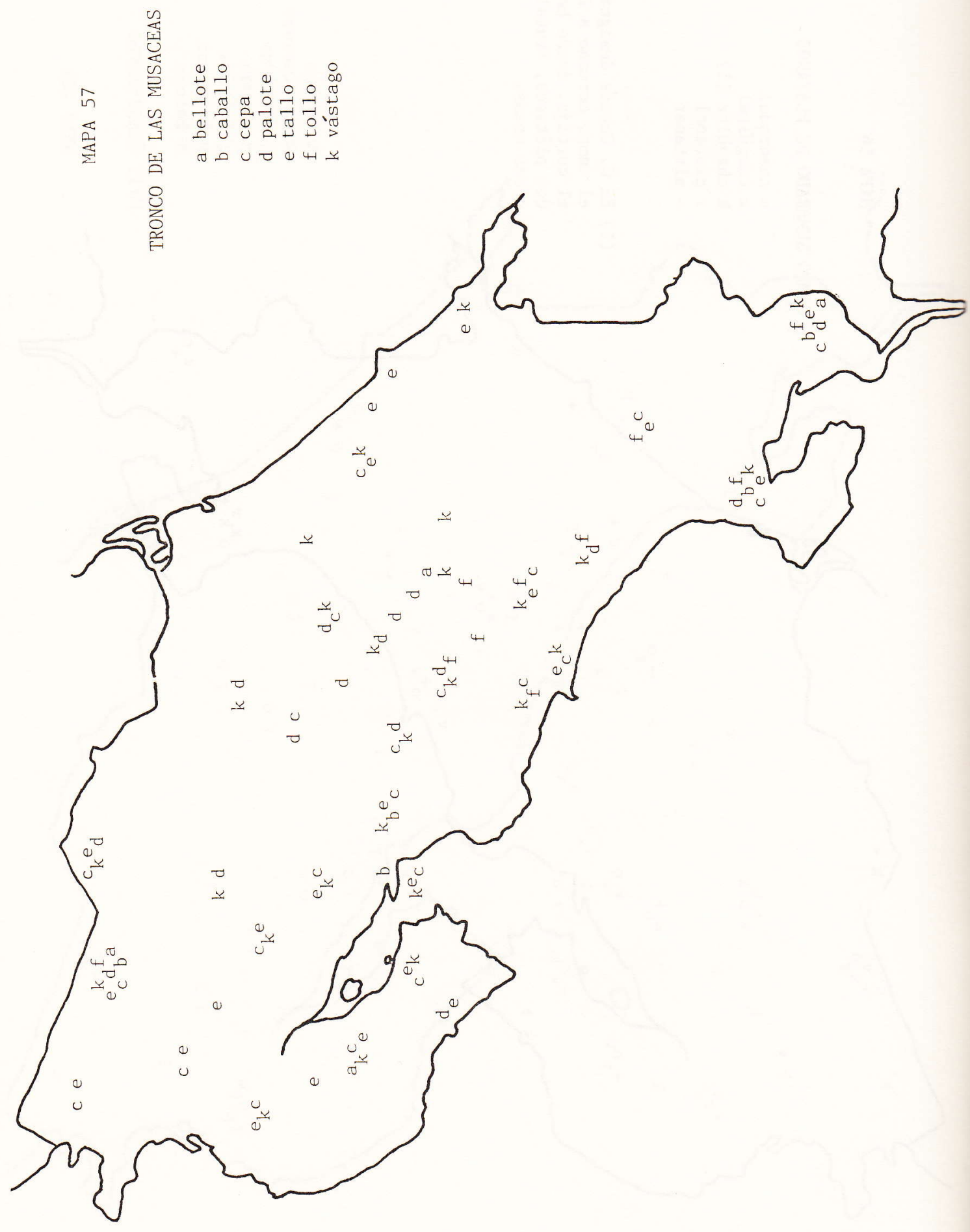




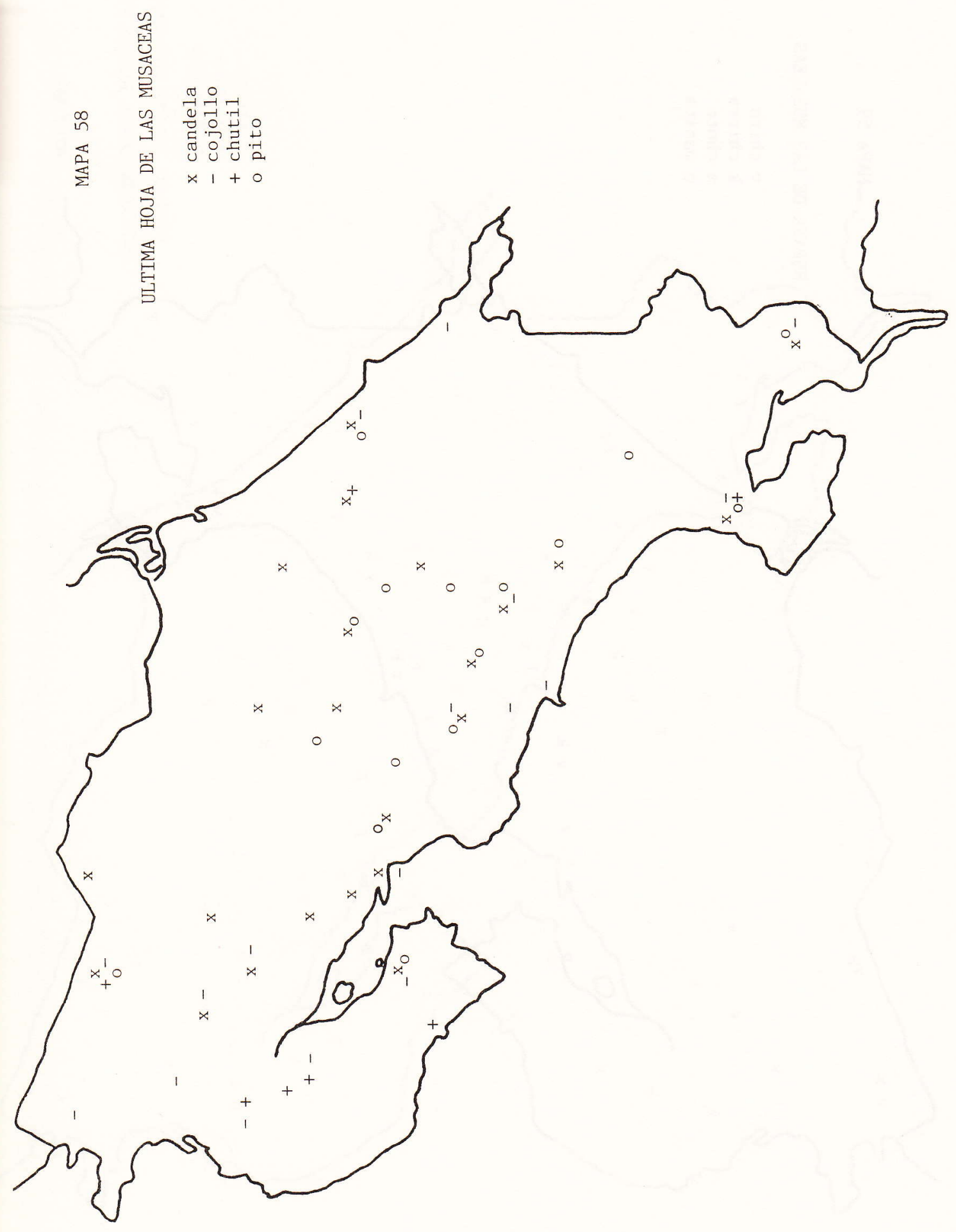




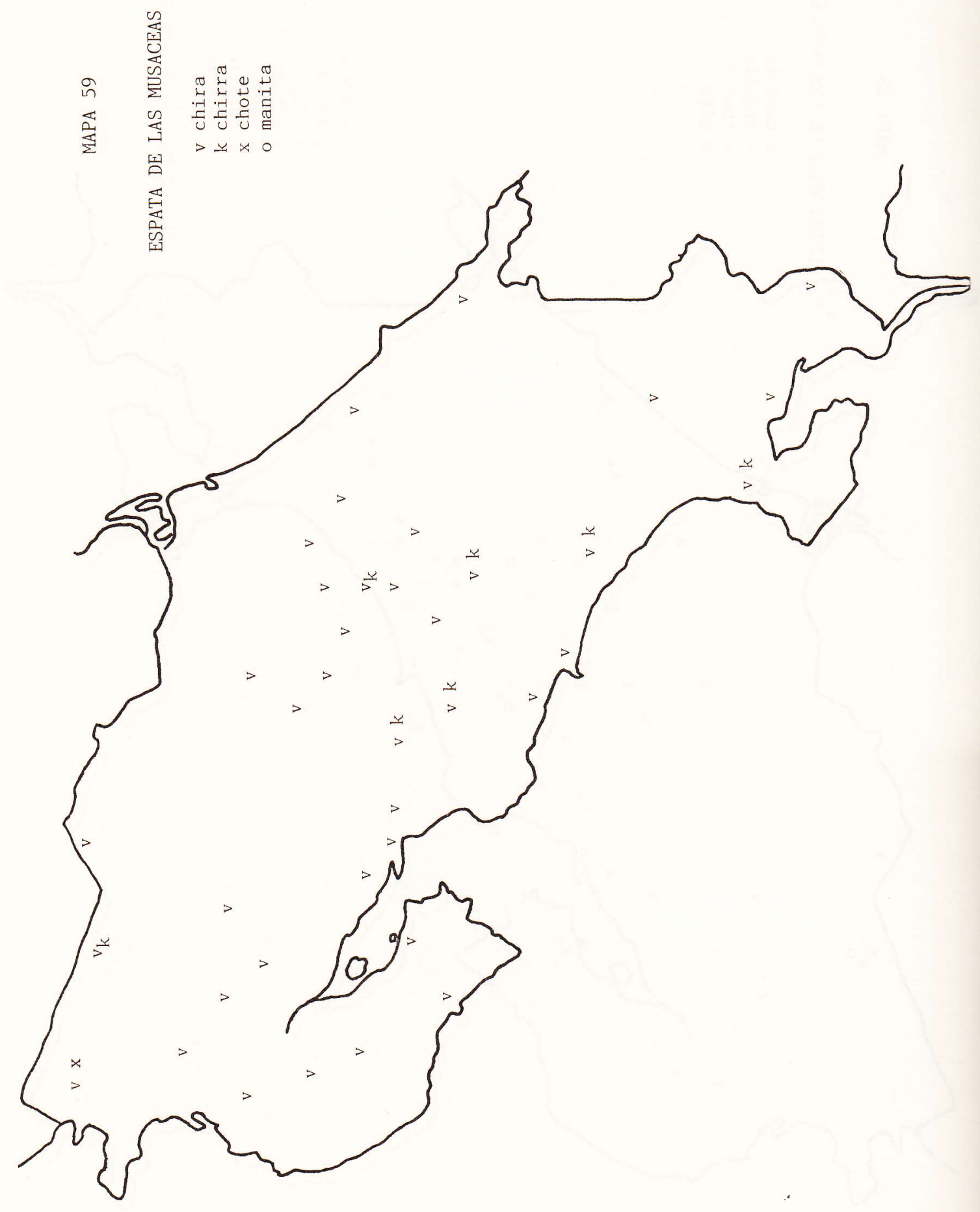



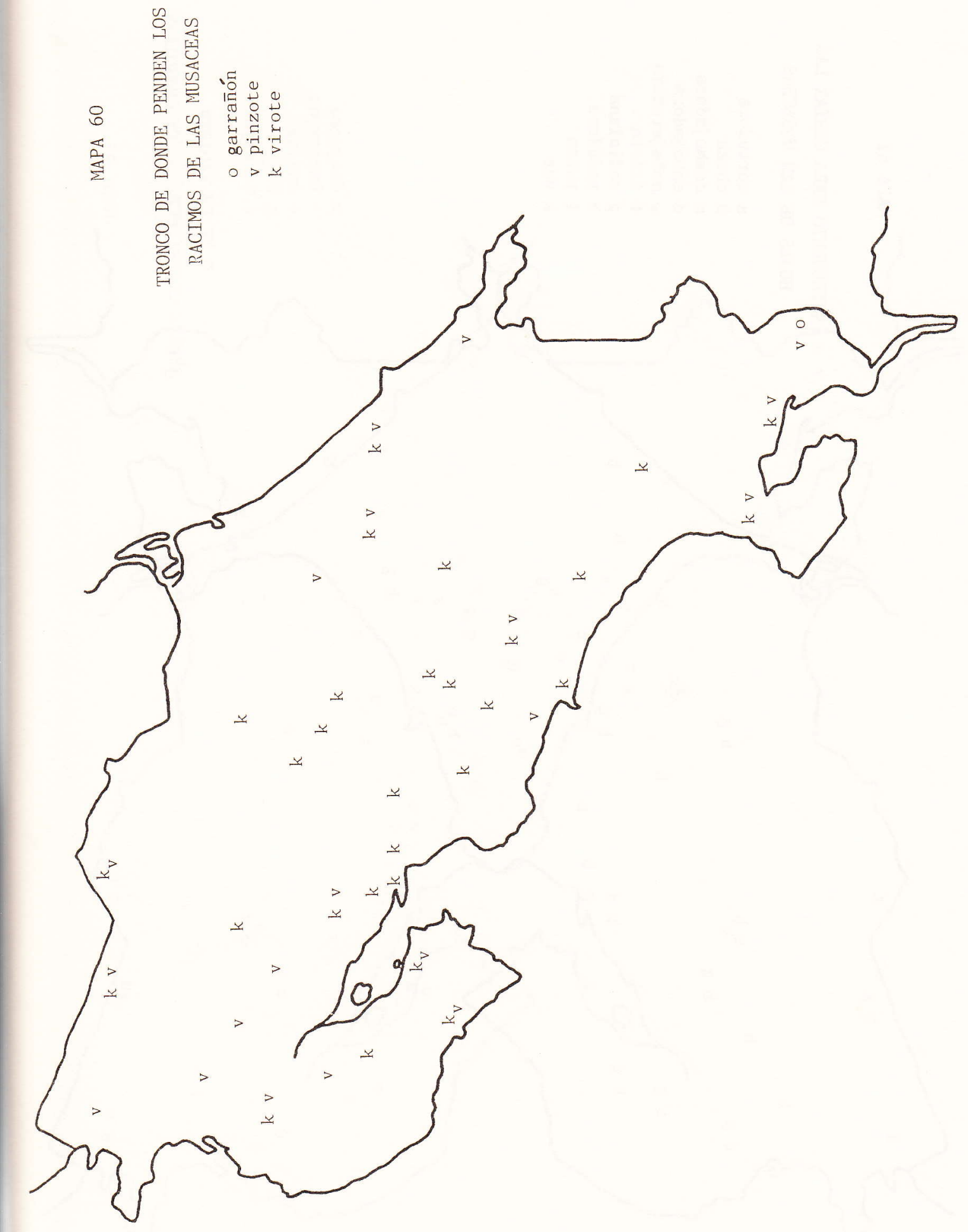


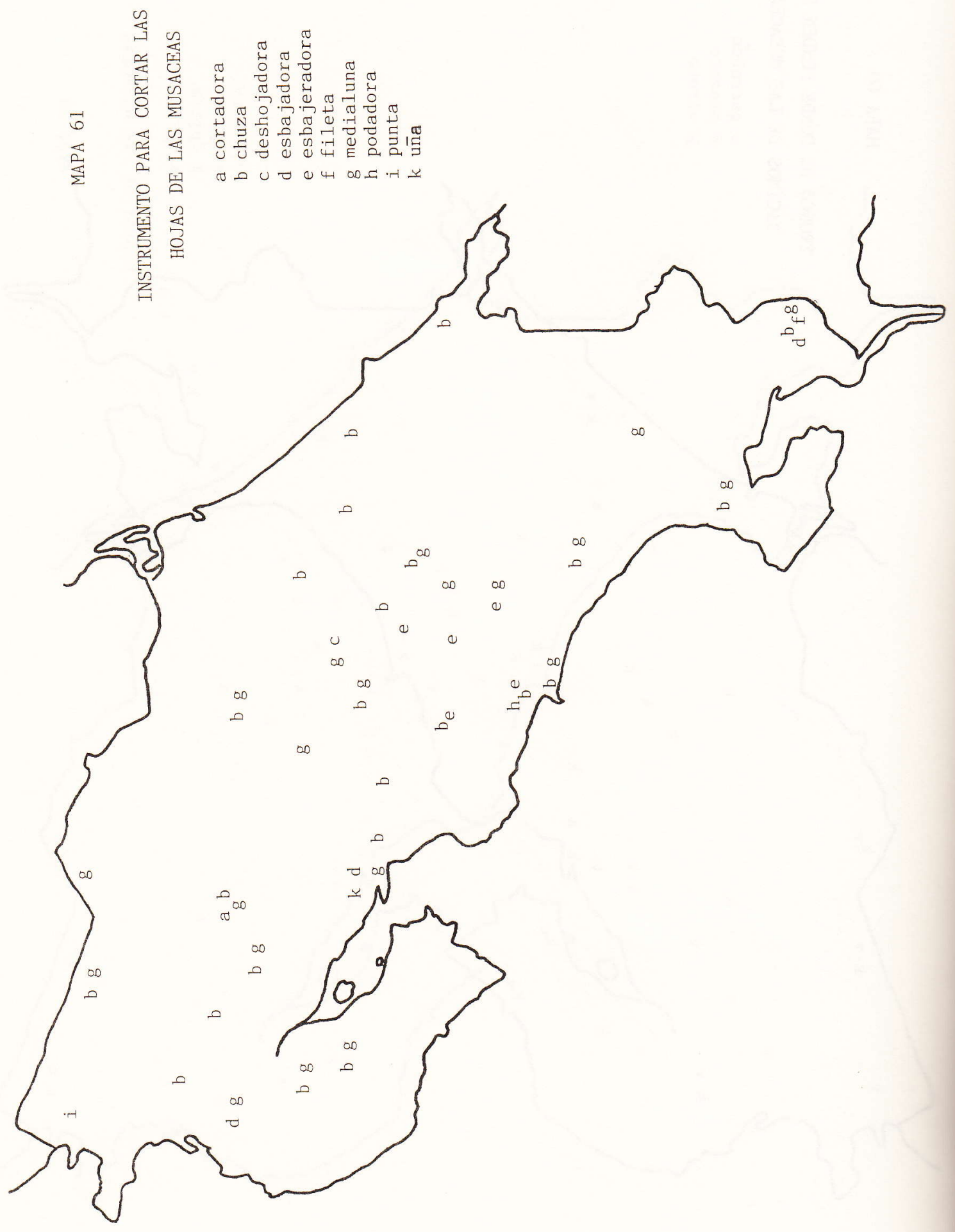




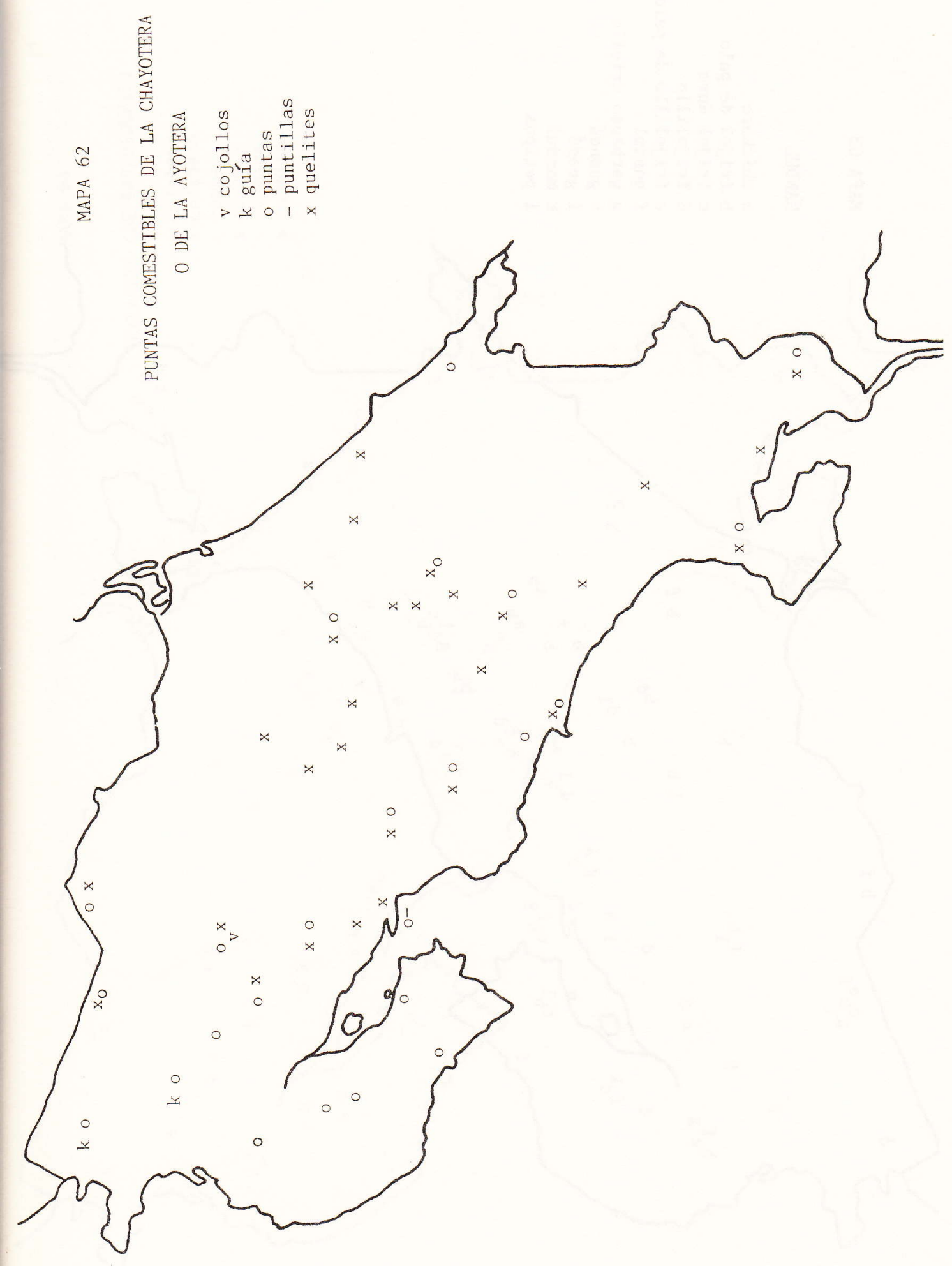



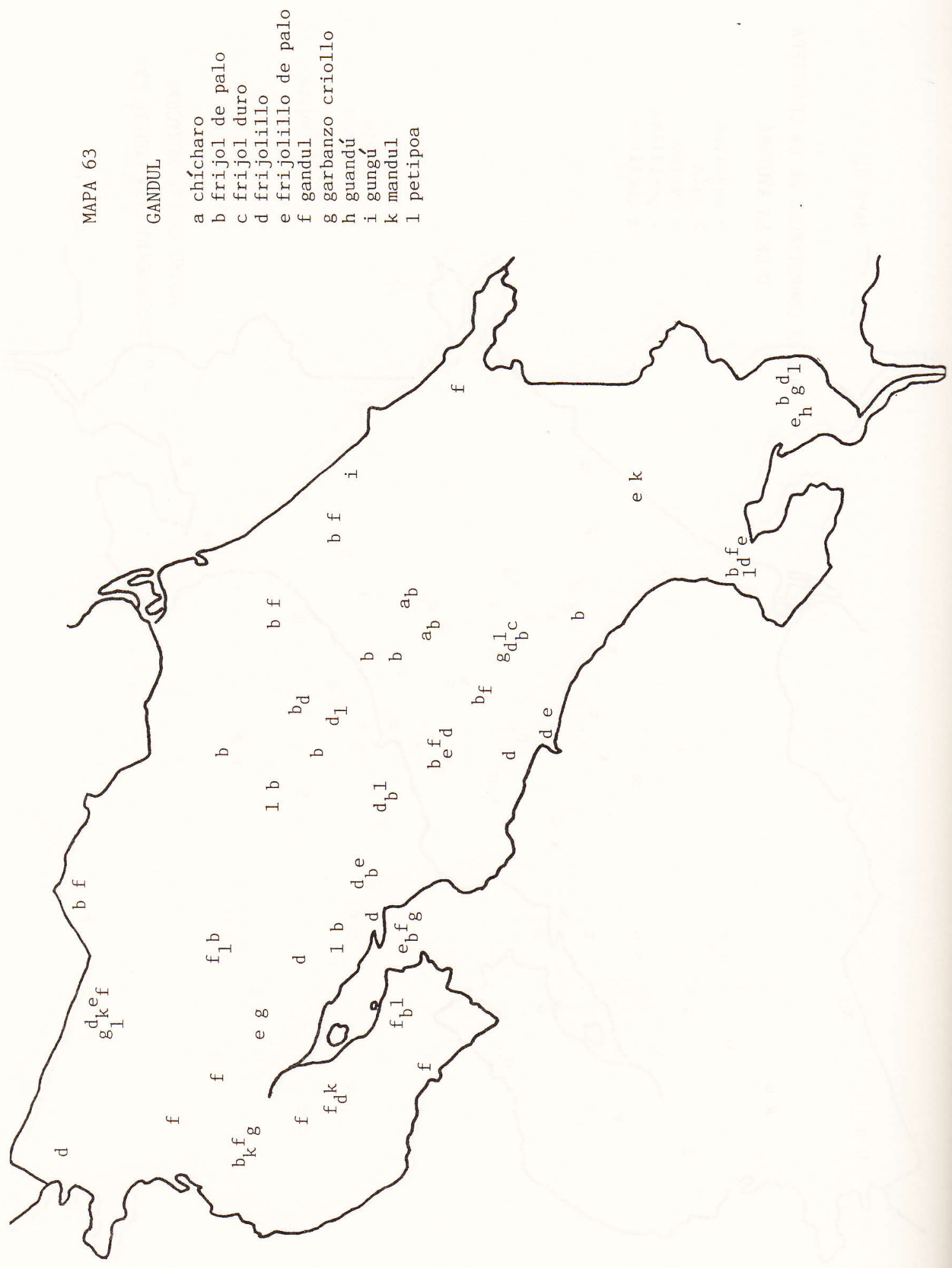

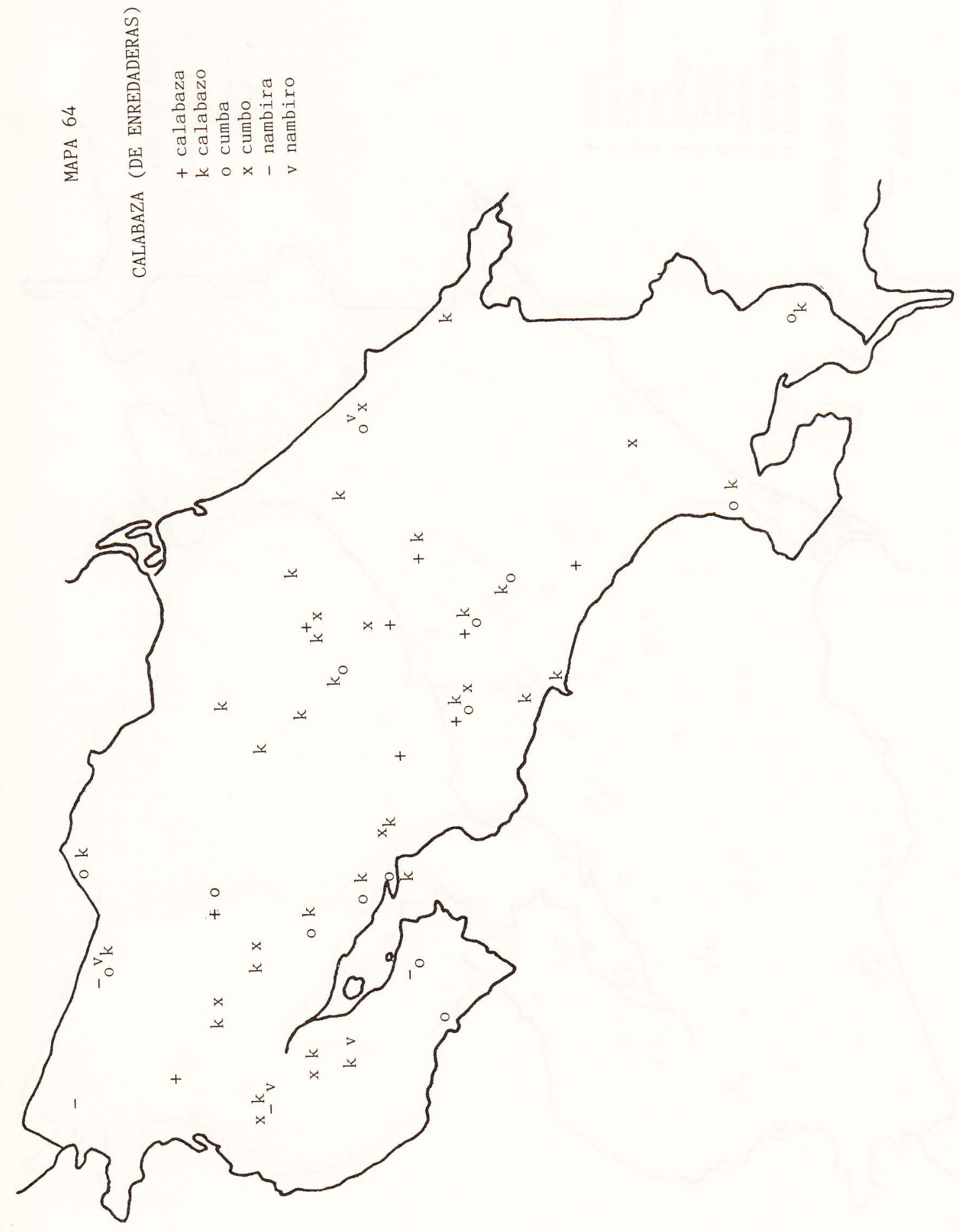


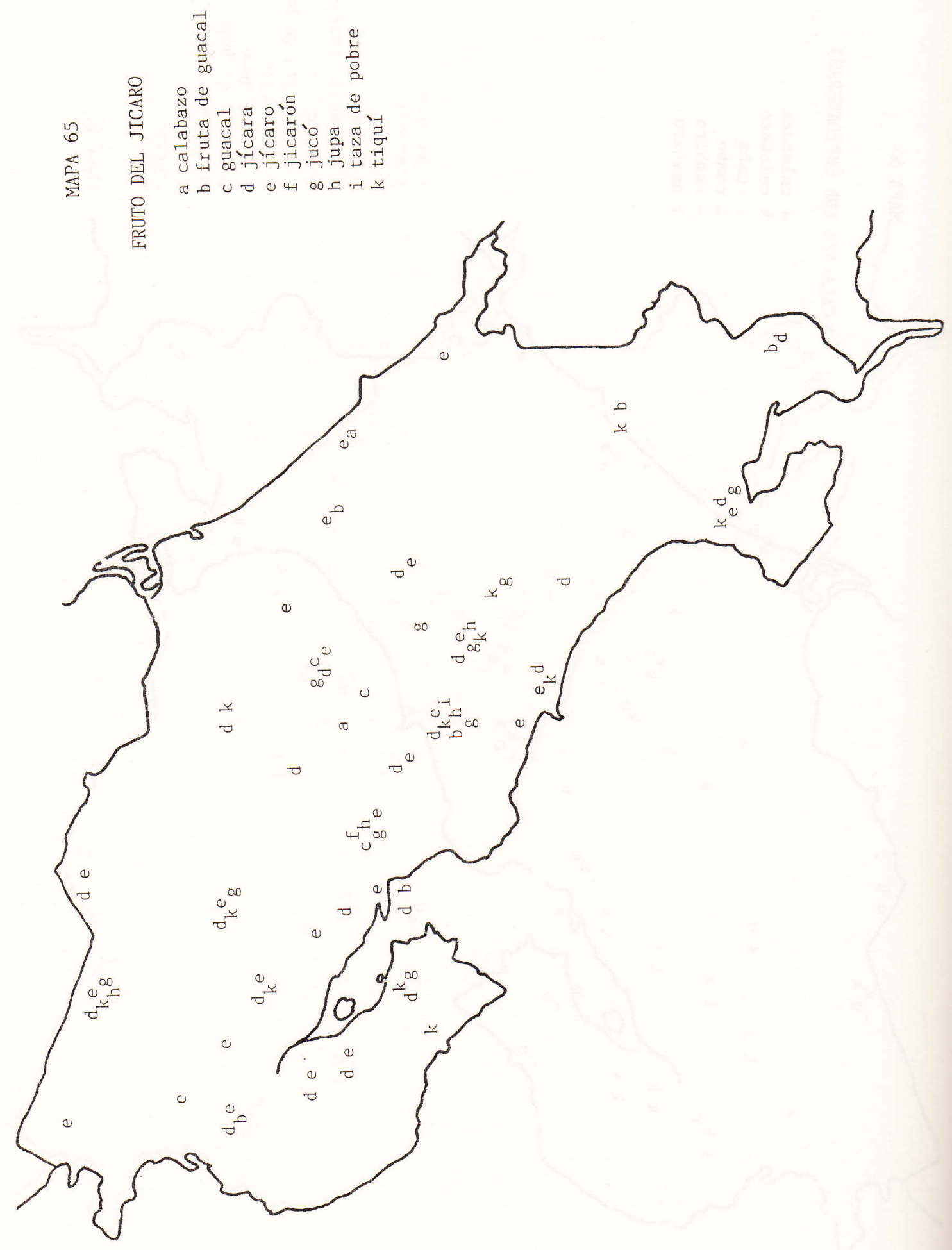




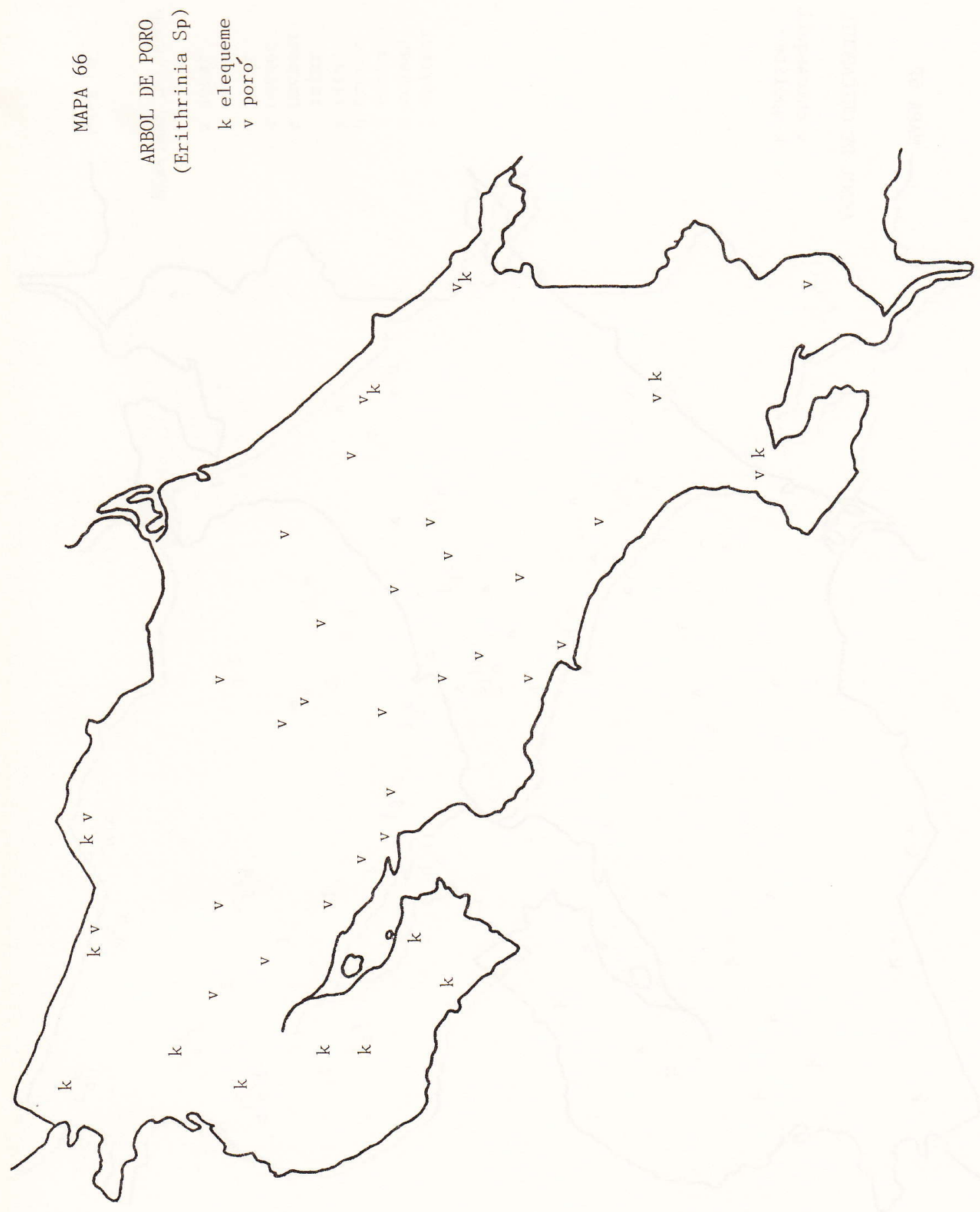




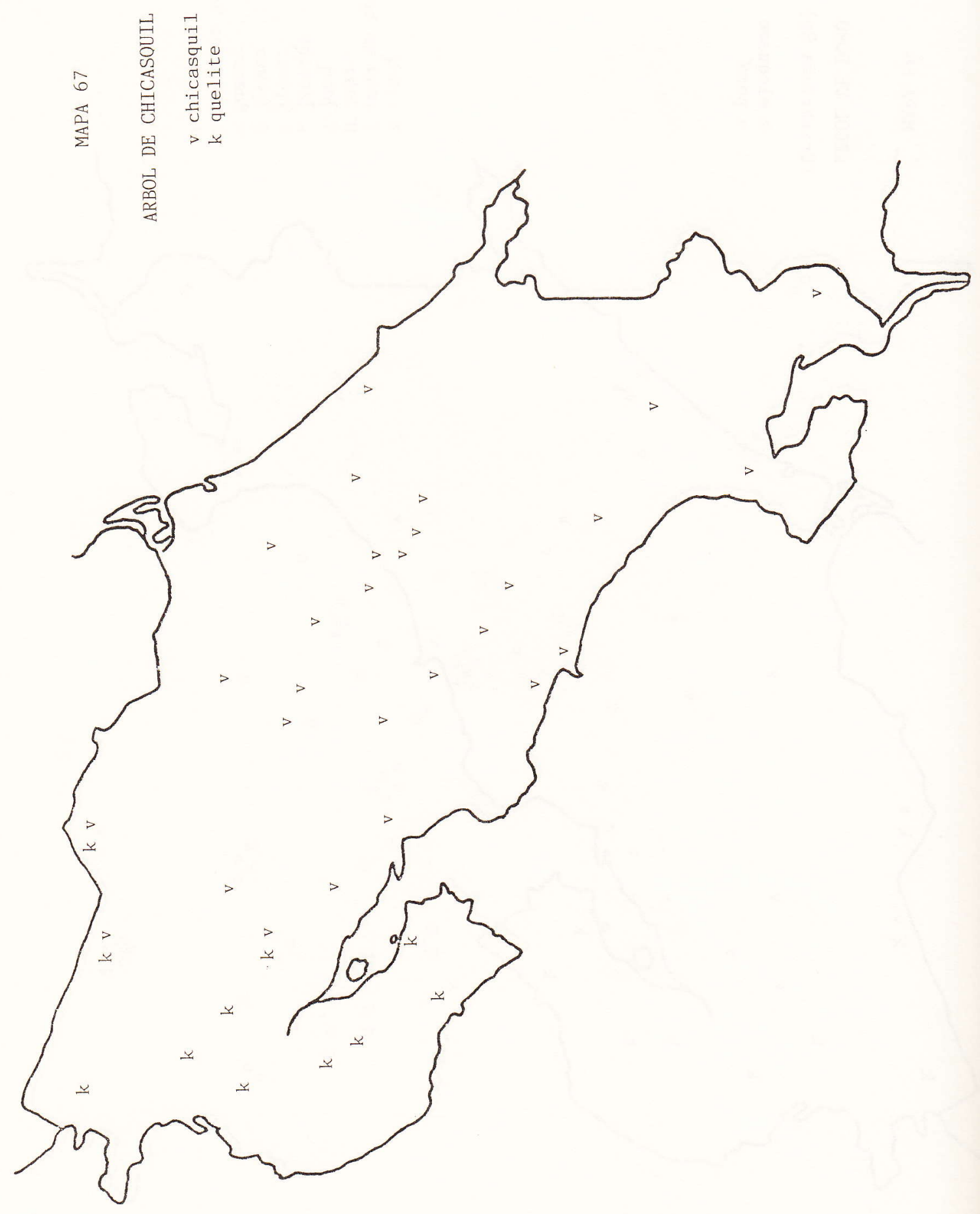




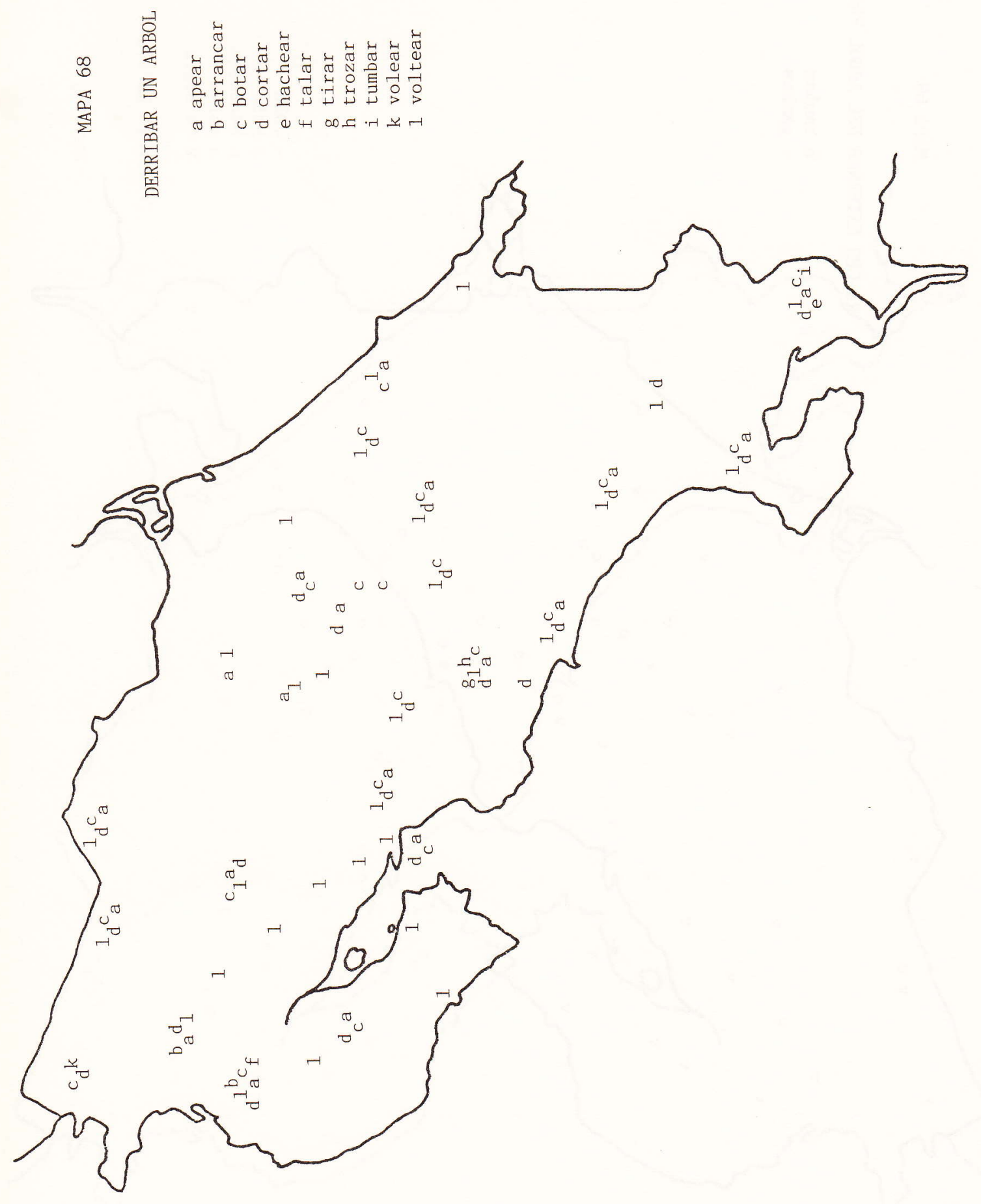




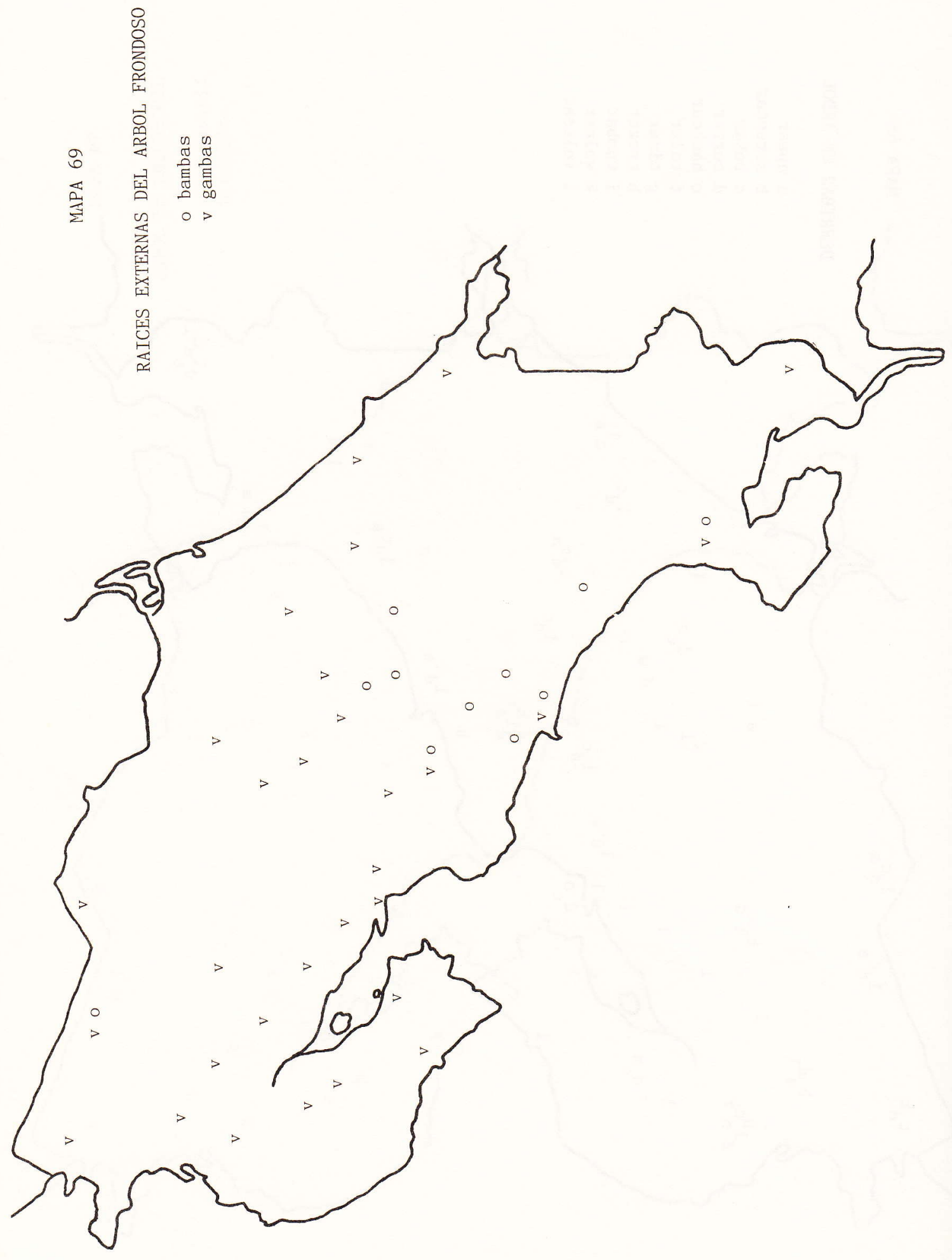




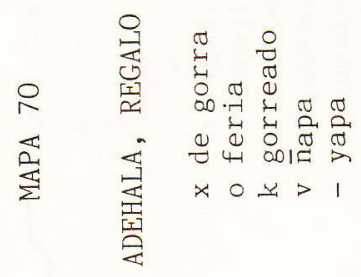

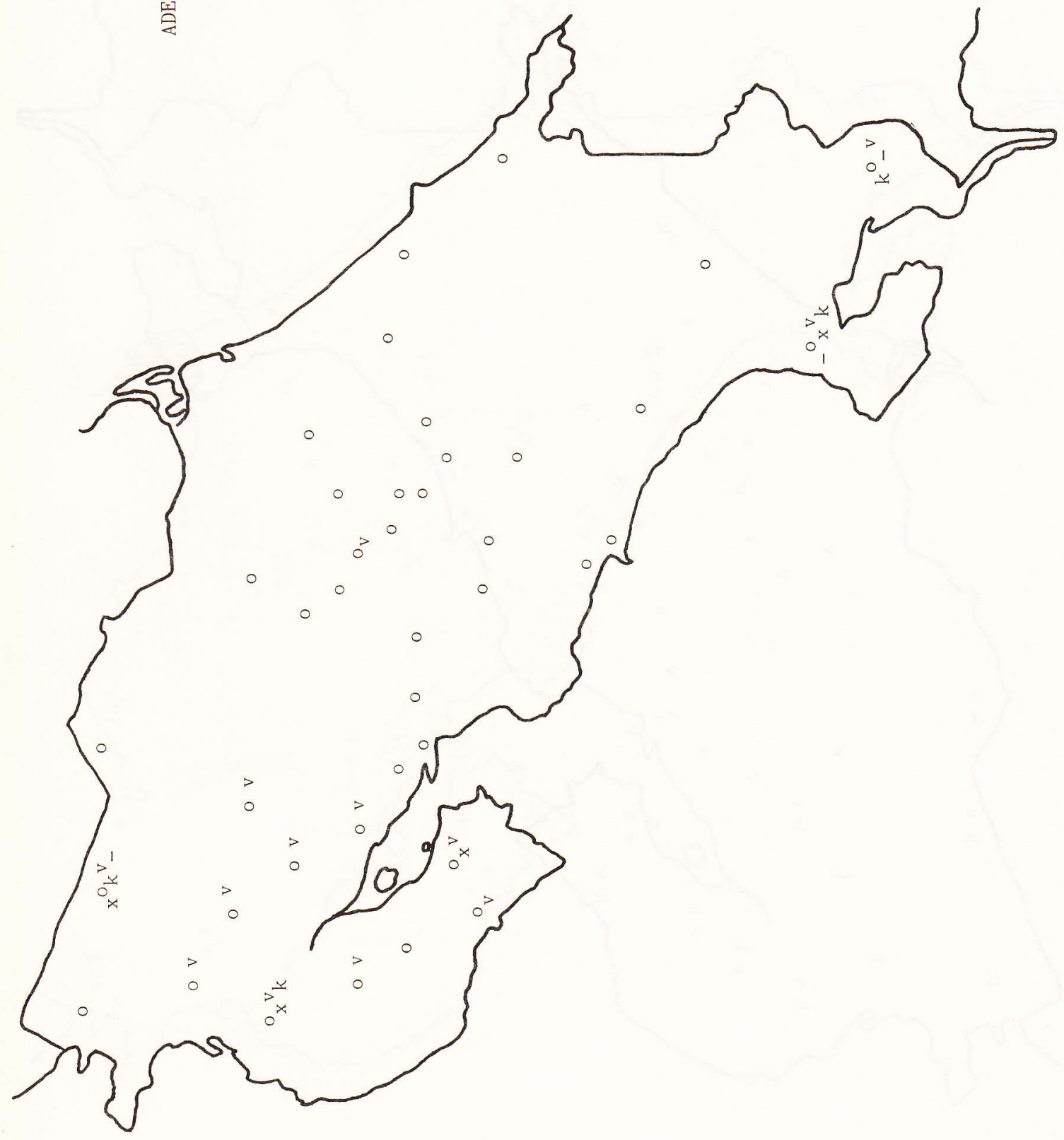




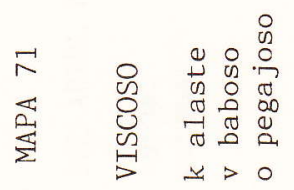

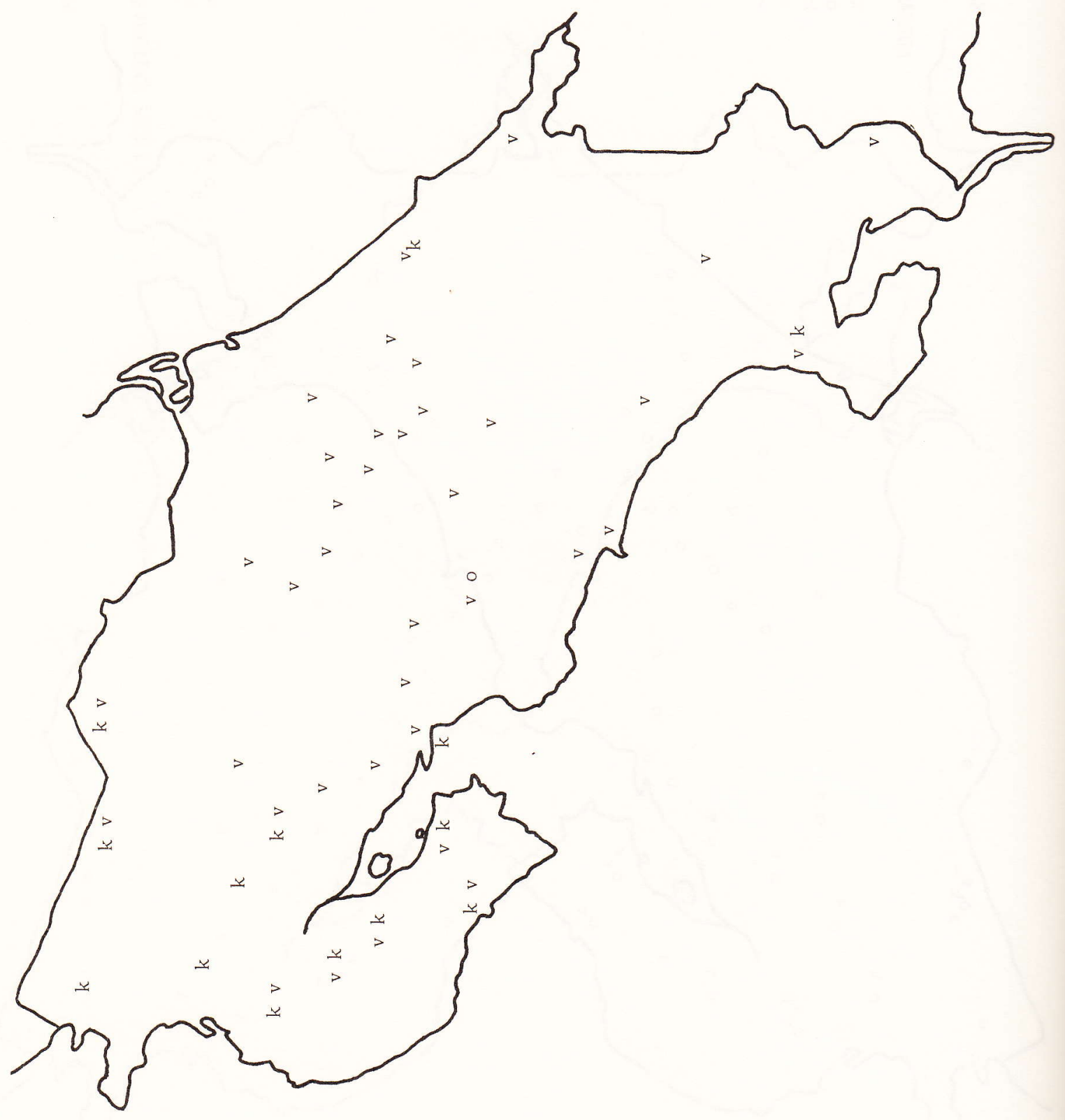



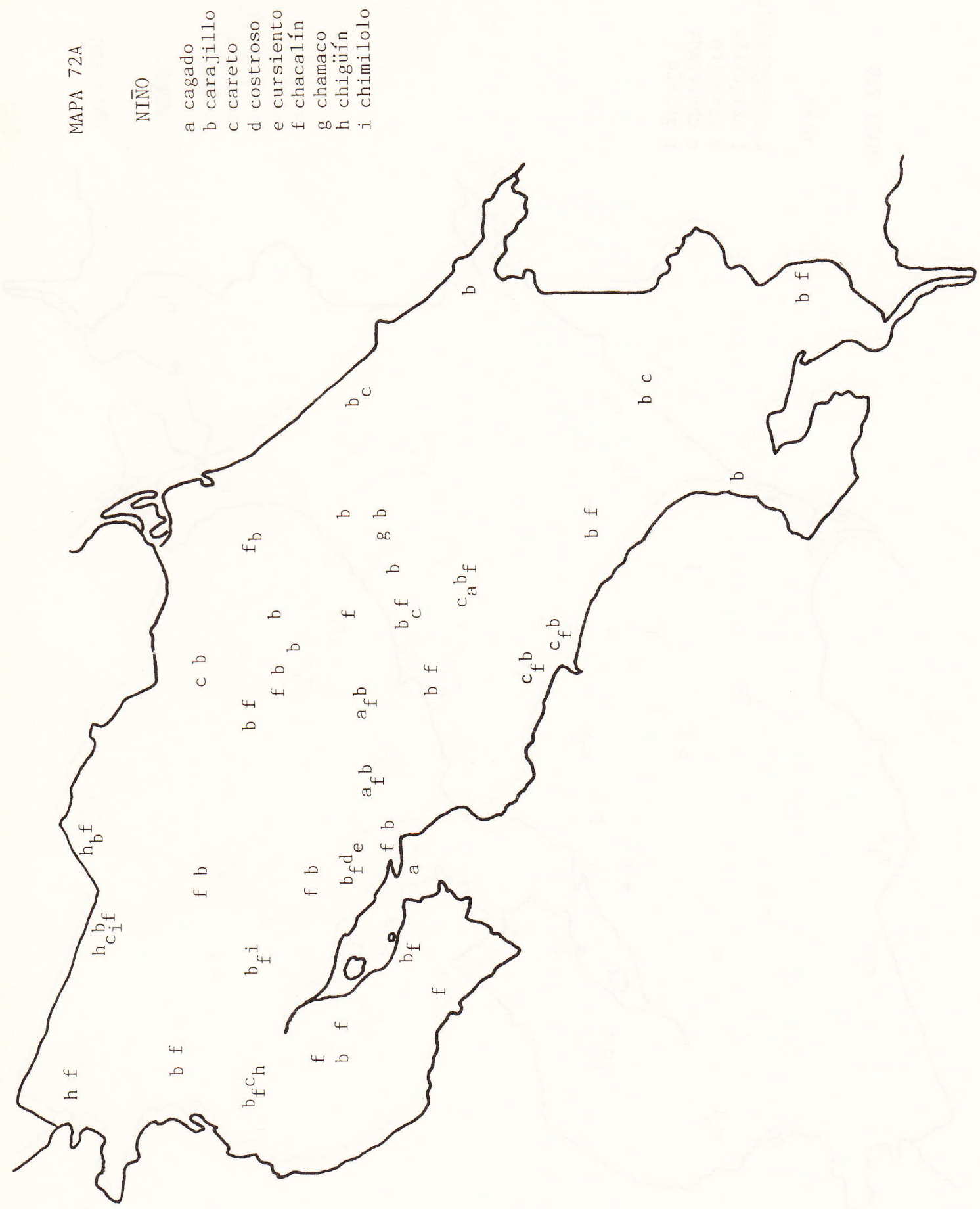

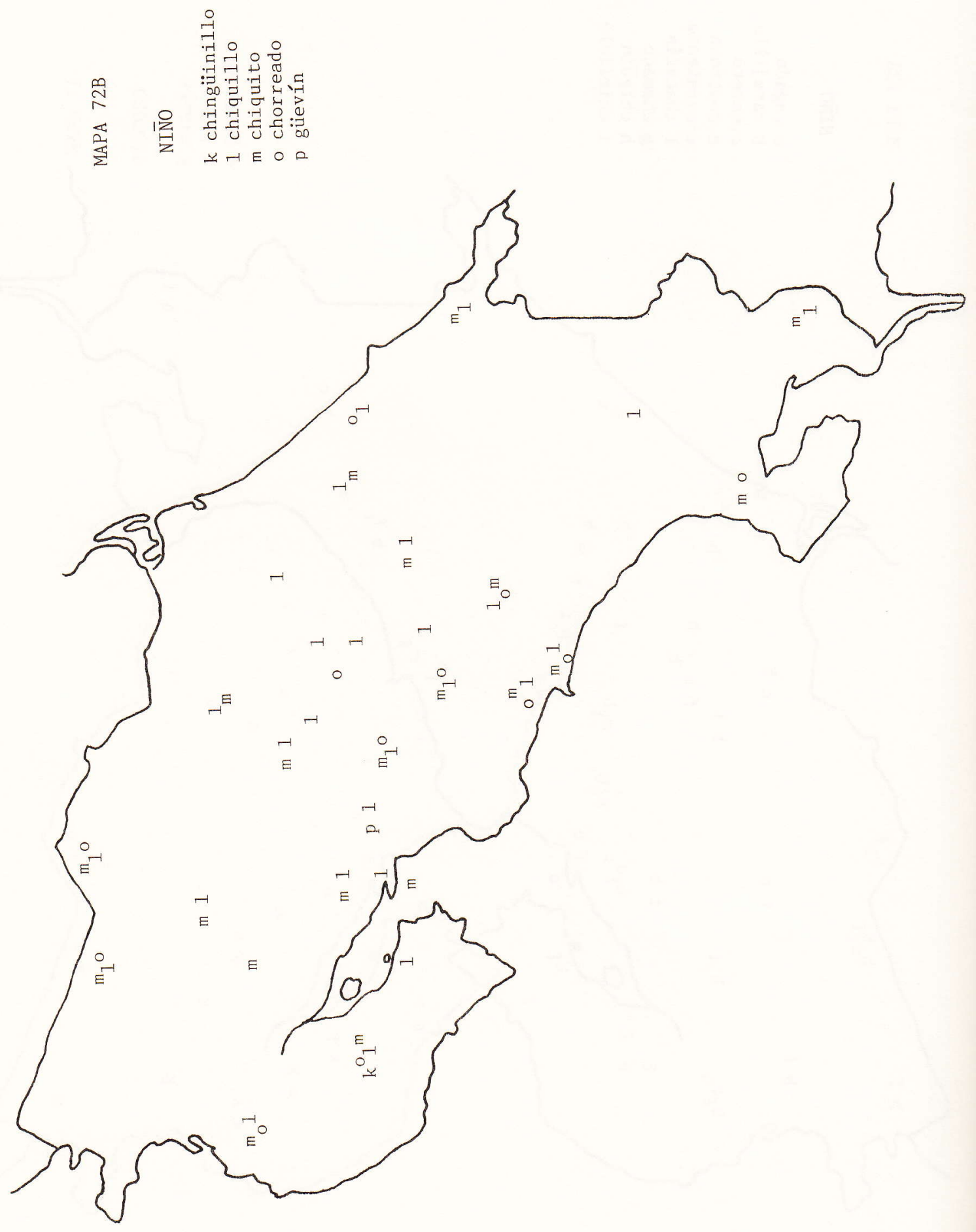


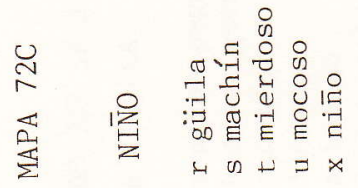

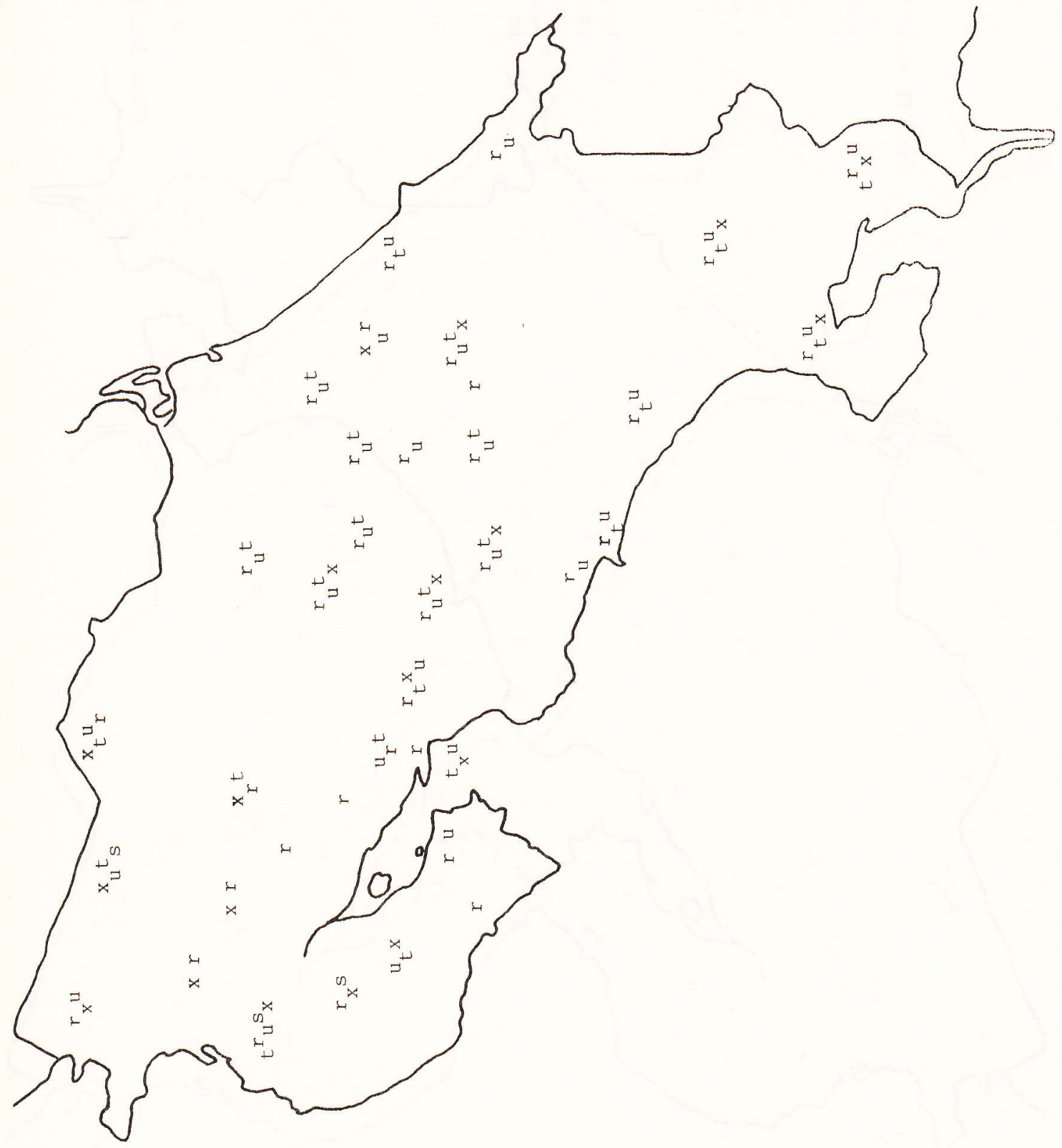




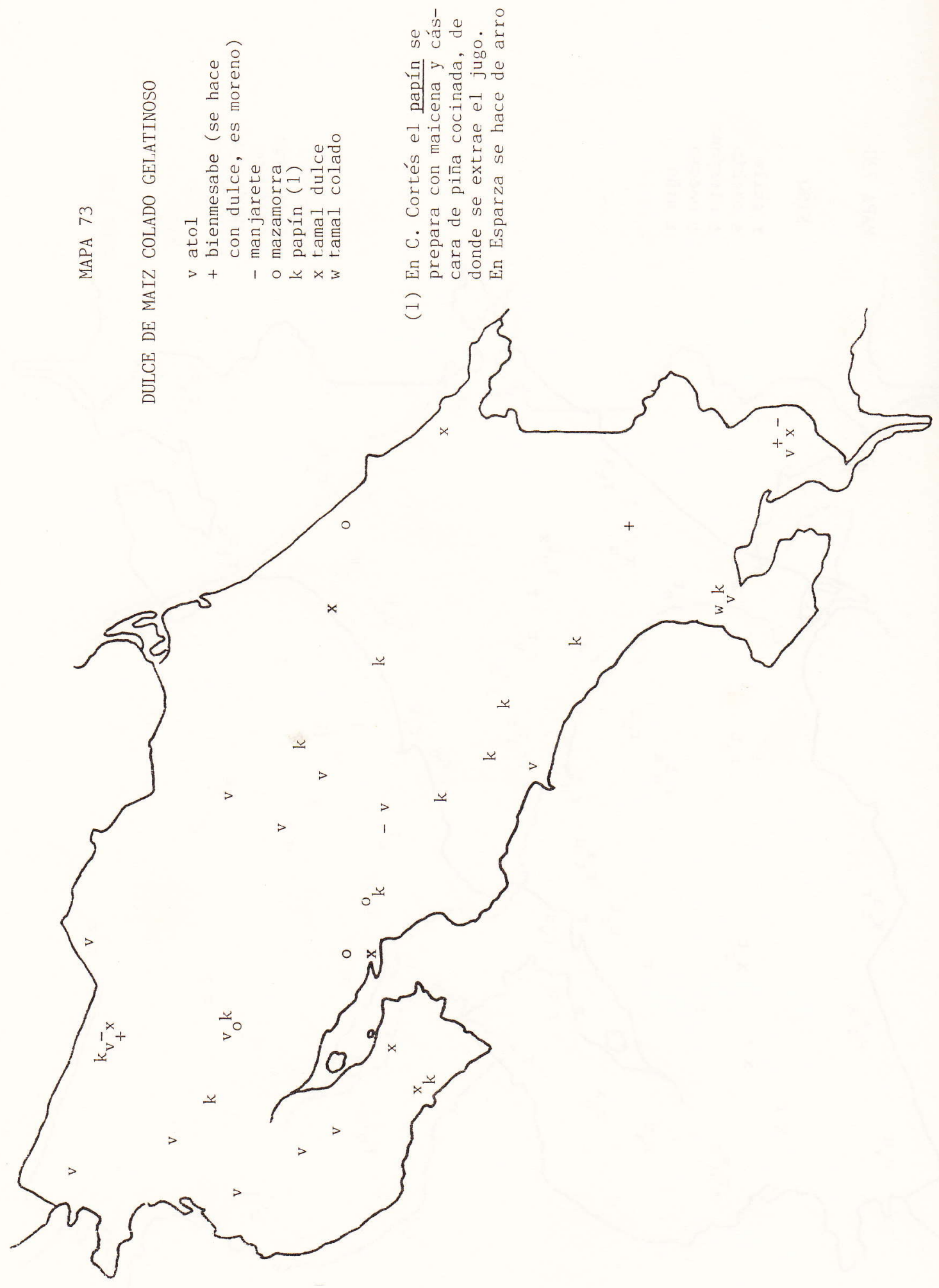



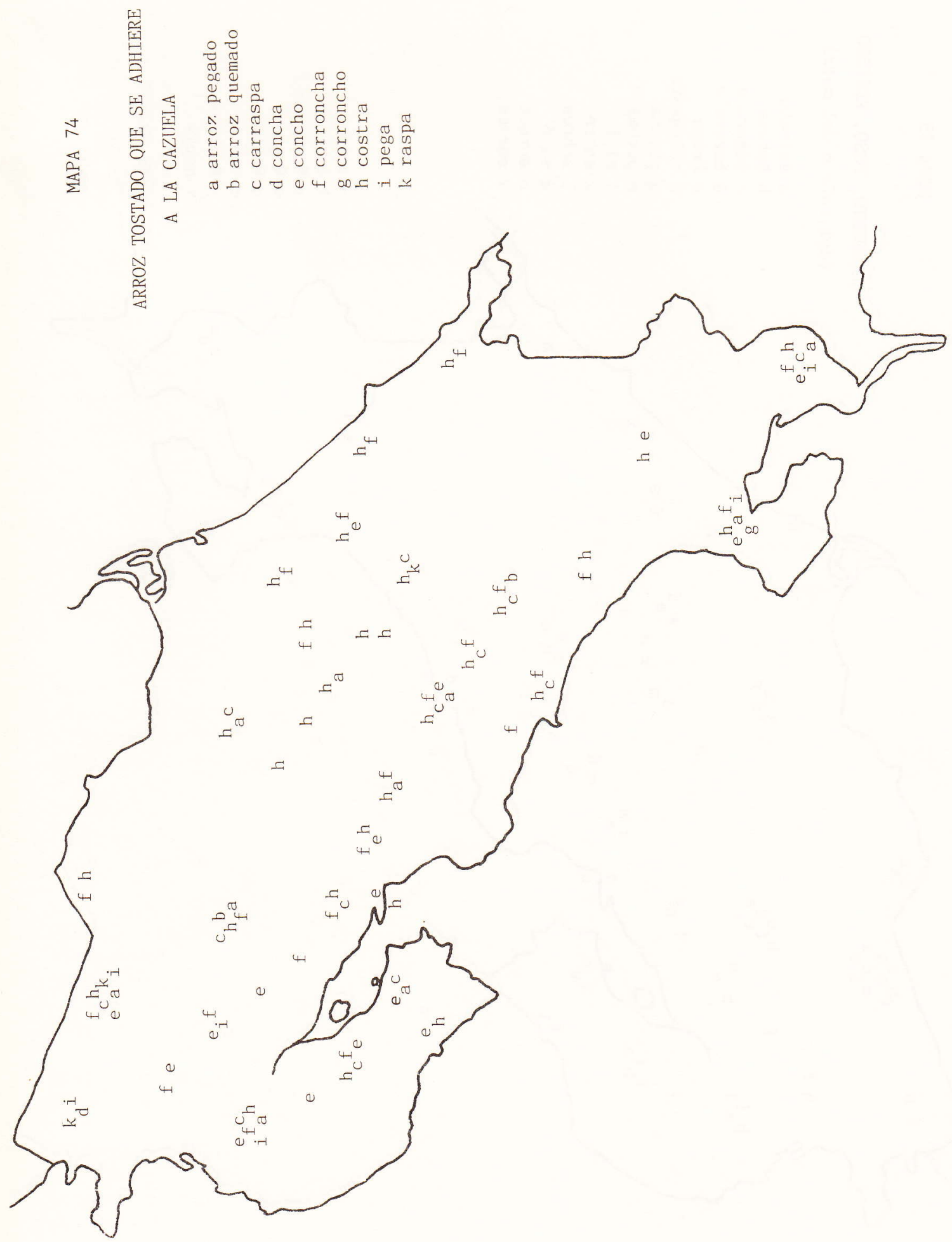


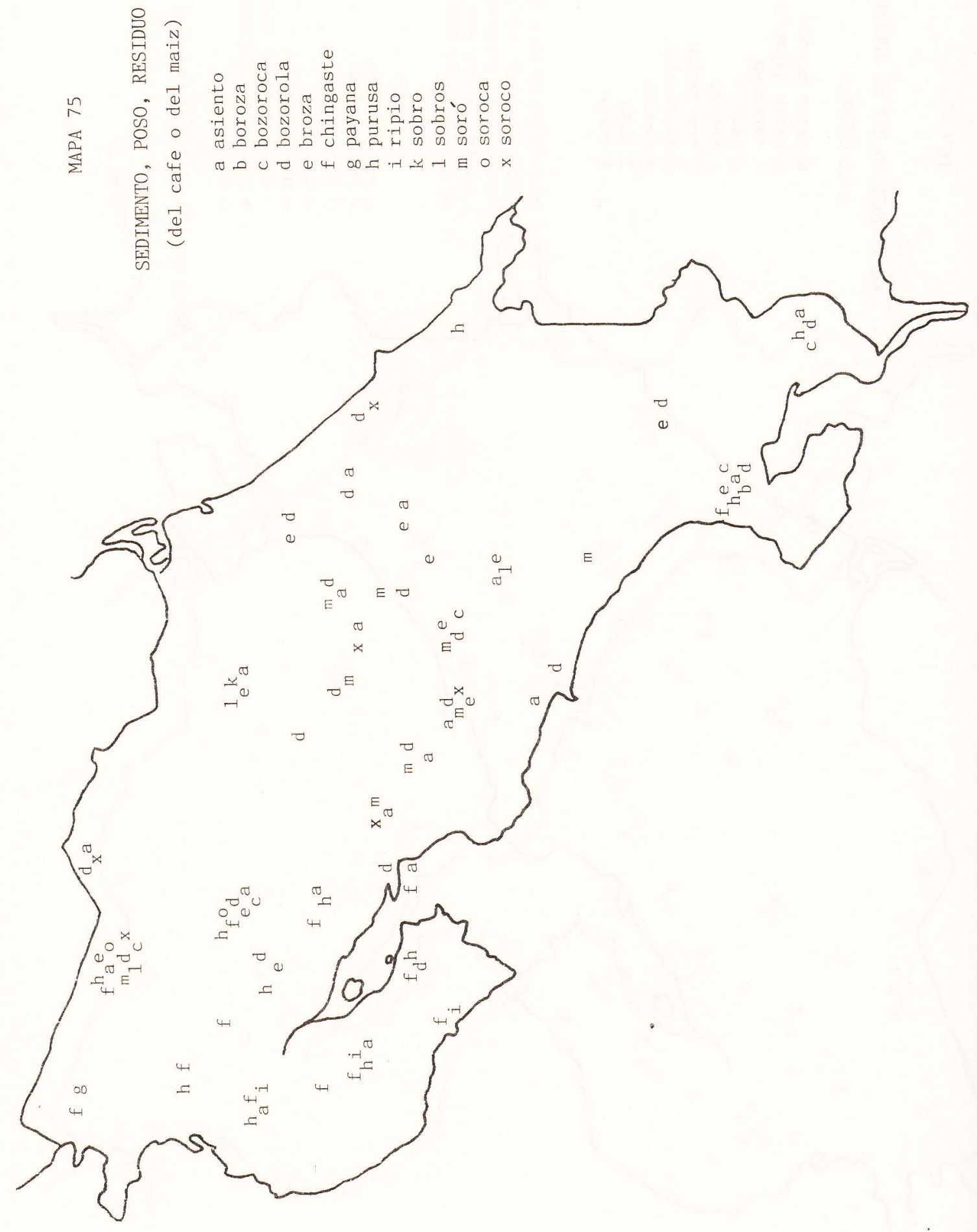



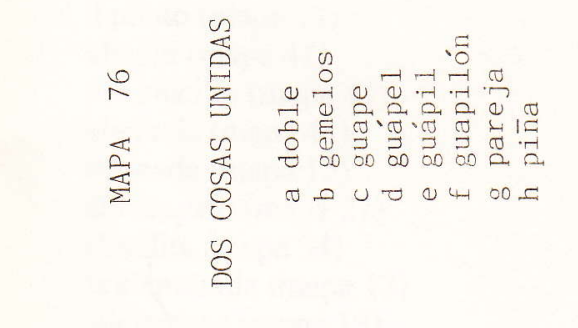


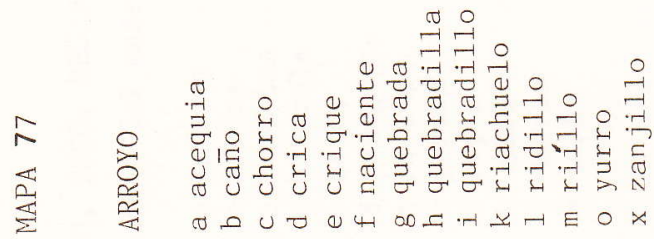

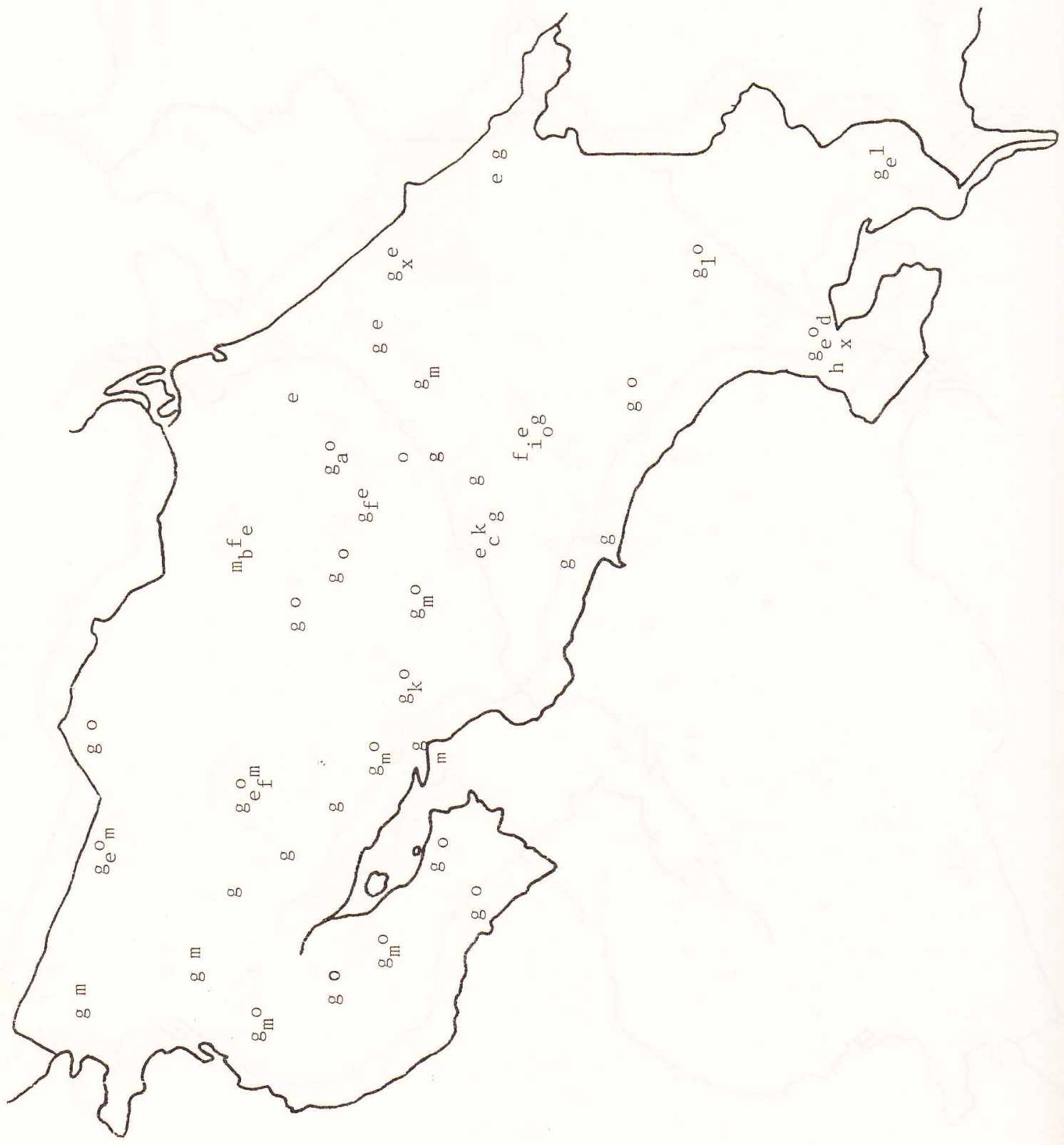




\section{Palabras registradas en los mapas}

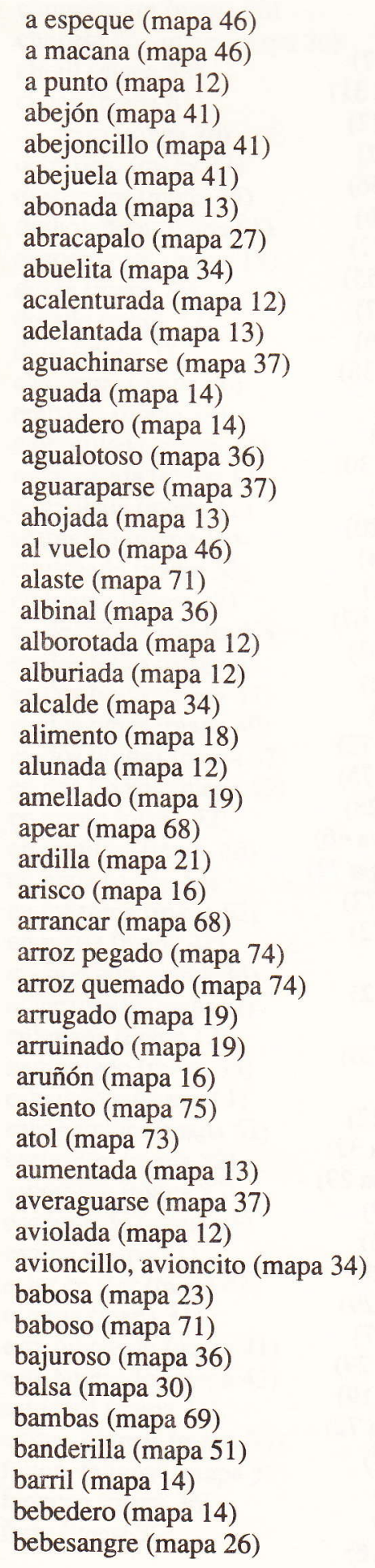

belitre (mapa 16)

bellote (mapa 57)

bienmesabe (mapa 73)

bigüelo (mapa 34)

birico (mapa 19)

biricho (mapa 19)

birringo (mapa 19)

boroza (mapa 75)

borrego (mapa 17)

botar (mapa 68)

botijón (mapa 28)

botoncito (mapa 48)

bozorola (mapa 75)

bravo (mapa 16)

breña (mapa 35)

breñón (mapa 35)

brioso (mapa 16)

brocho (mapa 55)

bronca (mapa 55)

bronco (map 55)

broza (mapa 75)

buchón (mapa 30 )

caballito (mapa 34)

caballo (mapa 57)

caballo del diablo (mapa 33)

cacaotera (mapa 21)

cacrá (mapa 54)

cacrás (mapa 54)

cafetal (mapa 40)

cagado (mapa 72)

cajcrás (mapa 54)

calabaza (mapa 64)

calabazo (mapa 64)

calabazo (mapa 65)

camagua (mapa 52)

camaleón (mapa 23)

candela (mapa 58)

cangrejear (mapa 50)

canoa (mapa 15)

canoa de la sal (mapa 15)

caño (mapa 77)

caracá (mapa 54)

caracrá (mapa 54)

carajillo (mapa 72)

careto (sucio) (mapa 72)

cargada (mapa 13)

carpintero (mapa 27)

carraspa (mapa 74)

carrilear para frijoles (mapa 46)

casetilla de sal (mapa 15)

cepa (mapa 57)

cequia (mapa 77) 
cerco (mapa 39)

cerco (mapa 40)

cerdo (mapa 17)

ciénaga (mapa 36$)$

ciénega (mapa 36)

ciéniga (mapa 36)

cimarrón (mapa 16)

cocorillo (mapa 17)

cochino (mapa 17)

coger de ajecho (mapa 44)

coger maíz (mapa 53)

coger repela (mapa 44)

coger todo junto (mapa 44)

coger verde y maduro (mapa 44)

cojollo (mapa 58)

cojollos (mapa 62)

cola de chocoyo (mapa 49)

cola de perico (mapa 49)

coleta de chucuyo (mapa 49)

colita de chocoyo (mapa 49)

come jícaro (mapa 19)

come rata (mapa 31)

comemaíz (mapa 28)

comepez (mapa 30)

comida (mapa 18)

compadre (mapa 34)

con chinga (mapa 46)

concha (mapa 74)

concho (mapa 74)

copete rojo (mapa 27)

copita (mapa 42)

copita (mapa 47)

copito (mapa 41)

corneja (mapa 31)

correcamino (mapa 24)

corroncha (mapa 74)

corroncho (mapa 74)

cortadora (mapa 61)

cortar (mapa 68)

cosorró (mapa 27)

cospó (mapa 52)

cosposo (mapa 52)

costra (mapa 74)

costroso (mapa 72)

cracrá (mapa 54)

crica (mapa 77)

criollo (mapa 19)

crique (mapa 77)

cuaco (mapa 30)

cuadradal (mapa 56)

cuango (mapa 30)

cuche (mapa 17) cuido (mapa 18)

cumba (mapa 64)

cumbo (mapa 64)

currucho (mapa 17)

currusposa (mapa 31)

cursiento (mapa 72)

chacalín (mapa 72)

chagüital (mapa 56)

chaguiite (mapa 56)

chamaco (mapa 72)

chancado (mapa 55)

chancho (mapa 17)

changua (mapa 36)

changüite (mapa 36)

charca (mapa 36)

charón (mapa 17)

charquero (mapa 30)

charral (mapa 35)

cherenga (mapa 20)

cherepo (mapa 24)

chibote (mapa 32)

chicasquil (mapa 67)

chícharo (mapa 63)

chigüín (mapa 72)

chilate (mapa 18)

chimilolo (mapa 72)

chingaste (mapa 75)

chingolo (mapa 28)

chingueado (mapa 46)

chingüinillo (mapa 72)

chiquillo (mapa 72)

chiquito (mapa 72)

chira (mapa 59)

chirbala (mapa 22)

chirra (mapa 59)

chirriche (mapa 26)

chisa (mapa 21)

chisbala (mapa 22)

chocorrón (mapa 32)

chocholpía (mapa 29)

cholpo (mapa 19)

chollar (mapa 45)

chorcha (mapa 29)

chorchín (mapa 29)

chorizo (mapa 17)

chorocha (mapa 29)

chorolpo (mapa 19)

chorreado (mapa 72)

chorro (mapa 77)

chote (mapa 59)

choto (mapa 48)

chúcaro (mapa 16) 
chucula (mapa 18)

chupadero (mapa 15)

chupasangre (mapa 26)

chupeta de sangre (mapa 26)

chutil (mapa 58)

chuza (mapa 61)

de gorra (mapa 70)

derretirse (mapa 37)

desbaratar (mapa 45)

deshojadora (mapa 61)

desperdicios (mapa 18)

doble (mapa 76)

dorado (mapa 52)

duro (mapa 52)

elequeme (mapa 66)

embalse (mapa 14)

embolillada (mapa 13)

embramada (mapa 12)

embullada (mapa 12)

embutido (mapa 19)

empozado (mapa 36)

en brama (mapa 12)

en desmonte (mapa 46)

en dos hojas (mapa 42)

en dos hojas (mapa 47)

en dos hojas (mapa 49)

en dos hojitas (mapa 47)

en dos hojitas (mapa 49)

en grano (mapa 52)

en lomillos (mapa 46)

en maíz (mapa 52)

en mazorca (mapa 52)

en patita (mapa 41)

enchorcado (mapa 36)

engarrotada (mapa12)

enlunada (mapa 12)

enmontado (mapa 35)

esbajadora (mapa 61)

esbajeradora (mapa 61)

escorpión (mapa 22)

escorpión (mapa 23)

espequiado (mapa 46)

espiga (mapa 51)

estar en flor (mapa 43)

estatua (mapa 31)

está hincando (mapa 41)

está hojeando (mapa 42)

estucurú (mapa 31)

extras, extrear (mapa 38)

fajina, fajinear (mapa 38)

fangoso (mapa 36)

feria (mapa 70) fileta (mapa 61)

flor (mapa 48)

flor (mapa 51)

florear (mapa 43)

foco (mapa 31)

frente roja (mapa 27)

frijol de palo (mapa 63)

frijol duro (mapa 63)

frijolillo (mapa 63)

frijolillo de palo (mapa 63)

fruta de guacal (mapa 65)

furioso (mapa 16)

gacilla (mapa 34)

gallego (mapa 24)

gallego (mapa 34)

gallillo (mapa 344)

gallina de palo (mapa 24)

gallina de palo (mapa 25)

gallinita (mapa 48)

gallito (mapa 34)

gambás (mapa 69)

ganchillo (mapa 34)

gandul (mapa 63)

garbanzo criollo (mapa 63)

garmelio (mapa 25)

garracho (mapa 25)

garrañón (mapa 60)

garrapatoso (mapa 19)

garrobilla (mapa 23)

garrobillo (mapa 22)

garrobillo (mapa 23)

garrobito (mapa 22)

garrobito (mapa 23)

garrobo (mapa 24)

garrobo (mapa 25)

gemelos (mapa 76)

gorreado (mapa 70)

guacal (mapa 65)

guacho (mapa 25)

guampiro (mapa 26)

guandú (mapa 63)

guape (mapa 76)

guapilón (mapa 76)

guate (mapa 54)

guatusa (mapa 20)

guápel (mapa 76)

guápil (mapa 76)

guievín (mapa 72)

guía (mapa 62)

guía del león (mapa 31)

gungú (mapa 63)

güila (mapa 72) 
güilo (mapa 17)

güirriza (mapa 24)

güirriza (mapa 25)

güirro (mapa 17)

habilitada (mapa 13)

hachear (mapa 68)

helicóptero (mapa 34)

hogapollos (mapa 32)

hojeando (mapa 47)

hojeando (mapa 49)

horqueta (mapa 42)

horqueta (mapa 47)

hortaliza (mapa 39)

hu del león (mapa 31)

húa del león (mapa 31)

huerta (mapa 39)

huerto (mapa 39)

iguana (mapa 25)

inquieta (mapa 12)

inundado (mapa 36)

jalaquesos (mapa 19)

jamelgo (mapa 19)

jarbaca, jarbaqueado (mapa 55)

jícara (mapa 65)

jícaro (mapa 65)

jicarón (mapa 65)

juancho (mapa 22)

juan palo (mapa 33)

jucó (mapa 65)

jujusa (mapa 31 )

jupa (mapa 65)

jurgagua (mapa 34)

jurujusa (mapa 31)

jusa (mapa 31)

lagartija (mapa 22)

lagartija (mapa 23)

laguna (mapa36)

lagunoso (mapa 36)

lajú (mapa 31)

lapeando (mapa 52)

lapo (mapa 25)

lavandera (mapa 34)

lechuza (mapa 31)

levantando (mapa 47)

limpiacasa (mapa 23)

loca (mapa 12)

loco (mapa 16)

lote (mapa 38)

lote (mapa 39)

lucia (mapa 23)

lucio (mapa 23)

machigua (mapa 18) machigüe (mapa 18)

machín (mapa 72)

madera de culebra (mapa 33)

majagüevos (mapa 19)

mal amansado (mapa 16)

mampliro (mapa 26)

mandul (mapa 63)

manguito (mapa 41)

manita (mapa 59)

manjarete (mapa 73)

manquito (mapa 41)

mañoso (mapa 16)

maromero (mapa 19)

marrano (mapa 17)

matapollos (mapa 32)

matorral (mapa 35)

mayarse (mapa 37)

mazamorra

mecanizado (mapa 46)

mecha (mapa 51)

media luna (mapa 61)

merienda (mapa 18)

mierdoso (mapa 72)

mocoso (mapa 72)

molca (mapa 54)

molesta (mapa 12)

montasal (mapa 35)

moracho (mapa 24)

mortadela (mapa 19)

mostrenco (mapa 16)

mula del diablo (mapa 33)

mulita (mapa 33)

murciégalo (mapa 26)

murciélago (mapa 26)

murcio (mapa 26)

naciente (mapa 77)

nació (mapa 47)

nambira (mapa 64)

nambiro (mapa 64)

neca (mapa 20)

niño (mapa 72)

no cuajó (mapa 54)

ñapa (mapa 70)

ñeque (mapa 20)

ñequi (mapa 27)

ojón (mapa 31 )

olopopo (mapa 31)

oropopo (mapa 31)

padrino (mapa 34)

palo seco (mapa 33)

palomita (mapa 47)

palomita (mapa 49) 
palote (mapa 57)

pantano (mapa 36)

panzona (mapa 13)

panzuca (mapa 13)

papín (mapa 73)

parcela (mapa 39)

pareja (mapa 76)

pava (mapa 16)

payana (mapa 55)

payana (mapa 75$)$

payano (mapa 55)

payanoso (mapa 55)

payaste (mapa 55)

pedacillo (mapa 39)

pedazo (mapa 39)

pega (mapa 74)

pegada (mapa 13)

pegadero (mapa 36)

pegajoso (mapa 71)

penco (mapa 19)

perrillo (mapa 22)

perro zompopo (mapa 23)

perro zompopo (mapa 24)

petipoa (mapa 63)

picota (mapa 19)

pichón (mapa 48)

pichonear (mapa 43)

piedra (mapa 48)

piedrita (mapa 48)

piernudo (mapa 28)

pila (mapa 14)

pilado (mapa 55)

pileta (mapa 14)

pintando (mapa 52)

pinzote (mapa 60)

piña (mapa 76)

pipilacha (mapa 34)

pirrí (mapa 28)

pirrís (mapa 28)

pitear (mapa 43)

pito (mapa 58)

plantita (mapa 49)

platanal (mapa 56)

platanar (mapa 56)

podadora (mapa 61)

podrirse (mapa 37)

poró (mapa 66)

premiada ( mapa 13)

preñada (mapa 13)

primavera (mapa 32)

púa del león (mapa 31)

puerco (mapa 17)

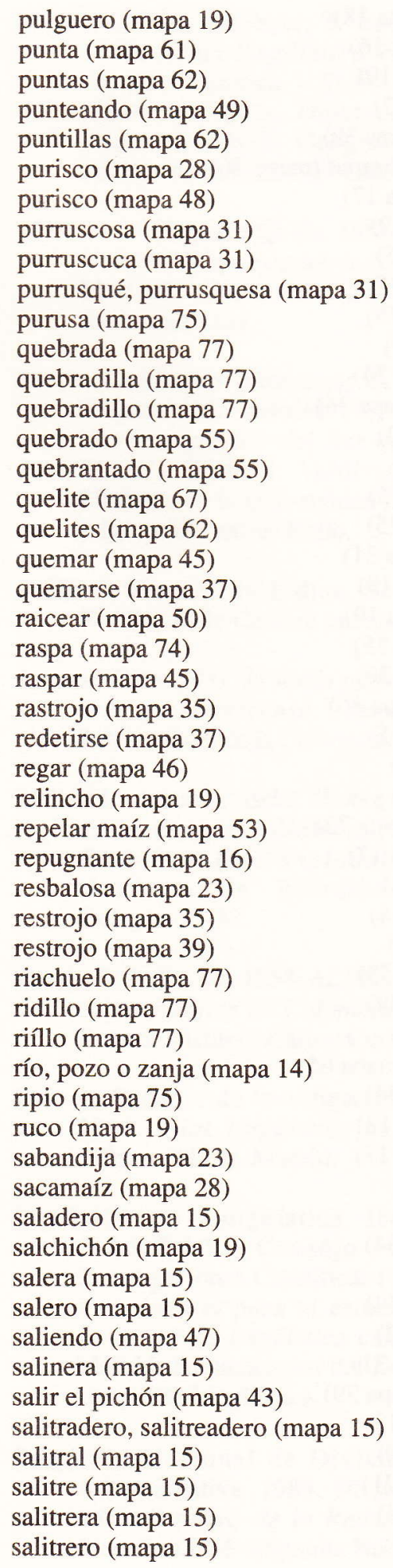




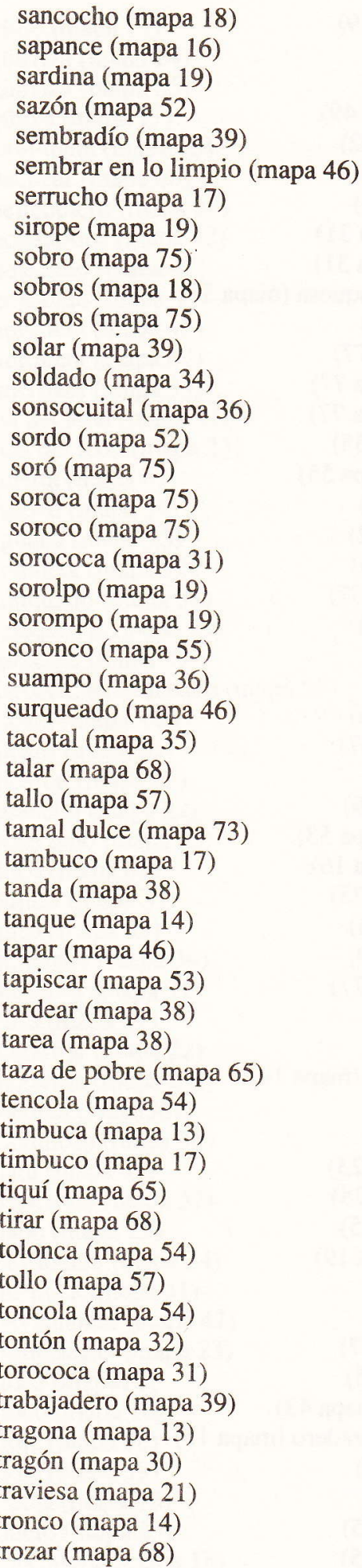

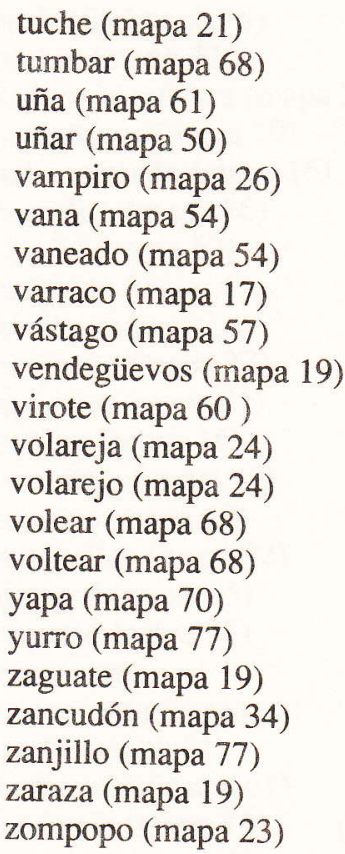

\section{Notas}

1. En la actualidad se encarga de publicarlos el Instituto de Investigaciones de la Lengua Alemana (Forschungsinstitut für Deutsche Sprache) con sede en Marburg, Alemania, y el primer tomo es Veith, Werner; Wolfgang Putschke. Kleiner deutscher Sprachatlas. Band I, Teil 1, 2. Tübingen: Niemeyer Verlag, 19831987. Aprovecho la ocasión para agradecer profundamente al Forschungsinstitut de Marburg (en particular al Prof. Dr. J. Göschel y al Sr. Harald Händler) por la acogida a mi proyecto del atlas lingüístico de Costa Rica, así como el haber puesto a mi disposición personal e instrumentos de trabajo durante mi estadía en Marburg en diciembre de 1991, enero y febrero de 1992. Mi agradecimiento se extiende al Deutscher Akademischer Austauschdienst (DAAD) por su apoyo financiero a mi visita de investigación en dicho Instituto.

2. No obstante, no he tenido noticia de que tal cuestionario haya sido aplicado en alguna parte del territorio nacional, quizá por la complejidad con que está concebido, la cual lo aleja de los cuestionarios tradicionales, prácticos, hechos para trabajar directamente en el terreno, sin mayores atrasos. De emplearse el cuestionario de Sánchez, habría que hacerle importantes enmiendas, como por ejemplo dejar un espacio para poner la respuesta a la pregunta en cuestión y tratar cada pregunta por separado, no en conglomerados.

3. El orden de las provincias y de los cantones dado acá es el propuesto por la Comisión Nacional de División 
Territorial Administrativa en la División territorial administrativa de Costa Rica (San José 1989).

4. Traigo a colación la importancia que guarda el río Virilla como frontera política desde la época precolombina. Era el límite entre el Reino Huetar de Oriente y el de Occidente. Así, en un juicio de 1590, Cateva, cacique de Purapura, declaró que "sabe e vio que dondequiera que el dicho don Fernando Correque estava poblado, allí tenían por cabecera y le acudían a servir todos los pueblos como a su señor que hera, porque le obedecían desde el río de el Virilla al poniente hasta adelante de Chirripó" (Archivo General de Indias, Escribanía de Cámara 371 B, folio 226 vuelta).

5. De modo que el fenómeno descrito por J. Solano (1986) está más extendido como se puede apreciar en el mapa Nㅜ‥1.

6. Visto desde las perspectivas histórica, geográfica y demográfica, un estudio que arroja luces a la problemática de la reciente colonización en el país es el de Morales y Sandner (1982).

\section{Bibliografia}

Academia Republicii Populare Romîne. 1956. Atlasul lingvistic Romîne 3 volúmenes. Editura Academiei Republicii Populare Romîne.

Agüero, Arturo. 1962. El español de América y Costa Rica. San José: Atenea, 1962.

.1964. "El español de Costa Rica y su atlas linguístico". En: Presente y futuro de la lengua española $I$. Actas de la Asamblea de Filología del I Congreso de Instituciones Hispánicas. Madrid; 135152.

Alvar, Manuel. 1969. Estructuralismo, geografía lingüística y dialectología actual. Madrid: Gredos.

1975. Atlas lingüístico etnográfico de las Islas Canarias (ALEICAN). 2 tomos. Gran Canaria: Ediciones del Cabildo Insular.

.A. Llorente y G. Salvador. 19631964. Atlas lingüístico etnográfico de Andalucía (ALEA). V. tomos. Universidad de Granada.
.A. Llorente; T. Buesa y E. Alvar. 1979. Atlas lingüístico etnográfico de Aragón, Navarra y Rioja (ALEANR). 12 tomos. Zaragoza: Diputación Provincial, Departamento de Geografía Lingüística, Institución Fernando El Católico.

Antonio Quilis. 1984. Atlas lingüístico de Hispanoamérica. Cuestionario. Madrid: Instituto de Cooperación Iberoamericana.

Araya, Guillermo (director); C. Contreras; C. Wagner y M. Bernales. 1973. Atlas lingüístico-etnográfico del Sur de Chile (ALE$S U C H)$. Tomo I. Valdivia: Instituto de Filología de la Universidad Austral de Chile y Editorial Andrés Bello.

Archivo General de Indias, Sevilla. Inédito. Escribanía de Cámara manuscrito 371, B.

Arroyo, Víctor. 1971. El habla popular en la literatura costarricense. Departamento de Publicaciones de la Universidad de Costa Rica.

Badía M., Antonio. 1952. "Sobre la metodología de la encuesta dialectal". En: Primer Congreso Internacional del Pirineo (Instituto de Estudios Pirenaicos). Zaragoza; 5-32.

Buesa, T.; L. Florez. 1954. ALEC. Atlas lingüístico etnográfico de Colombia. Cuestionario. Bogotá: Instituto Caro y Cuervo.

Consejo Superior de Investigaciones Científicas. 1962. Atlas lingüístico de la Península Ibérica (ALPI). Madrid.

Comisión de Linguística Iberoamericana (P.I.L.E.I.); Consejo Superior de Investigaciones Científicas (C.S.I.C.). 1971. Cuestionario para el estudio coordinado de la norma lingüística culta, III. Léxico. Madrid: Publicaciones del Departamento de Geografía Linguística.

Comisión Nacional de División Territorial Administrativa. 1989. División territorial administrativa de la República de Costa Rica. San José: Imprenta Nacional. 
Coseriu, Eugenio. 1977a. "La geografía lingüística". En: El hombre y su lenguaje. Madrid: Gredos; 103-158.

.1977b. "Panorama lingüístico de la lingüística iberoamericana. En: Tradición y novedad en la ciencia del lenguaje. Madrid: Gredos; 264-364.

Chambers, J. K.; Peter Trudgill. 1986. Dialectology. Cambridge University Press.

Chavarría, Q.; A. Soto y M. Quesada. 1977. El habla de Quitirrisí. Fonología, forma lingüística, léxico. Universidad de Costa Rica: Tesis.

Flórez, Luis et. al. 1981-1982. Atlas lingüístico etnográfico de Colombia. Cuestionario. Bogotá: Instituto Caro y Cuervo.

Gagini, Carlos. 1918. Diccionario de costarriqueñismos. San José: Tipografía Nacional.

Gaínza, Gastón. 1976. "El español de Costa Rica. Breve consideración acerca de su estudio". En: Revista de Filología y Lingüística de la Universidad de Costa Rica, vol. 2, №.4; 79-84.

Gardette, Pierre. 1968. Atlas linguistic ethnographique du lyonnais, IV. Exposé methodologique et tables. Paris: Centre National de la Recherche Scientifique.

.Paulatte Durdilley. 1976. Atlas linguistic du lyonnais, V. Commentaires. Paris: Centre National de la Recherche Scientifique.

Gómez Córdoba, Carlos E. 1975. Vocabulario cafetero de la provincia de Cartago. Universidad de Costa Rica: Tesis.

Griera, Antonio. 1960. Atlas linguistic d'Andorra. Andorra.

1968. Interpretación de mapas de los atlas lingüísticos románicos. Abadía de San Cougat del Valles: Instituto Internacional de Cultura Románica.
Jaberg, K.; J. Jud. 1928. Sprach- und Sachatlas Italiens und der Südschweiz. 2 volúmenes. Zofingen (Suiza): Verlagsantstalt Ringier \& Co.

Jaén García, Xinia. 1989. Léxico de la cultura del maiz en el distrito de Sardinal, Carrillo, provincia de Guanacaste. Universidad de Costa Rica: Tesis.

Meza, Hortensia. 1980. El habla de los sabaneros liberianos y tilaranenses. Estudio léxico-semántico con anotaciones fonológicas, morfológicas y sintácticas. Universidad de Costa Rica: Tesis.

Monge E., Rodrigo. 1971. Lengua y cultura de Tobosi y sus aledaños. Trabajo de Graduación. Heredia: Escuela Normal Superior.

Morales, Miguel; Gerhard Sandner. 1982. Regiones periféricas y ciudades intermedias en Costa Rica. San José: EUNED.

Moreno de Alba, José. 1988. El español en América. México: Fondo de Cultura Económica.

Navarro, Tomás. 1974. El español en Puerto Rico. Río Piedras: Editorial Universitaria.

Quesada Pacheco, Miguel Angel. 1981. Análisis sociológico lingüístico del espanol de San Gabriel, Monterrey y La Legua de Aserrí. Universidad de Costa Rica: Tesis.

1985. Diccionario regional de los distritos de San Gabriel, Monterrey y La Legua de Aserrí. San Gabriel: Centro de Producciones Audiovisuales.

1987a. "Léxico ganadero de la Costa Rica Colonial". En: Revista de Filología y Lingüística de la Universidad de Costa Rica XIII, 2; 147-165.

$.1987 \mathrm{~b}$. "Factores históricos en la formación de las zonas dialectales de Costa Rica". En: Káñina XI, 1; 123 128. 
1989. "La geografía lingüística en Costa Rica: sus problemas y sus logros". En: I Seminario de Tradición e Historia Oral. [Universidad de Costa Rica, 3 y 4 de diciembre de 1987]. Universidad de Costa Rica: Oficina de Publicaciones, 45-56.

1989. "Actitudes hacia el habla campesina de Costa Rica a través de la historia". En: Herencia (Universidad de Costa Rica) 1,$2 ; 72-82$.

.1990. El español colonial de Costa Rica. Editorial de la Universidad de Costa Rica.

.1991a. El español de Guanacaste. Editorial de la Universidad de Costa Rica.

.1991b. Nuevo diccionario de costarriqueñismos. Cartago: Ed. Tecnológica.

Altas lingüístico etnográfico de Costa Rica: cuestionario. (En prensa).

Robe, Stanley. 1960. The Spanish of Rural Panama. Berkeley: University of California Publications in Linguistics.

Rodríguez B., Edgar. 1977. El lenguaje hampesco costarricense. Universidad de Costa Rica: Tesis.

Román J., María N. 1976. El uso del español en Desamparados de Alajuela. Universidad de Costa Rica: Tesis.

Sánchez, Víctor. 1983. Cuestionario lingüístico costarricense. Editorial de la Universidad de Costa Rica.
Skoruppa, Sabine. 1982. "Diferenciación agraria y relaciones ciudad-campo en áreas periféricas de Costa Rica. El caso de las subregiones de Ciudad Quesada/San Carlos y Liberia/Guanacaste". En: Morales, Miguel y Gerhard Sandner (editores). Regiones periféricas y ciudades intermedias en Costa Rica. San José: EUNED, 255-317.

Solano, Yamileth. 1986. "Una variación lingüística en el habla costarricense". En: Revista de Filología y Lingüística de la Universidad de Costa Rica XII, 1; 133 143.

Veith, Werner; Wolfgang Putschke. 1983-1987. Kleiner deutcher Spachatlas. Band I, Teil 1, 2. Tübingen: Niemeyer Verlag.

Vindas Chaves, Francisco. 1971. Vocabulario del banano. Universidad de Costa Rica: Tesis.

Wilson, Jack. 1970. A Generative Phonological Study of Costa Rican Spanish. Universidad de Michigan: Tesis.

Zamora Araya, Xinia. 1977. El léxico de los oficios en el habla popular costarricense. Universidad de Costa Rica: Tesis.

Zamora Munné; Jorge Guitart. 1988. Dialectología hispanoamericana. Teoría, descripción, historia. 2a. edición. Salamanca: Publicaciones del Colegio de España.

Zamora Vicente, Alonso. 1985. Dialectología española. Madrid: Gredos. 